\title{
ELECTROCHEMISTRY IN THIN LAYERS OF SOLUTION
}

\author{
Thesis by \\ Arthur Thornton Hubbard
}

In Partial Fulfillment of the Requirements

For the Degree of

Doctor of Philosophy

California Institute of Technology

Pasadena, California

1967

(Submitted November 22, 1966) 
$-\mathrm{ii}-$

Acknowledgments

It is a pleasure to acknowledge that these studies were carried out under the direction of Professor F. C. Anson.

Financial support was provided in part by the National Science Foundation and the California Institute of Technology. 


\begin{abstract}
New electrodes for electrochemistry in thin layers of solution have been constructed which are easier to use and give more reproducible data than previous designs. The theory of voltammetry, chronopotentiometry and chronocoulometry in thin layers is derived and verified for simple systems using these electrodes. The particular advantages of the thin layer approach for study of systems in which adsorption of the reactants can occur and for elucidation of the stoichiometry of complicated reactions have been exploited in the present work.

The extent of adsorption of the $\mathrm{I}_{2}-\mathrm{I}^{-}, \mathrm{CoY}^{-}-\mathrm{CoY}^{-2}$ and $\mathrm{FeY}^{-}-\mathrm{FeY}^{-2}$ couples $\left(\mathrm{H}_{4} \mathrm{Y}=\right.$ ethylenediaminetetraacetic acid) at platinum electrodes has been determined. About $2 \times$ $10^{-9} \mathrm{~mole} / \mathrm{cm} .^{2}$ of iodide ion or $2 \times 10^{-9} \mathrm{~mole} / \mathrm{cm} .^{2}$ iodine were shown to be adsorbed in a non-electroactive state. An additional $1 \times 10^{-9} \mathrm{~mole} / \mathrm{cm}^{2}$ of iodine but no iodide was adsorbed in an electroactive state. About $3.1 \times 10^{-10} \mathrm{~mole} / \mathrm{cm} .^{2}$ of $\mathrm{CoY}^{-}$or $4.7 \times 10^{-10} \mathrm{~mole} / \mathrm{cm}^{2}$ of $\mathrm{CoY}^{-2}$ are adsorbed at bright platinum electrodes. No adsorption of $\mathrm{FeY}^{-}$or $\mathrm{FeY}^{-2}$ was detected.
\end{abstract}


The stoichiometry of the electrochemical oxidation of $\mathrm{PtCl}_{4}{ }^{-2}, \mathrm{PtBr}_{4}{ }^{-2}$ and $\mathrm{PtI}_{4}{ }^{-2}$, and of the electrochemical reduction of $\mathrm{PtCl}_{6}{ }^{-2}, \mathrm{PtBr}_{6}{ }^{-2}$ and $\mathrm{PtI}_{6}{ }^{-2}$ and their hydrolysis products has been examined. The effect of acidity and halide concentration on these reactions was investigated. The reduction of $\mathrm{PtCl}_{6}{ }^{-2}$ leads to $\mathrm{PtCl}_{4}{ }^{-2}$ in solutions containing sufficient acid or chloride, but proceeds directly to platinum metal in neutral, chloride-free solutions. The reduction of $\mathrm{PtBr}_{6}{ }^{-2}$ yields $\mathrm{PtBr}_{4}{ }^{-2}$ in $1 \mathrm{~F}$ bromide solutions, but proceeds to the metal in either acid or neutral bromide-free solutions. The oxidation of $\mathrm{PtCl}_{4}{ }^{-2}$ in $1 \mathrm{~F}$ chloride solutions appears to give a mixture of $\mathrm{PtCl}_{6}{ }^{-2}$ and $\mathrm{Pt}(\mathrm{OH})_{2} \mathrm{Cl}_{4}{ }^{-2}$, whereas the oxidation of $\mathrm{PtBr}_{4}{ }^{-2}$ in $1 \mathrm{~F}$ bromide solutions gives simply $\mathrm{PtBr}_{6}{ }^{-2}$. The products of hydrolysis of $\mathrm{PtCl}_{6}{ }^{-2}$ and $\mathrm{PtBr}_{6}{ }^{-2}$ are more readily reduced than are the parent complexes. 


\section{CONTENTS}

II

Theory

1. Linear Potential Sweep Voltammetry in Thin Layers of Solution

2. Chronocoulometry in Thin Laycrs of Solution

3. Chronopotentiometry in Thin Layers of Solulion

Appendix 1. Conditions for Thin Layer Voltammetry

Appendix 2. Conditions for Total

Irreversibility in Thin Layer Voltammetry

Appendix 3. Minimum 'l'ime Required for $\mathrm{Q}$ to Become Constant in Thin Layer Chronocoulometry

III

Apparatus

1. Glass Capillary-Wire Electrode

2. Micrometer Electrode

3. Micrometer Mercury Electrode 
CONTENTS

Part

Title

Page

IV Testing of Apparatus and Theory

48

1. Testing of the Electrodes

48

2. Thin Layer Voltammetry of the $\mathrm{Fe}$ (III)-Fe(II) Couple

3. Thin Layer Chronocoulometry of the $\mathrm{Fe}$ (III) $-\mathrm{Fe}$ (II) Couple

4. Ohmic Potential-Difference Effects 58

$\mathrm{V}$ Examples

1. Determination of Reactants Adsorbed on Platinum Electrodes

(i) A Study of the $I_{2}-I^{-}$Couple at Platinum Thin Layer Electrodes

(ii) A Study of the $\mathrm{CoY}^{-}-\mathrm{CoY}^{-2}$ and

$\mathrm{FeY}^{-}-\mathrm{FeY}^{-2}$ Couples at Platinum Thin Layer Electrodes

2. Elucidation of the Stoichiometry of Complicated Reactions--A Study of the Electrochemistry of the Chloride, Bromide and Iodide Complexes of Platinum (II) and (IV) by Means of Thin Layer Electrochemistry 
-vii -

\section{CONTENTS}

Part

Page

(i) Experimental

(ii) $\mathrm{PtCl}_{4}{ }^{-2}$ and $\mathrm{PtCl}_{6}{ }^{-2}$

(iii) Hydrolysis of $\mathrm{PtCl}_{6}{ }^{-2}$

(iv) Supporting Electrolyte Effects

(v) $\mathrm{PtBr}_{6}{ }^{-2}$ and $\mathrm{PtBr}_{4}{ }^{-2}$

131

(vi) Hydrolysis of $\mathrm{PtBr}_{6}{ }^{-2}$

137

(vii) $\mathrm{PtI}_{6}{ }^{-2}$ and $\mathrm{PtI}_{4}{ }^{-2}$

142

(v111) Conclusions

146

Propositions

148 


\section{INTRODUCTION}

The potential usefulness of thin layer electrochemical experiments in which diffusion limitation of mass transfer may be neglected was first recognized by Christensen and Anson (1). Equations for thin layer chronopotentiometry were derived by them and verified experimentally for the $\mathrm{Fe}$ (III)-Fe(II) couple in perchloric acid. Allhough Schnidl and Gygax constructed a "chamber electrode" which resembled one of the designs described in reference (1), it appears that diffusion-limited mass transfer prevailed in their experiments (2).

In the present work practical thin layer electrodes have been constructed which are much simpler to use than those previously employed; equations for thin layer voltammetry and chronocoulometry of reversible and irreversible systems have been derived; and the thin layer electrochemical approach has been exploited for the study of several chemical problems which are typical of the many to which it appears well suited.

The equations which govern the design and use of electrodes for chronopotentiometry, voltammetry and chronocoulometry in thin layers are develuped in Parl II.

${ }^{1}$ C. R. Christensen and F. C. Anson, Anal. Chem., 35, 205 (1963).

${ }^{2}$ G. Schmidt and H. R. Gygax, Chimia, 16, 165 (1962). 
The details of construction and manipulation of the thin layer electrodes employed are given in Part III; in Part IV the results obtained with these electrodes for systems whose behavior is well known are compared with the theory. The suitability of thin layer electrochemistry for the study of systems where reactant adsorption occurs, and for the elucidation of the stoichiometry of complicated reactions is illus trated in Part $\mathrm{V}$, where studies of the $\mathrm{I}_{2}-\mathrm{I}^{-}, \mathrm{CoY}^{-}-\mathrm{CoY}^{-2}$, $\mathrm{FeY} \mathrm{Y}^{-}-\mathrm{FeY}^{-2}\left(\mathrm{II}_{4} \mathrm{Y}\right.$ - ethylenediaminetetra-acelic acid $)$ and $\mathrm{PtX}_{6}^{-2}-\mathrm{PtX}_{4}^{-2}(X=\mathrm{Cl}, \mathrm{Br}, \mathrm{I})$ couples are reported. 


\section{THEORY}

The equations for linear potential sweep voltammetry, chronocoulometry and chronopotentiometry in thin layers of solution are derived here for reversible and totally irreversible reactions. The equations for reactions of intermediate reversibility, which are complicated by the presence of insoluble integrals, are of limited practical usefulness and will not be given here. In an attempt to make this section as readable as possible, consideration of convection, electrical migration, ohmic potential differences and the electrical double layer as possible sources of complicated behavior has been reserved for Part IV.

1. Linear Potential Sweep Voltammetry in Thin

Layers of Solution

Case i: Reversible Reactions (3)

Consider a general reaction

$$
\mathrm{Ox}+\mathrm{ne}^{-} \rightleftharpoons \mathrm{R}
$$

which obeys the Nernst equation. For linear potential sweep rates that are sufficiently small, the concentrations of $\mathrm{Ox}$ and $\mathrm{R}$

3 A. T. Hubbard and F. C. Anson, Anal. Chem., 38, 58 (1966). 
in the thin layer cavity can be assumed uniform throughout the cavity (the conditions under which this is a good approximation are derived in Appendix 1). Using the Nernst equation, we have:

$$
\begin{aligned}
& C_{O X}=C_{O X}^{0}\left[1+\exp \frac{n F}{R T}\left(E^{0}-E\right)\right]^{-1} \\
& C_{R}=C_{R}^{0}\left[1+\exp \frac{n F}{R T}\left(E^{0}-E\right)\right]^{-1}
\end{aligned}
$$

If $\mathrm{Ox}$ and $\mathrm{R}$ are soluble in the solution, the current flowing through the thin layer cell is given for a negalive-going potential sweep by

$$
i=-n F V \frac{d C_{o x}}{d t}
$$

where $\mathrm{V}$ is the volume of the solution in the thin layer.

The rate of the potential sweep is

$$
\frac{d E}{d t}=r \text {. }
$$

Equations 1, 2, and 3 can be combined to give an equation for the current-potential curve

$$
i=\frac{n^{2} F^{2} V(-r) C_{O X}^{0} \exp \left[\frac{n F}{R T}\left(E^{0}-E\right)\right]}{R T\left\{\exp \left[\frac{n F}{R T}\left(E^{0}-E\right)\right]+1\right\}^{2}}
$$


A plot of Equation 4 is given in Figure 1. The peak current $i_{p}$ occurs at $E^{0}$ and is given by

$$
i_{p}=\frac{n^{2} F^{2}(-r) V C_{o x}^{0}}{4 R T}
$$

As would be expected, Equations 4 and 5 are identical to those derived by Scott for voltammetry with linear voltage sweep using a conventional coulometric cell and assuming infinitely. good stirring (4).

Comparison of Equation 4 with the Randles-Ševěik equation $(5,6)$ points out at once the greater simplicity inherent in thin layer potential sweep voltammetry owing to the absence of diffusion limited mass transfer. The peak-current expression for thin layers does not contain the diffusion coefficient and applies without change to stepwise reactions or mixed reactants provided that the standard potentials of the reactants differ by $\frac{0.2}{n}$ volt (otherwise the current components are additive). Two peaks can be distinguished qualitatively when the standard potentials differ by about 0.05 volt. Multiple-sweep experiments

${ }^{4}$ F. A. Scott, et.al., Anal. Chem., 33, 1024 (1961).

5 J. E. B. Randles, Trans. Farad. Soc., 4ㅗ, 327 (1948).

${ }^{6}$ A. Sevčik, Coll. Czech. Chem. Commun., 13, 349 (1948). 
$-6-$

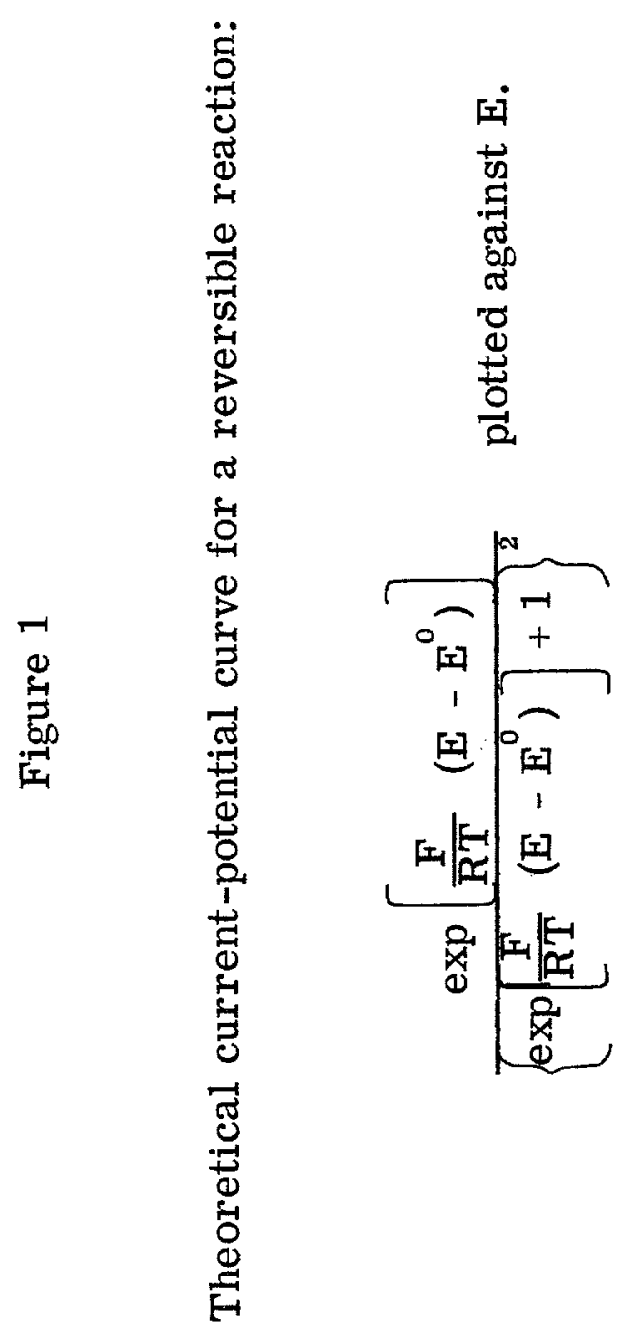




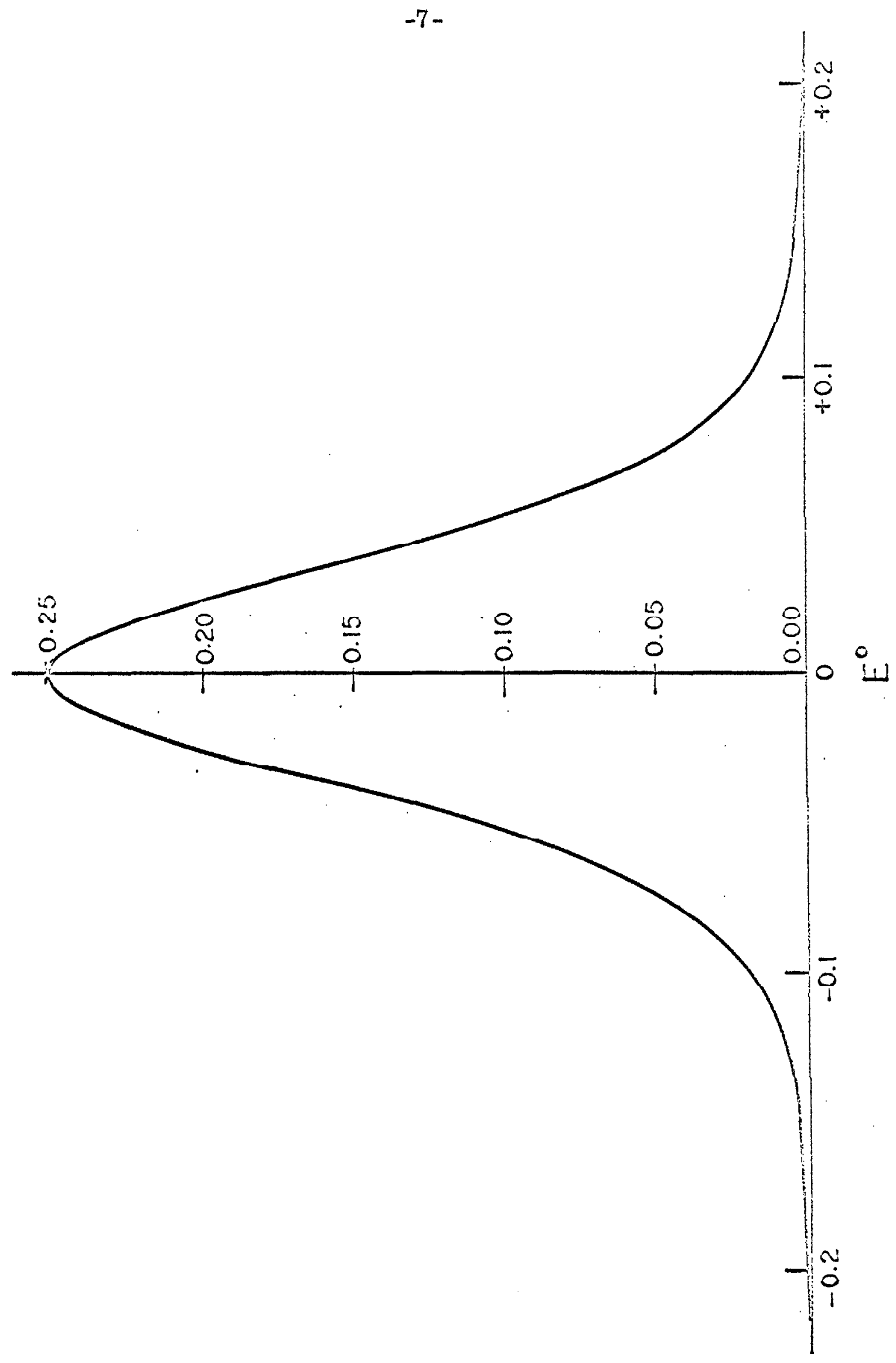


in thin layers of solution involve no additional complications. The peak current expression is identical for the anodic and cathodic sweeps for any number of cycles.

More than an order of magnitude smaller current densities are necessary than in ordinary linear sweep voltammetry, which allows the otherwise impossible study of irreversible systems that react quite close to the supporting electrolyte. This can be seen from the following calculation: the expression for $i_{p}$ in ordinary voltammetry is

$$
i_{p}=\frac{0.452 \mathrm{n}^{\frac{3}{2}} \mathrm{~F}^{\frac{3}{2}} \mathrm{~A} \mathrm{C}_{\mathrm{ox}}^{0} \mathrm{D}^{\frac{1}{2}} \mathrm{r}^{\frac{1}{2}}}{\mathrm{R}^{\frac{1}{2}} \mathrm{~T}^{\frac{1}{2}}}
$$

Thus, making all the corresponding parameters equal, we have the ratio of current densities

$$
\frac{i_{p}}{i_{p} \text { (thin layer) }}=\left[\frac{R T D}{n F}\right]^{\frac{1}{2}} \frac{3.616}{r^{\frac{1}{2}} \ell}=\frac{0.579 \mathrm{D}^{\frac{1}{2}}}{r^{\frac{1}{2}} \ell}
$$

For instance if $r=10^{-3} \frac{\text { volt }}{\text { sec. }}, \ell=10^{-3} \mathrm{~cm}$. and $\mathrm{D}=6 \times 10^{-6}$ $\frac{\mathrm{cm}^{2}}{\text { second }}$, we have

$$
\frac{i_{p}}{i_{p}(\text { thin layer })}=45
$$


Case ii. Irreversible Reactions

In the event that the reaction does not obey the Nernst equation, the preceeding equations do not apply. Instead, for sufficiently small sweep rates (Appendix 1), the current will be given for a cathodic sweep by

$$
i=-n F V \frac{d C_{o x}}{d t}=n F A\left(k_{f} C_{o x}-k_{b} C_{R}\right)
$$

If the anodic component of the current can be neglected (the conditions under which this is a good approximation are derived in Appendix 2), Equation 7 becomes

$$
\frac{\mathrm{dC}_{\mathrm{ox}}}{\mathrm{dt}}=\frac{-\mathrm{A}}{\mathrm{V}} \mathrm{k}_{\mathrm{f}} \mathrm{C}_{\mathrm{ox}}
$$

which after integration yields

$$
C_{o x}=C_{o x}^{n} \exp \frac{A}{\bar{V}} \frac{R T}{n_{0} F} \frac{1}{\alpha r} k_{f}
$$

$\mathrm{k}_{\mathrm{f}}$ is related to $\mathrm{E}$ by

$$
\mathrm{k}_{\mathrm{f}}=\mathrm{k}^{0} \exp \frac{-\alpha \mathrm{n}_{0} \mathrm{~F}}{\mathrm{RT}}\left(\mathrm{E}-\mathrm{E}^{0}\right)
$$

$\mathrm{n}_{0}$ is the number of electrons involved in the rate-determining step and $\alpha$ is the charge-transfer coefficient of the electrode 
process. Equations 7, 8, and 9 can be combined to give the equation for the current-potential curve

$$
\begin{aligned}
& i=n F^{0} C_{o x}^{0} \exp \left\{\frac{-\alpha n_{0} F}{R T}\left(E-E^{0}\right)\right. \\
& \left.+\frac{A}{V} \frac{R T}{\alpha n_{0} F} \frac{k^{0}}{r} \exp \left[\frac{-\alpha \mathrm{n}_{0} F}{R T}\left(E-E^{0}\right)\right]\right\}
\end{aligned}
$$

A plot of Equation 10 for several values of $\mathrm{k}^{0}$ appears in Figure 2.

The shape of the curves is not affected by $k^{0}$ in the range for which Equation 10 applies; the curves are merely shifted along the axis of potentials. However, the breadth of the current-potential curve increases substantially with decreasing values of $\alpha \mathrm{n}_{0}$. The peak potential is

$$
\mathrm{E}_{\mathrm{p}_{\text {(cathodic) }}}=\mathrm{E}^{0}+\frac{2.303 \mathrm{RT}}{\alpha \mathrm{n}_{0} \mathrm{~F}} \log \left[\frac{\mathrm{ART} \mathrm{k}}{\alpha \mathrm{n}_{0} \mathrm{~F}(-\mathrm{r}) \mathrm{V}}\right]
$$

The peak current is

$$
i_{p}=\frac{\alpha n_{0} F^{2} V(-r) C_{o x}^{o}}{\text { e RT }}
$$

where e = 2.718. Dividing Equation 12 with Equation 5, we have the ratio

$$
\frac{i_{p}(\text { thin layer, irreversible })}{i_{p}(\text { thin layer, reversible })}=1.470 \frac{n_{0} \alpha}{n}
$$




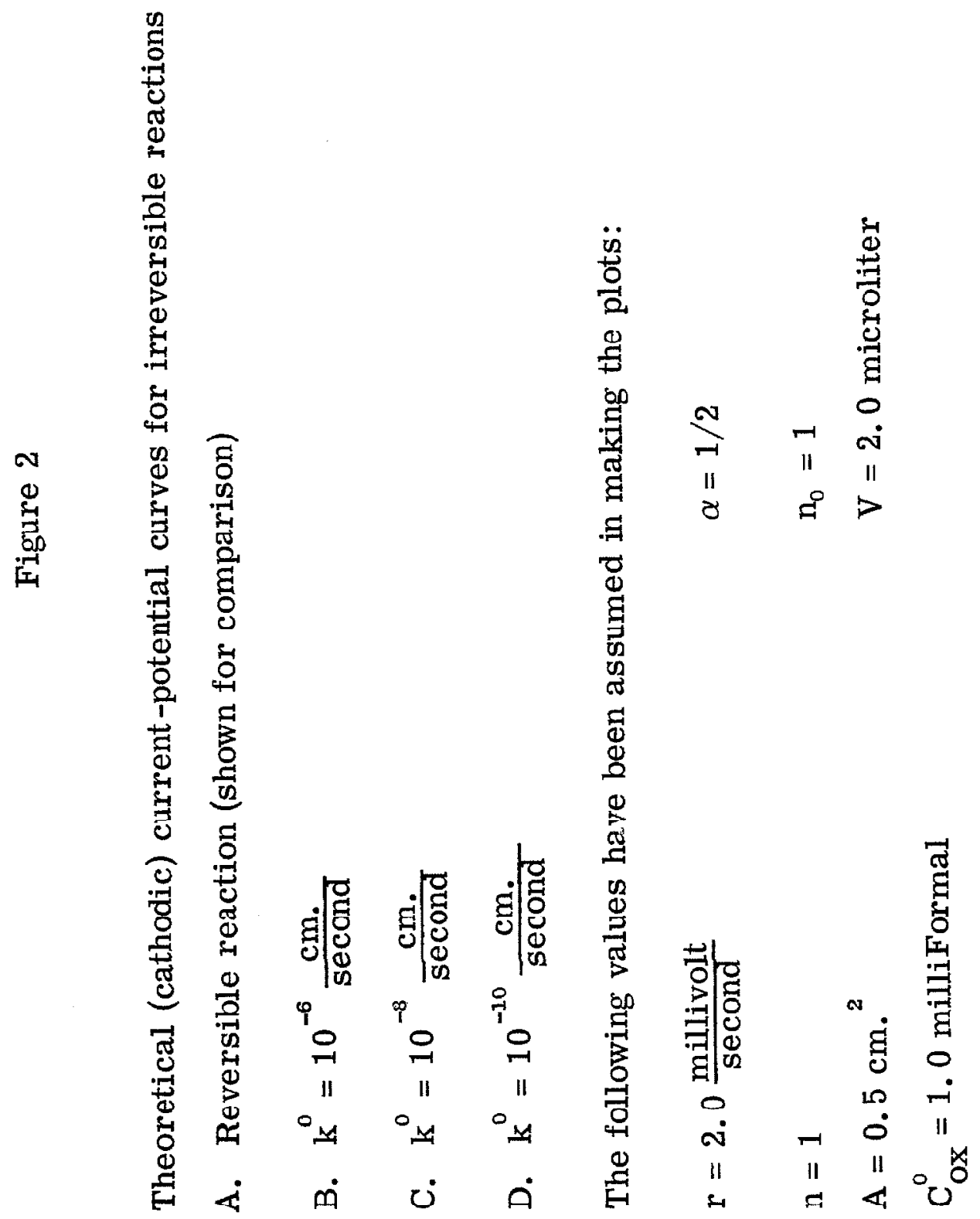




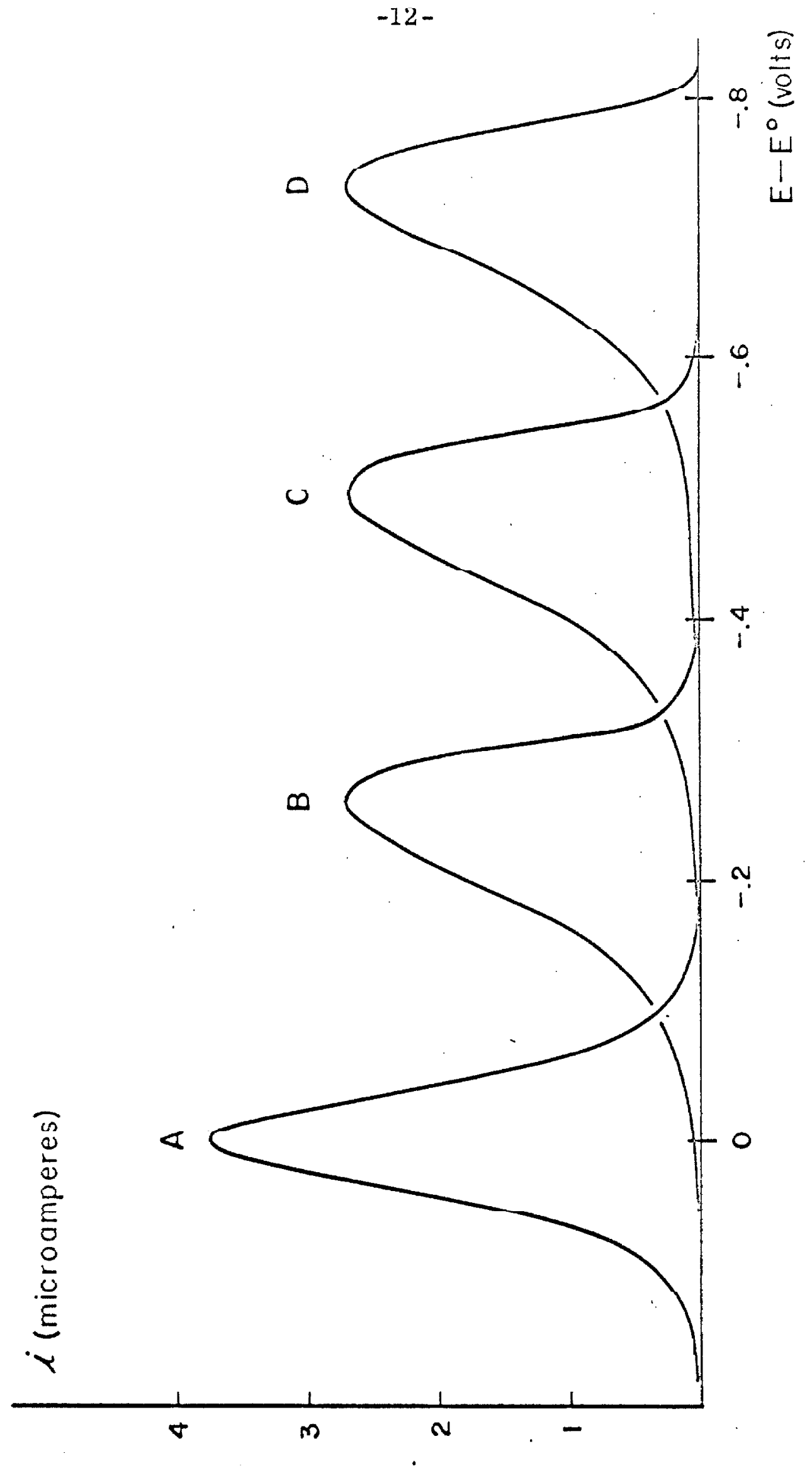


Thus, since $n_{0} \leqq n$, the peak current expected for irreversible cases will be smaller than for the reversible except when $\alpha$ is greater than about 0.7 .

Equations 10, 11, and 12 apply to anodic processes after the following changes are made: $\alpha$ is replaced by $(1-\alpha), \mathrm{C}_{\mathrm{ox}}^{0}$ by $\mathrm{C}_{\mathrm{R}^{0}}^{0}$, and $\mathrm{n}_{0}$ (cathodic) by $\mathrm{n}_{\mathrm{o}}$ (anodic).

By combining Equations 11 and 12 and solving for $\mathrm{k}^{0}$ we obtain

$$
k^{0}=\frac{i_{p} e}{n F A C_{O X}^{0}} \exp \left[\frac{i_{p} e\left(E_{p}-E^{0}\right)}{n F V(-r) C_{o x}^{0}}\right]
$$

Equation 13 allows the calculation of the rate constant $\mathrm{k}^{0}$ from the measured values of the peak current and potential whenever the standard potential $\mathrm{E}^{0}$ of the reaction is known. 
2. Chronocoulometry in Thin Layers of Solution (7)

In a typical chronocoulometric experiment the electrode potential is varied instantaneously from a potential $E_{1}$ at which no current flows to a potential $E_{2}$ at which the electrochemical reaction can occur, and the current integrated electronically. In thin layers of solution the charge $Q$ required for complete consumption of the reactant is given by Faraday's law

$$
\mathrm{Q}=\mathrm{nFV} \mathrm{C}^{0}
$$

Equation 14 is applicable whether or not the reaction is reversible so long as it is allowed to proceed to completion. The time required for $Q$ to become constant is about 0.1 second for reversible systems, but is somewhat longer (depending on the values of $k^{0}$ and $E_{9}$ ) for irreversible ones (see Appendix 3).

${ }^{7}$ A. T. Hubbard, F. C. Anson, and R. A. Osteryoung, Anal. Chem., 38, 692 (1966). 
3. Chronnontentiometry in Thin Layers of Solution

Although the chronopotentiometric measuring technique can usually he ahandoned in favor of voltammetry and chronocoulometry, there are instances in which its constant current density or uncomplicated circuitry make it the best approach. The theory of thin layer chronopotentiometry was derived by Christensen and Anson (1) for reversible reactions; a summary of their results is included in what follows.

Case i. Reversible Reactions (1)

Consider the general reaction

$$
\mathrm{Ox}+\mathrm{ne}^{-} \rightleftharpoons \mathrm{R}
$$

which obeys the Nernst equation

$$
E=E^{0}+\frac{R T}{n F} \ln \frac{C_{o x}(O, t)}{C_{R}(O, t)}
$$

If $O x$ is reduced at constant current and $\frac{l^{2}}{3 D \tau}$ is made sufficiently small, we have

$$
C_{R}(O, t)=C_{o x}^{0}-C_{o x}(O, t)=\frac{i t}{n F V}
$$


Combining Equations 16 and 17 gives

$$
E=E^{0}+\frac{R T}{n F} \ln \left(\frac{C_{\mathrm{ox}}^{0} \mathrm{nFV}}{i t}-1\right)
$$

A plot of Equation 17 appears in Figure 3. The transition time $\tau$, at which $\mathrm{C}_{\mathrm{ux}}(\mathrm{O}, \mathrm{t})$ becomes zero, is given by

$$
\tau=\frac{\mathrm{nFVC}}{i}
$$

within a relative error less than $\epsilon$, provided that $\frac{l^{2}}{3 \mathrm{D} \tau}<\epsilon$. For instance, if $\ell=10^{-5} \mathrm{~cm}, D=10^{-5} \frac{\mathrm{cm}^{2}}{\text { second }}$, and we require $\epsilon<10^{-2}$ (1\% relative error), then the experimental conditions must be adjusted to give $\tau$ values in the range $\tau>3.3$ second.

\section{Case ii. Irreversible Reactions}

In the event that the Nernst equation is not obeyed, the transition time $\tau$ is given by Equation 19 as for a reversible reaction; however, Equation 18 for the current-time curve is no longer applicable. It is easy to show that for $k_{f}<\frac{i}{A^{0} F}$ the back reaction can be neglected so that

$$
i=\mathrm{nFAk}^{0} \mathrm{C}_{\mathrm{ox}} \exp \left[\frac{-\alpha \mathrm{n}_{0} \mathrm{~F}}{\mathrm{RT}}\left(E-E^{0}\right)\right]
$$




\section{Figure 3}

Theoretical chronopotentiometric potential-time curves
A. reversible reaction
B. irreversible reaction

The following values have been assumed in making the plot:

$$
\begin{array}{ll}
\mathbf{E}^{0} & =0.00 \\
\mathbf{T} & =298^{\circ} \mathrm{k} \\
\mathbf{n} & =\mathrm{n}_{0}=1 \\
\mathbf{C}_{\mathrm{ox}}^{0} & =1.0 \text { milliFormal } \\
\mathrm{V} & =1.0 \text { microliter } \\
\mathbf{i} & =10 \text { microampere } \\
\mathrm{A} & =0.5 \mathrm{~cm} . \\
\mathrm{k}^{0} & =10^{-6} \frac{\mathrm{cm} .}{\text { sec. }} \\
\alpha & =0.5
\end{array}
$$


$-18-$

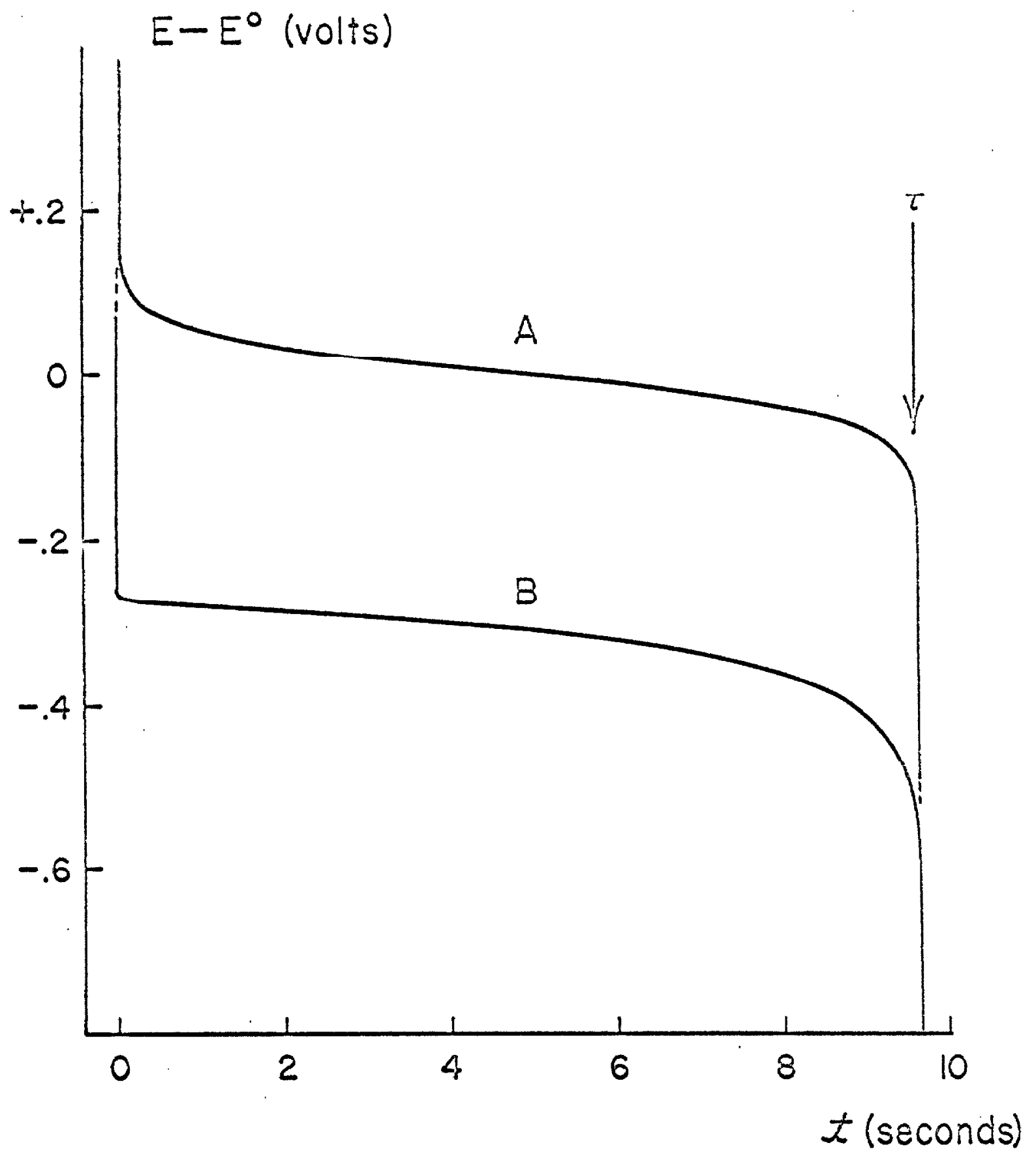


Equation 19 can be written

$$
i=n F A k^{\circ}\left(C^{0}-\frac{i t}{n F^{\prime} V}\right) \exp \frac{-\alpha n_{0} F}{R T}\left(E-E^{0}\right)
$$

Solving for $\mathrm{E}$ we have

$$
\mathrm{E}=\mathrm{E}^{0}+\frac{\mathrm{RT}}{\alpha \mathrm{m}_{0} \mathrm{~F}} \ln \left(\mathrm{C}^{0}-\frac{\mathrm{it}}{\mathrm{nFV}}\right)\left(\frac{\mathrm{nFAk}}{\mathrm{i}}\right)
$$

A plot of Equation 21 appears in Figure 3.

A theoretical basis for obtaining the transition time from the chronopotentiometric curve of sufficient generality to allow its use in practical situations (where currents of uncertain magnitude are required by double-layer-charging and by background reactions) has not been deduced. In the present work a graphical method has been employed which appears to give consistent results (Part IV). 


\section{Appendix 1}

\section{Conditions for Thin Layer Voltammetry}

In order to estimate the maximum sweep rate for which Equations 1, 4, and 5 hold, it is necessary to solve the problem taking diffusion effects into account, and to determine the conditions under which this exact solution becomes identical with the simple theory. We seek a solution of the diffusion equation in the form

$$
\frac{\partial \mathrm{C}_{\mathrm{ox}}(\mathrm{x}, \mathrm{t})}{\partial t}=\mathrm{D}_{\mathrm{Ox}} \frac{\partial^{2} \mathrm{C}_{\mathrm{ox}}(\mathrm{x}, \mathrm{t})}{\partial \mathrm{x}^{2}}
$$

subject to the boundary conditions that $\mathrm{C}_{\mathrm{ox}}$ and $\mathrm{C}_{\mathrm{R}}$ be given by the Nernst equation at the electrode surface. The analogous problem in heat diffusion has been solved by Carslaw and Jaeger (8). If the thin layer cavity is composed of parallel planar electrode surfaces, the solution is

$$
\begin{gathered}
\mathrm{C}_{\mathrm{ox}}=\mathrm{C}_{\mathrm{ox}}^{0} \sum_{\mathrm{k}=0}^{\infty} \exp \left(\frac{\left(-(2 \mathrm{k}+1)^{2} \pi^{2} \mathrm{Dt}\right.}{\ell^{2}}\right) \sin \frac{(2 \mathrm{k}+1) \pi \mathrm{x}}{\ell} \times \\
{\left[\frac{4}{\pi(2 \mathrm{k}+1)^{+}}+\frac{4 \mathrm{D} \pi}{\ell^{2}}(2 \mathrm{k}+1) \int_{0}^{\mathrm{t}} \frac{\exp \left(\frac{(2 \mathrm{k}+1)^{2} \pi^{2} \mathrm{Dy}}{\ell^{2}}\right)}{1+\exp \left(\frac{\mathrm{nF}}{\mathrm{RT}}[\mathrm{E}-\mathrm{E}(0)]-\mathrm{ry}\right)} d \mathrm{dy}\right.}
\end{gathered}
$$

${ }^{8}$ H. S. Carslaw and J. C. Jaeger, Conduction of Heat in Solids, 2nd ed., Section 3.5, Oxford: Clarendon Press, 1959. 
$\ell$ is the thickness of the thin layer cavity and $D$ is the diffusion coefficient of $O x$.

For values of $\mathrm{r}$ sufficiently small the integral appearing in Equation (i) can be approximated according to Equation (ii):

$$
\begin{aligned}
& \left.I \equiv \int_{0}^{t} \frac{\exp \left(\frac{(2 k+1)^{2} \pi^{2} D y}{l^{2}}\right)}{1+\exp \left(\frac{n F}{R T}\left[E^{0}-E(0)\right]-r y\right.}\right) d y \approx \\
& \frac{\ell^{2} \exp \left(\frac{(2 k+1)^{2} \pi^{2} D t}{l^{2}}\right)}{\pi^{2} D(2 k+1)^{2}\left[1+\exp \left(\frac{n F}{R T}\left[E^{0}-E(0)\right]-r t\right)\right]}
\end{aligned}
$$

so that Equation (i) becomes

$$
\begin{aligned}
C_{\text {ox }}=C_{\text {ox }}^{0} & {\left[\frac{1}{\exp \left(\frac{n F}{R T}\left[E^{0}-E(0)\right]-r t\right)+1}\right] } \\
& =C_{o x}^{0} \frac{1}{\exp \left[\frac{n F}{R T}\left(E^{0}-E\right)\right]+1}
\end{aligned}
$$

That is, for sufficiently small values of $r$, Fquation (i) reduces to the Nernst equation.

The values of $r$ for which Equation (ii) applies can be determined as follows: decompose the range of integration $(0, t)$ into $N$ equal parts (where $N \approx t$ ) 
$I=\sum_{\lambda=1}^{N} \int_{\frac{(\lambda-1) t}{N}}^{\lambda t} \frac{\exp \left(\frac{(2 k+1)^{2} \pi^{2} D y}{\ell^{2}}\right)}{1+\exp \left(\frac{n F}{R T}\left[E^{0}-E(0)\right]-r y\right)} d y$

For typical values of the experimental parameters $\left(l^{2}=10^{-6} \mathrm{sq} . \mathrm{cm}\right.$., $\mathrm{D}=10^{-5} \mathrm{sq} . \mathrm{cm} . / \mathrm{sec} ., \mathrm{E}^{0}-\mathrm{E}(0)=-0.2$ volt, and $\mathrm{T}=298^{\circ} \mathrm{K}$.), the numerator of the integrand increases very rapidly with y for all values of $\mathrm{k}$ while the denominator changes much more slowly; thus, for suitable values of $r$, we have

$$
\begin{aligned}
& I \approx \sum_{\lambda=1}^{N} \frac{1}{1+\exp \left(\frac{n F}{R T}\left[E^{0}-E(0)\right]-\frac{r \lambda t}{N}\right)} \\
& \times \int_{\frac{(\lambda-1) t}{N}}^{\frac{\lambda t}{N}} \exp \left(\frac{(2 K+1)^{2} \pi^{2} D y}{l^{2}}\right) d y
\end{aligned}
$$

wh1ch after integralion yields

$$
1 \approx \sum_{\lambda=1}^{N} \frac{l^{2}\left[\exp \left(\frac{(2 k+1)^{2} \pi^{2} D \lambda t}{l^{2} N}\right)-\exp \left(\frac{(2 k+1)^{2} \pi^{2} D(\lambda-1) t}{l^{2} N}\right)\right]}{\pi^{2} D(2 k+1)^{2}\left\{1+\exp \left(\frac{n F}{R T}\left[E^{0}-E(0)-\frac{r \lambda t}{N}\right]\right)\right\}}
$$

The summation (vi) is clearly dominated by its $\lambda=N$ term; 
keeping only this term we obtain

$$
I \approx \ell^{2} \frac{\left[\exp \left(\frac{(2 \mathrm{k}+1)^{2} \pi^{2} \mathrm{Dt}}{\ell^{2}}\right)-\exp \left(\frac{(2 \mathrm{k}+1)^{2} \pi^{2} \mathrm{D}(\mathrm{N}-1) \mathrm{t}}{\mathrm{N}}\right)\right]}{\pi^{2} \mathrm{D}(2 \mathrm{k}+1)^{2}\left[1+\exp \left(\frac{\mathrm{nF}}{\mathrm{RT}}\left[\mathrm{E}^{0}-\mathrm{E}(0)-\mathrm{rt}\right]\right)\right]}
$$

$\frac{N-1}{N}$ can be chosen so that $\exp \left(\frac{(2 K+1)^{2} \pi^{2} D t}{l^{2}}\right)$ is always larger than $\exp \left(\frac{(2 k+1)^{2} \pi^{2} \mathrm{D}(\mathrm{N}-1) \mathrm{t}}{\mathrm{N} l^{2}}\right)$ by some factor $M$ in which case case Equation (vii)takes the simpler form of Equation (ii)

$$
\begin{aligned}
& I \approx \frac{1}{\pi^{2} \mathrm{D}(2 \mathrm{k}+1)^{2}} \times \\
& \quad \frac{\ell^{2} \exp \left(\frac{(2 \mathrm{k}+1)^{2} \pi^{2} \mathrm{Dt}}{\ell^{2}}\right)}{\left[1+\exp \left(\frac{\mathrm{nF}}{\mathrm{RT}}\left[\mathrm{E}^{0}-\mathrm{E}(0)\right]-\mathrm{rt}\right)\right]}
\end{aligned}
$$

the relative error incurred in this approximation being $1 / \mathrm{M}$; the required values of $\mathrm{N}$ are:

$$
\mathrm{N} \leqq \frac{(2 \mathrm{k} \cdot+1)^{2} \pi^{2} \mathrm{Dt}}{(2.3 \log \mathrm{M}) \ell^{2}}
$$

It remains to find the range of $\mathbf{r}$ for which the approximations (v) through (vii) included in the derivation of (ii) lead to a relative error of less than $\epsilon$. Since the error in the approximation leading to (ii) arises from the departure of the denominator 
of the integrand from its assumed constancy, we have the relation

$$
\frac{1+\exp \left(\frac{n F}{R T}\left[E^{0}+E(0)-r t\right]\right)}{1+\exp \left(\frac{n F}{R T}\left[E^{0}-E(0)\right]-r \frac{(N-1)}{N} t\right)}-1<\epsilon
$$

where $\frac{N-1}{N}$ is to be calculated from (viii). Since the accuracy of the approximations improves sharply with increasing $k$, it is sufficient to consider only the case for which $\mathrm{k}=0$. For convenicnec in manipulation of (ix) assume that

$$
t=\frac{E^{n}-E(0)}{r}
$$

Thus, from (viii) and (ix) we obtain an expression giving the maximum sweep rate for which $\mathrm{C}_{\mathrm{ox}}$ will be given by the Nernst equation with a relative error less than $\epsilon$ :

$$
\begin{aligned}
& |r| \leqq \\
& \frac{R T}{n F} \frac{\pi^{2} D}{\ell^{2} \ln M} \log _{e}\left(\frac{2}{\epsilon+1}-1\right)
\end{aligned}
$$

It is easily seen that the relative errur in $\mathrm{i}$ is lwice that in $\mathrm{C}_{\mathrm{ox}}$; to assure that the relative error in $i$ will be less than $\epsilon$ we 
must have

$$
|r| \leq\left|\cdots \frac{\mathrm{RT}}{\mathrm{nF}} \frac{\pi^{2} \mathrm{D}}{\ell^{2} \log _{e} M} \log \left(\frac{4}{\epsilon+2}-1\right)\right|
$$

As examples, if $\ell^{2}=10^{-6} \mathrm{sq}$. cm., $\mathrm{D}=10^{-5} \mathrm{sq} . \mathrm{cm} . / \mathrm{sec}$, $\mathrm{E}^{0}-\mathrm{E}(0)=-0.2$ volt, $\mathrm{M}=10^{3}$, and $\mathrm{T}=298^{\circ} \mathrm{K}$, Equation (xi) becomes

$$
|r| \leqq \log \left[\frac{2}{1+1 / 2 \epsilon}-1\right] \mid
$$

and if $\epsilon=0.05$ we must have

$$
|r| \leqq 22 \mathrm{mv} . / \mathrm{sec} \text {. }
$$

or if $\epsilon=0.01$ we must have

$$
|\mathrm{r}| \leqq 5 \mathrm{mv} . / \mathrm{sec} .
$$

Equation (xi) is useful in the construction and use of thin layer electrodes, since it relates the thin layer cavily lhickness $\ell$ to the relative error $\epsilon$ incurred in the use of the simplified theory for a given set of experimental conditions. 


\section{Appendix 2}

Conditions for Total Irreversibility in Thin

Layer Voltammetry

The conditions under which Equation 7 applies can be obtained from the following calculation: The back reaction, which is most rapid near the beginning of the sweep, leads to a hrger reactant concentration at a given potential than would be observed in the absence of a back reaction. 'I'hus, the relative error entailed in neglecting the back reaction will be less than $\epsilon$ provided that

$$
\frac{\mathrm{C}_{\mathrm{R}}}{\mathrm{C}_{\mathrm{ox}}^{0}}=\frac{\mathrm{C}_{\mathrm{ox}}^{0}-\mathrm{C}_{\mathrm{ox}}}{\mathrm{c}_{\mathrm{ox}}^{0}} \leqq \epsilon
$$

whenever

$$
\frac{\mathrm{k}_{\mathrm{b}}}{\mathrm{k}_{\mathrm{f}}} \geqq \epsilon
$$

Thus, we have

$$
\mathrm{C}_{\mathrm{ox}}^{\mathrm{o}}-\mathrm{C}_{\mathrm{ox}}=\frac{1}{\mathrm{nFV}} \int_{0}^{\mathrm{t}} \mathrm{idt} \leqq \epsilon \mathrm{C}_{\mathrm{ox}}^{0}
$$

Calculation of (iii) is simplified by employing the relation $i \leqq n F A$ $\mathrm{C}_{\mathrm{ox}}^{0} \mathrm{kf}$. Combining Equations (i), (ii) and (iii) and solving for $\mathrm{k}^{0}$, 
we have

$$
\mathrm{k}^{0} \leqq \frac{\epsilon \alpha \mathrm{n}_{0} V F(-r)}{A R T}\left\{\epsilon^{-\alpha}-\exp \left[\frac{-\alpha \mathrm{n}_{0} F}{R T}\left(\mathrm{~F}(0)-E^{0}\right)\right]\right\}^{-1} \text { (iv) }
$$

The exponential term is vanishingly small and

$$
\mathrm{k}^{0} \leqq \frac{\alpha \mathrm{n}_{0} \mathrm{VF}(-\mathrm{r})}{\operatorname{ART}} \epsilon^{1+\alpha}
$$

Thus, for a typical set of experimental conditions

$\left(\mathrm{E}^{0}=0, \mathrm{r}=2 \mathrm{mv} / \mathrm{second}, \mathrm{C}_{\mathrm{Ox}}^{0}=10^{-3} \mathrm{M}, \mathrm{A}=0.5 \mathrm{~cm} .^{2}\right.$,

$\mathrm{V}=1 \times 10^{-3} \mathrm{~cm}^{3}, \alpha=1 / 2, \mathrm{n}_{0}=1, \mathrm{~T}=298^{\circ} \mathrm{K}$ ), we must have

$\mathrm{k}^{0} \leqq 10^{-6} \frac{\text { cin. }}{\text { sec. }}$ in order that $\epsilon \leqq 0.05$. 


\section{Appendix 3}

Minimum Time Required for $\mathrm{Q}$ to Become

Constant in Thin Layer Chronocoulometry.

Consider a general reaction

$$
\mathrm{Ox}+\mathrm{ne}{ }^{-} \rightleftharpoons \mathrm{R}
$$

which obeys the Nernst equation. Before the start of the experiment the potential is adjusted to $E_{1}$, where virtually all of the reactant should be present in the oxidized form; at $t=0$ the potential is changed instantaneously to $E_{2}$ where virtually complete reduction to $\mathrm{R}$ can occur. If the rate of reduction at $\mathrm{E}_{2}$ is controlled solely by the rate of diffusion of Ox to the surface of the thin layer electrode, and the thin layer cavity is composed of parallel planar electrode surfaces, the concentration of $\mathrm{Ox}$ in the cavity will be given (8) by

$$
C(x, t)=\frac{4 C^{0}}{\pi} \sum_{m=1}^{\infty} \frac{1}{2 m-1} \exp \left[\frac{-(2 m-1)^{2} \pi^{2} D t}{l^{2}}\right] \sin \frac{(2 m-1) \pi x}{\ell}
$$

The current-time equation is

$$
i(t)=n F A D\left(\frac{\partial C(x, t)}{\partial x}\right)_{x=0}=\frac{4 n F A D C^{0}}{\ell} \sum_{m=1}^{\infty} \exp \left[\frac{-(2 m-1)^{2} \pi^{2} D t}{l^{2}}\right]
$$


which after integration yields

$\mathrm{Q}(\mathrm{t})=\mathrm{nFVC} \mathrm{C}^{0}\left\{1-\frac{8}{\pi^{2}} \sum_{\mathrm{m}=1}^{\infty}\left(\frac{1}{2 \mathrm{~m}-1}\right)^{2} \exp \left[\frac{-(2 \mathrm{~m}-1)^{2} \pi^{2} \mathrm{Dt}}{\ell^{2}}\right]\right\}$

The summation on the right of Equation (iii) tends rapidly to zero as $t$ increases, so that $Q(t)$ is given simply by Faraday's law for $t$ sufficiently large. If $\ell^{2}<10^{-5} \mathrm{~cm}^{2}$ and $t>0.02$ second, (iii) takes the simpler form

$$
\mathrm{Q}(\mathrm{t})=\mathrm{nFVC} \mathrm{C}^{\circ}\left\{1-\exp \left[\frac{-\pi^{2} \mathrm{Dt}}{l^{2}}\right]\right\}
$$

From Equation (iv) we obtain

$$
\tau_{\text {IIIIn }}=\frac{-l^{2}}{\pi^{3} \mathrm{D}} \ln \epsilon
$$

which gives the minimum time $\tau_{\text {min }}$ required to complete a thin layer chronocoulometric measurement. For instance, if $\mathrm{D}=10^{-5} \frac{\mathrm{cm}^{2}}{\mathrm{sec}}$, and $\epsilon=0.01$ ( $1 \%$ relative error), $\tau_{\min }$ will be 0.046 and 0.46 second for $\ell^{9}$ equal to $10^{-5}$ and $10^{-6} \mathrm{~cm}_{j}^{2}$ respectively.

In case the Nernst equation is not obeyed, Equations (i)-(iv) are not applicable. Instead, if the reaction is totally irreversible (that is, if $\mathrm{k}_{\mathrm{f}}\left(\mathrm{E}_{2}\right)=\mathrm{k}^{0} \exp \left[\frac{-\alpha \mathrm{n}_{\mathrm{o}} \mathrm{F}}{\mathrm{RT}}\left(\mathrm{E}_{2}-\mathrm{E}^{\circ}\right.\right.$ ) $]$ $<10^{-4} \frac{\mathrm{cm} \text {. }}{\mathrm{sec}}$-- see Appendix 2) the current density will always be sufficiently small that the reactant concentration can be 
assumed relatively uniform throughout the cavity, and we have

$$
\frac{\mathrm{dC}(\mathrm{t})}{\mathrm{dt}}=\frac{\mathrm{Ak}_{\mathrm{f}}\left(\mathrm{E}_{2}\right) \mathrm{C}(\mathrm{t})}{\mathrm{V}}
$$

which leads to

$$
C(t)=C^{0} \exp \left[\frac{-A k_{f}\left(E_{2}\right) t}{V}\right] .
$$

The current is

$$
i=n F V \frac{d C}{d t}=n F V A k_{f} C^{0} \exp \left[\frac{-A_{f}\left(E_{2}\right) t}{V}\right]
$$

and after integration we have

$$
\mathrm{Q}(\mathrm{t})=\mathrm{nFVC} \mathrm{C}^{0}\left\{1-\exp \left[\frac{-\mathrm{Ak}_{\mathrm{f}}\left(\mathrm{E}_{2}\right) \mathrm{t}}{\mathrm{V}}\right]\right\}
$$

Putting $Q(t)=(1-\epsilon)$ nFVC $^{\circ}$ in Equation (ix) we obtain $\tau_{\text {min }}$ (irreversible) $=\frac{-\mathrm{V}}{\mathrm{Ak}_{\mathrm{f}}\left(\mathrm{E}_{2}\right)} \ln \epsilon$. For instance, if $\mathrm{V}=1 \times 10^{-3} \mathrm{~cm}^{3}$., $\mathrm{A}=\frac{1}{2} \mathrm{~cm}^{2}$, and $\mathrm{k}_{\mathrm{f}}=10^{-4} \frac{\mathrm{cm} \cdot}{\mathrm{sec} .}$, then $\tau_{\min }$ (irreversible) $=92$ seconds as compared with ca. 0.1 second for a reversible reaction. 


\section{Apparatus}

Although the thin layer electrodes employed prior to this study (1) served to demonstrate the potential usefulness of the thin layer approach, they were unnecessarily difficult to use. In this study (9), three new electrodes were devised which were simple to construct and could be rapidly filled and cleaned.

The first electrode imprisoned the thin layer of solution between the inner wall of a short section of precision-bore glass capillary tubing and a close-fitting platinum wire inserted into the tubing (Figure 4). The second electrode was constructed from a micrometer to which platinum faces had been attached; the thin layer of solution was confined between the faces of the micrometer which were equipotential (Figure 6). A more difficult task, construction of a thin layer electrode having a mercury surface, was also accomplished (Figure 8).

1. The Glass Capillary-Wire Electrode

The glass capillary-wire electrode (Figure 4)

${ }^{9}$ A. T. Hubbard and F. C. Anson, Anal. Chem., 36, 723 (1966). 
Figure 4

Glass capillary-wire electrode

A. Unit constructed with standard-taper glass supporting members.

B. Unit constructed with Teflon supporting members. 
$-33-$

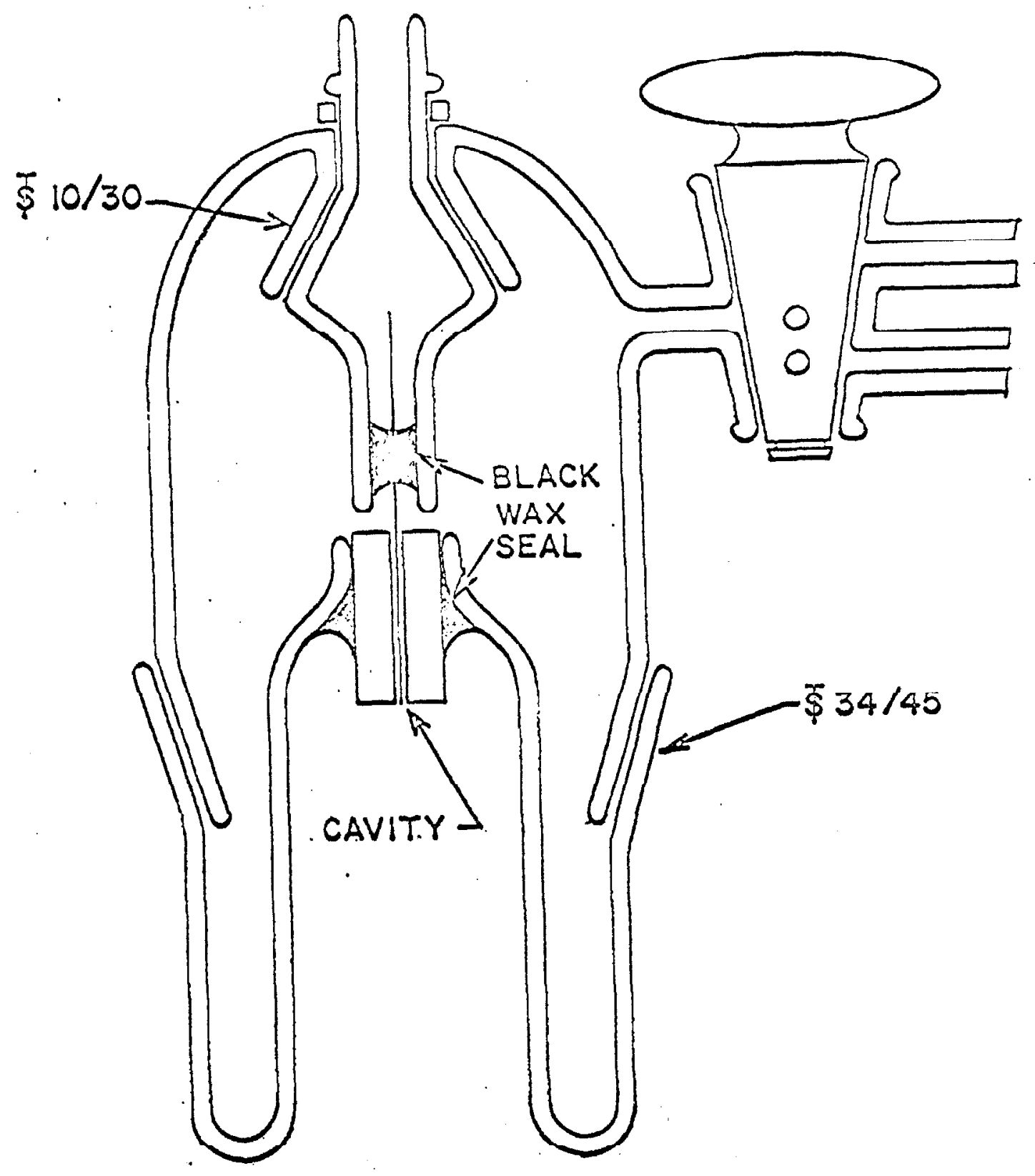

4-A 


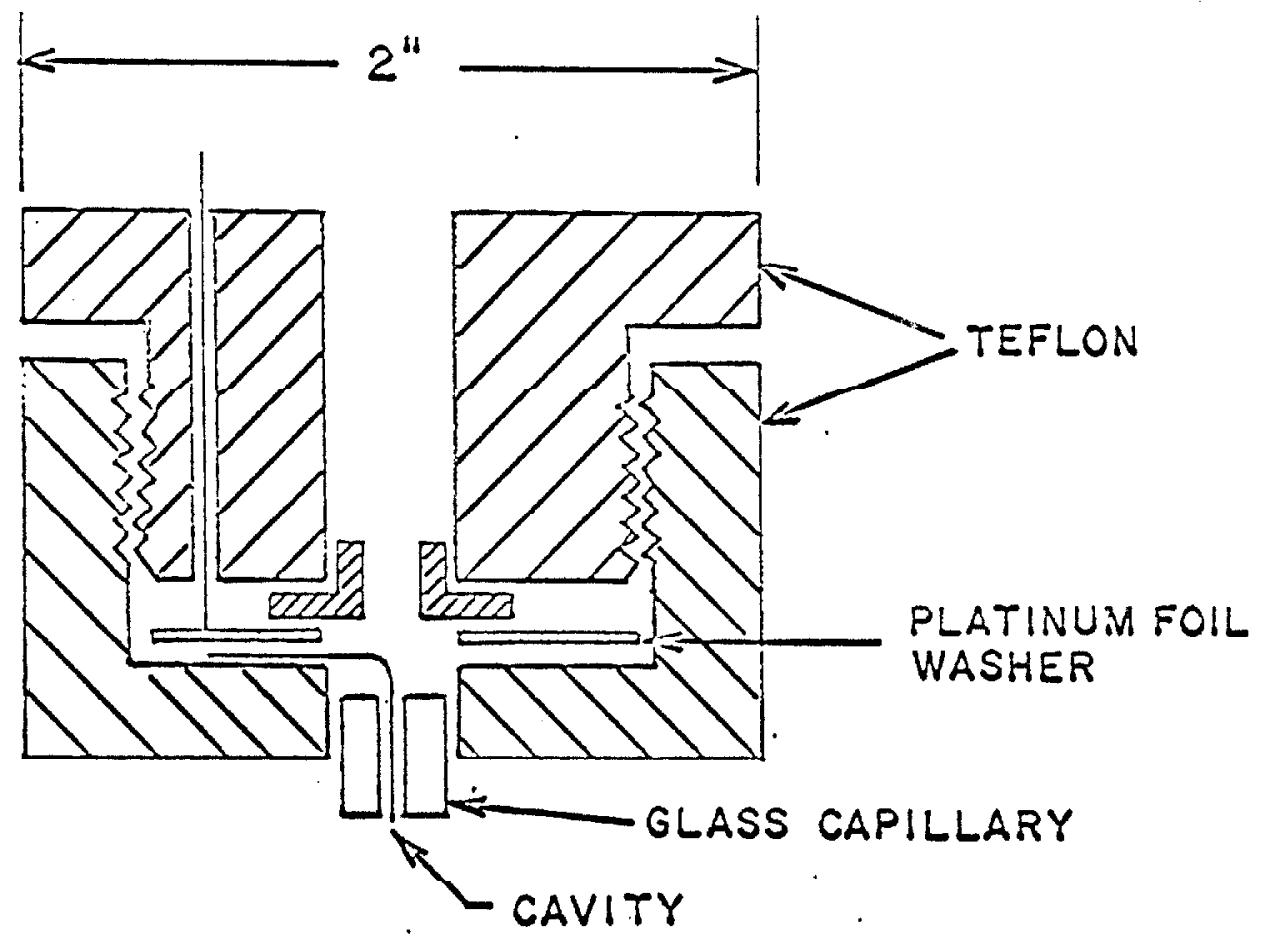

4-B 
was made from readily available standard glass pieces. Precision-bore capillary tubing, having inside diameters of from $0.003+0.0002$ inch to $0.031+0.0002$ inch, was obtaincd from the Wilmad Glass Co., Buena, N. J. The capillary tubing was cut to approximately the desired length on a glass saw and polished to exact tolerances on a glass-grinding wheel; capillary lengths of $0.500,1.000$, and $1.500 \mathrm{~cm}$. were used. Each capillary length was fitted with a platinum wire having a diameter exactly 0.001 inch smaller than the inside diameter of the capillary. Although the tolerance of the tube diameters specified in the guarantee, \pm 0.0002 inch, would introduce an uncertainty of about $20 \%$ into the geometry of the electrodes, the present set of electrodes, when calibrated against a standard iron(III) solution, agreed with the prescribed dimensions within a few per cent.

The function of the glassware shown in Figure 4-A was to hold the capillary and wire in position and to allow removal of solution by a flow of nitrogen. The three-way stopcock allowed convenient application and release of nitrogen pressure; during the electrolysis it was positioned with the cell arm blocked. Use of the glass capillary electrode was simplified by construction of a modified $\mathrm{H}$-cell of the type shown in Figure 5. Supporting electrolyte was deaerated in the solution reservoir, $R$, and allowed to flow into the contact arm; the protruding tip of the 
$-36-$

Figure 5

$\mathrm{H}$-cell for glass capillary-wire electrode

R. Supporting electrolyte reservoir

D. Sintered glass disk

C. Compartment for auxilliary and reference electrodes. 


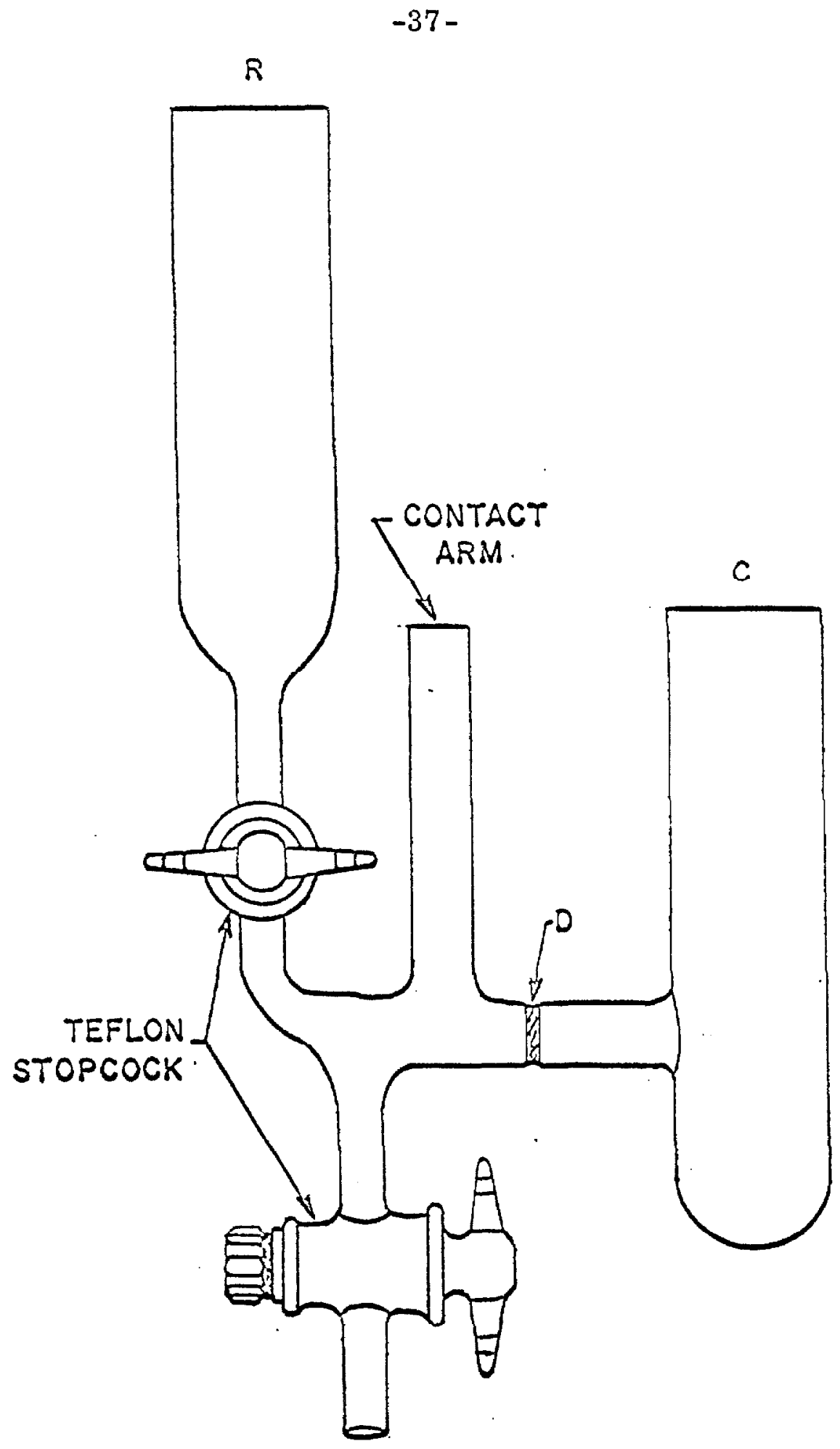


capillary tube was placed in contact with the liquid in the contact arm of the $\mathrm{H}$-cell. Both the auxilliary electrode and the reference electrude were placed in compartment C.

The glass-capillary electrode had a slight disadvantage in that it was difficult to position the capillary tip precisely in the H-cell because visibilily was reslricled by lle lower standardtaper glass member. To overcome this drawback a second type of glass-capillary electrode was designed in which some of the glass members were replaced by ones made from Teflon. The design is shown in Figure 4-B. With this electrode it was much easier to position the capillary tip precisely. All of the glass-capillary wire electrode data reported in this paper were obtained with the electrode in Figure 4-A. 


\section{The Micrometer Electrode}

In construction of the micrometer electrode, the faces of a metric micrometer caliper with removable anvil (L.S. Starrett Co., Athol, Mass., Model No. 2MARL) were replaced by a pair of pure platinum cylinders which were connected to the original faces by a pair of Teflon adapters (Figure 6). The platinum pieces were carefully machined and polished to have a geometry and finish as nearly as possible like those of the original micrometer.

The micrometer electrode was used with a modified $\mathrm{H}$-cell of the type shown in Figure 7. The micrometer was mounted in a horizontal position and the contact arm of the H-cell brought to within $1 \mathrm{~mm}$. of the cavity; a slight flow of liquid in the contact arm was permitted until the liquid at the tip of the arm extended into contact with the electrode cavity; the unit was then ready for use. The deaerated electrolyte was stored in the upper solution reservoir and the auxiliary and reference electrodes were contained in the solution compartments. 
$-40-$

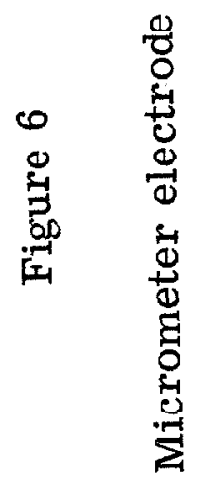




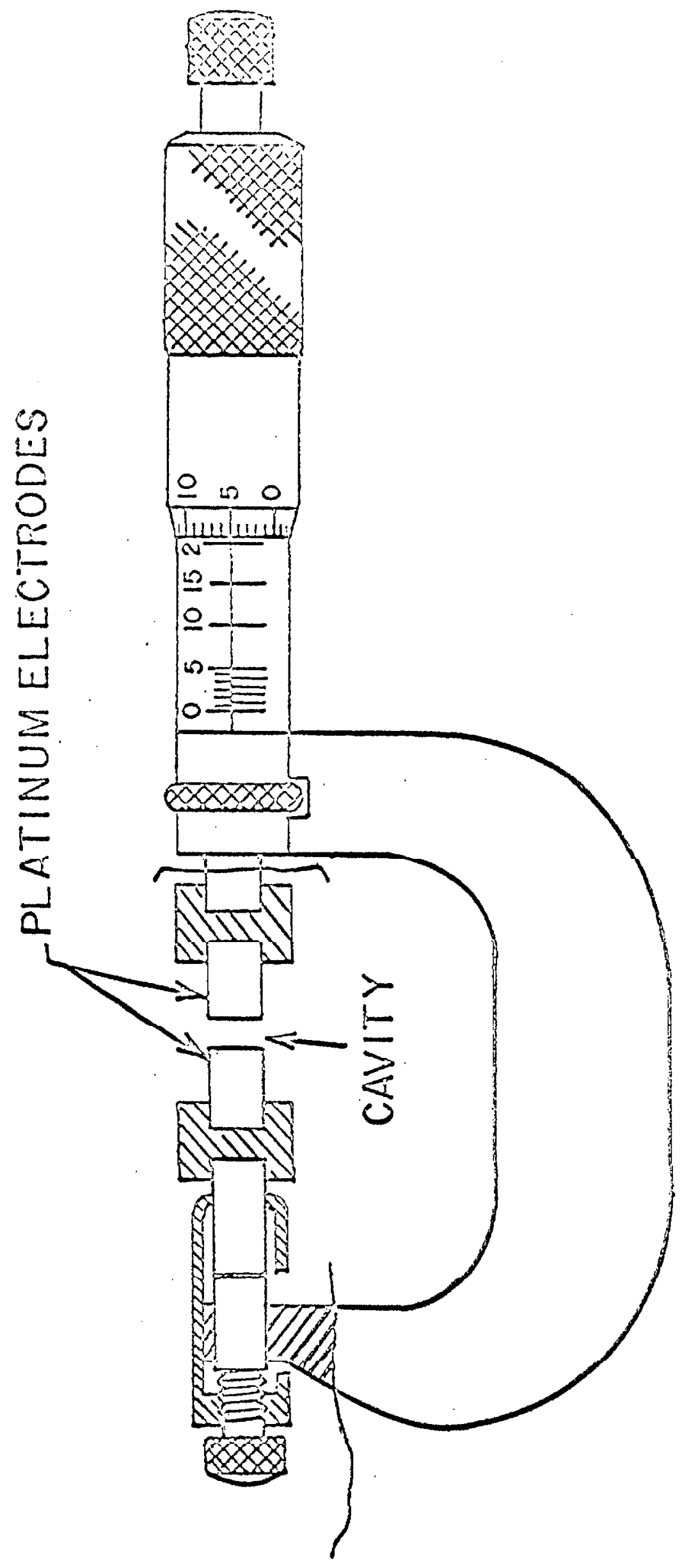




\section{Figure 7}

$\mathrm{H}$-cell for micrometer electrode

Right-hand compartment contained auxiliary and lefthand compartment contained reference electrode. 


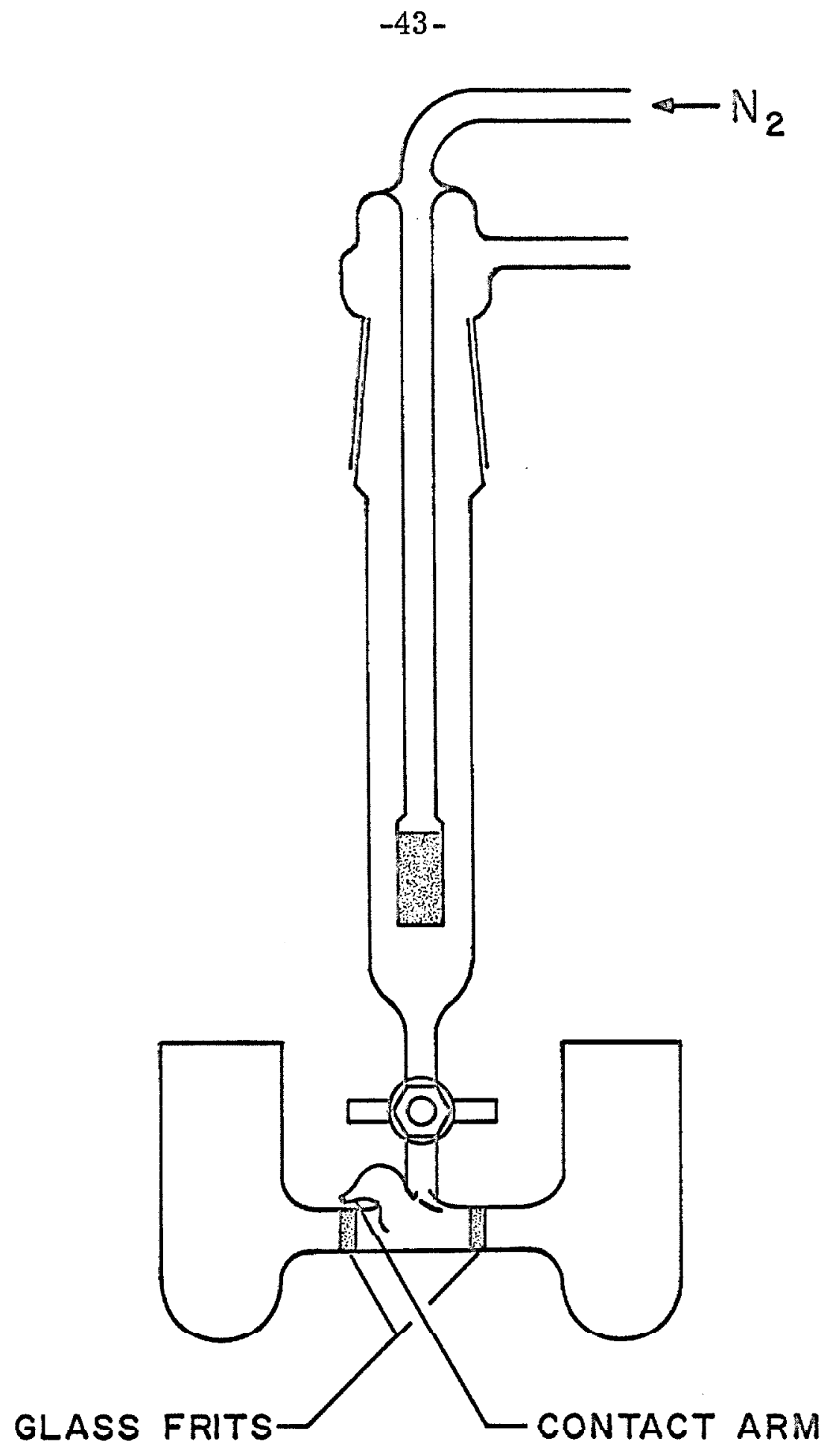


3. The Micrometer Mercury Electrode

The construction and use of the thin layer electrode having a mercury surface were similar to that of the micrometer electrode. The thin layer of solution was contained between a mercury-coated platinum rod which had a convex hemispherical end and a matching glass piece which had a concave hemispherical end of 20 micron larger radius (Figure 8). The platinum piece was wetted with a film of mercury. Wetting was achieved by treating the platinum surface with sodium amalgam, followed by thorough rinsing, first with water, and then with pure mercury. The micrometer was mounted vertically with the mercury-wetted platinum piece at the bottom. The H-cell shown in Figure 7 was employed. The thickness of the mercury film was reproducible; the extent of its variation was, in fact, too small to be observed in the present measurements. The total thickness of the mercury film at the center of the hemisphere was ca. $4 \times 10^{-4} \mathrm{~cm}$. 
$-45-$

Figure 8

Micrometer mercury electrode

Micrometer is shown in Figure 6. 


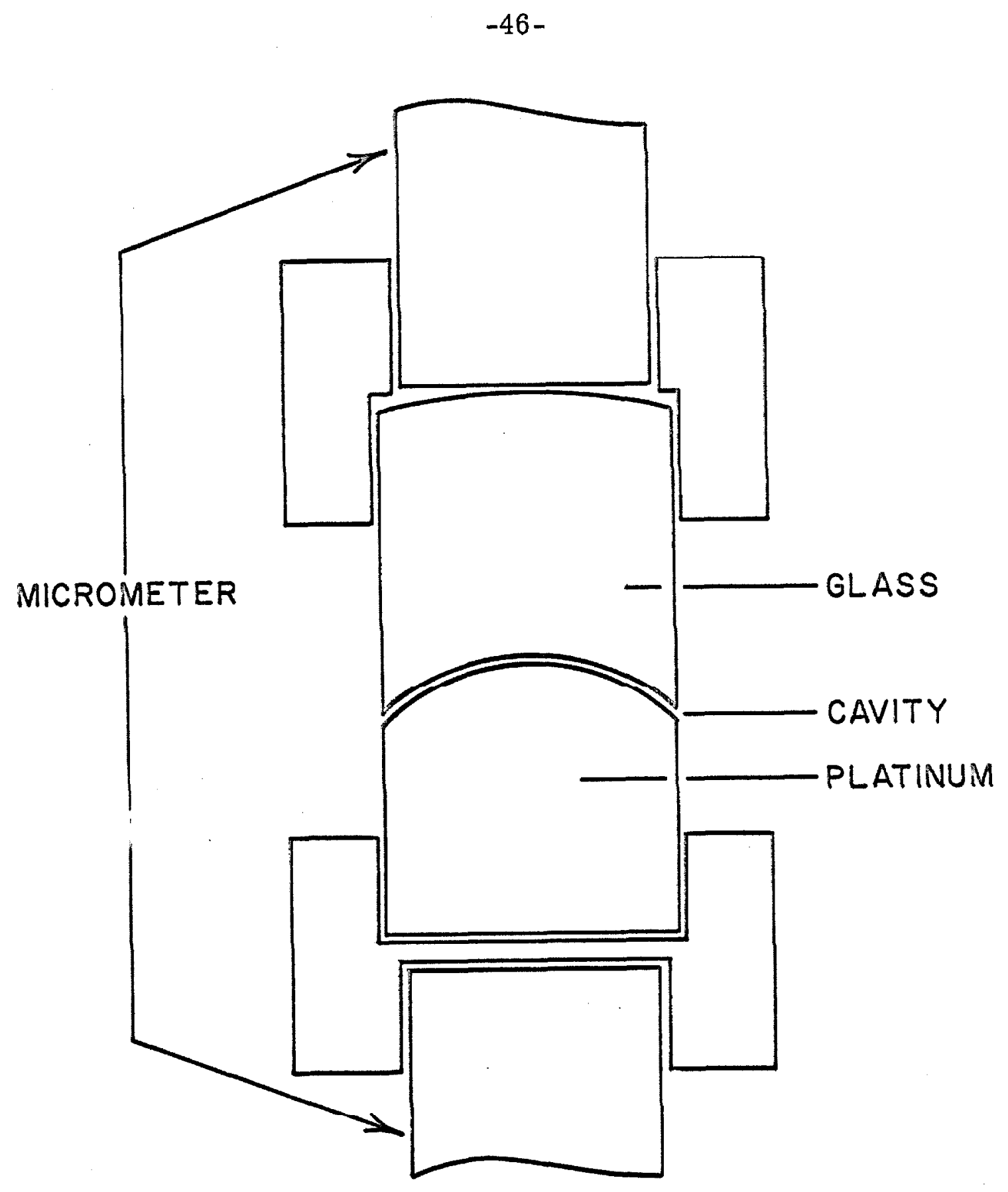




\section{Circuitry}

The circuitry employed was conventional (10). Measurement of electrode potentials, current and current-integrals was achieved with the use of operational amplifiers (George Philbrick Researches, Inc., Type P 65 and P 75). All potentials were measured vs. the saturated calomel electrode (S. C.E.) and are reported as such.

${ }^{10}$ G. Lauer, et. al, Anal. Chem., 35, 1789 (1963). 
IV. Testing of the Apparatus and Theory

The accuracy and reproducibility of the electrodes described in Section III were tested for chronopotentiometric reduction of $\mathrm{Fe}$ (III) in $1 \mathrm{~F} \mathrm{HClO}_{4}$. The equations for thin layer voltammetry and chronocoulometry of reversible systems were verified experimentally for the $\mathrm{Fe}$ (III) - $\mathrm{Fe}$ (II) couple using electrodes of the micrometer type.

\section{Testing of the Electrodes}

To prepare the electrodes for use, they were subjected to alternate anodic and calhodic polarization in $1 \mathrm{~F} \mathrm{H}_{2} \mathrm{SO}_{4}$; the final cycle was cathodic and the electrodes were held at ca. 0.4 volt S. C.E. for several minutes before each trial. The glass-capillary electrodes were filled before each trial by thorough rinsing with the solution to be used in the experiment. Rinsing and filling were accomplished in about 5 minutes. A drop of solution was placed at the tip of the capillary and the cavity filled itself by capillary attraction. The liquid was removed from the cavity by a flow of nitrogen introduced into the cavity through the stopcock. After several rinsings, the electroactive material was introduced into the cleaned cavity in the same manner and the chronopotentiogram was recorded。 
Filling of the micrometer electrode was extremely simple and was accomplished by placing a drop of solution containing the electroactive material on une face of the micrometer and adjusting the micrometer to give the desired distance setting (from 1 to $5 \times 10^{-3} \mathrm{~cm}$.). The solution that was squeezed from the crevice during the adjustment flowed down the side of the lower electrode face and away from the crevice. The crevice height (ca. $0.001 \mathrm{~cm}$.) was small in comparison with electrode diameter (ca. $0.7 \mathrm{~cm}$.) and irregularities in the shape of the exposed portion of the body of solution contained in the crevice had no appreciable effect on the volume contained by the crevice.

Typical data demonstrating the accuracy and reproducibility obtainable with the capillary-wire and micrometer electrodes appear in Tables I and II.

The graphical method suggested by Reinmuth (11) was employed to obtain the transition time from the chronopotentiometric curves.

The precision of the micrometer electrode was limited primarily by the precision of the caliper movement which had as its smallest scale division $0.001 \mathrm{~cm}$. The cavity thickness of the electrode could be varied from 1 to $10 \times 10^{-3} \mathrm{~cm}$. without noticeable effect on the performance of the electrode except for an accurately predictable change in the cavity volume and in

${ }^{11} \mathrm{~W}_{\text {: H. Reinmuth, Anal. Chem. }}$ 33, 485 (1961). 
Table 1. Calibration and Reproducibility

Data for Thin Layer Electrodes

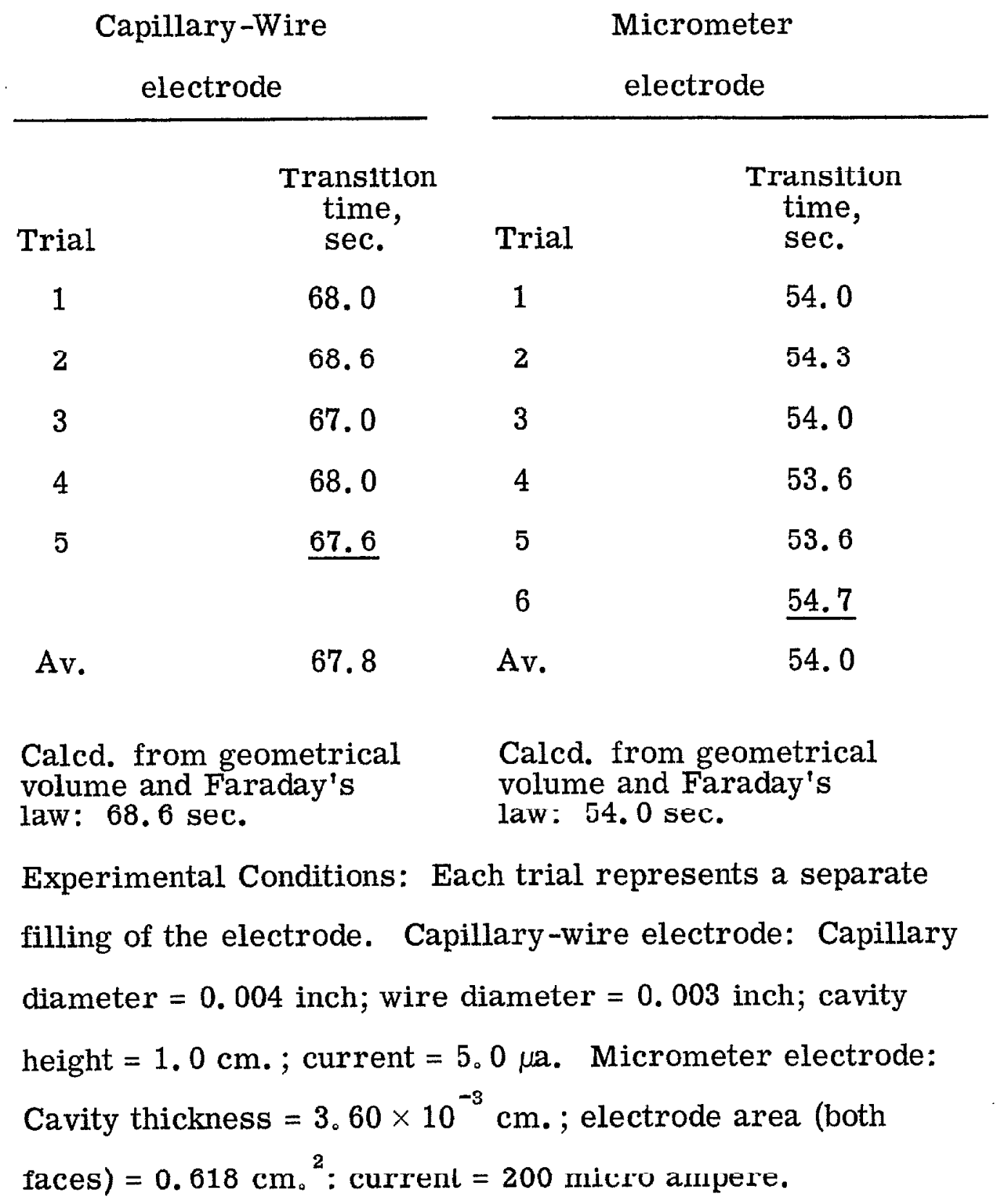


Table II. Current-Transition Time Data for Micrometer Electrode $0.139 \mathrm{~F} \mathrm{Fe}$ (III) in $1 \mathrm{~F} \mathrm{HClO}_{4}$ Cavity thickness $=2.6 \times 10^{-3} \mathrm{~cm}$.

Current, $\mu a$ 。

$\begin{array}{cc}\text { Observed } & \text { Theoretical } \\ \text { transition } & \begin{array}{c}\text { transition } \\ \text { lime, } \\ \text { lime, }\end{array} \\ \text { seconds } & \text { seconds }\end{array}$

50

100

200

400

1000
215

106

53

28.0

a
216

108

54

27

10.8

Cavity thickness $=1.6 \times 10^{-3} \mathrm{~cm}$.

$\begin{array}{ccc}50 & 140 & 130.4 \\ 100 & 64.5 & 65.2 \\ 200 & 34.8 & 32.6 \\ 400 & 16.0 & 16.3 \\ 600 & \mathrm{a} & 10\end{array}$

a Chronopotentiogram too ill-defined to measure $\tau$, but approximate $\tau$ much too short. 
the transition time for the trial.

The rates of loss of $\mathrm{Fe}$ (III) from the electrode cavities resulting from diffusion into the iron-free supporting electrolyte were measured and found to be quite small. For example, the capillary-wire electrode used to obtain the data of Table I showed diffusive losses of less than $1 \%$ in 20 minutes with the electrode dipping in iron-free $1 \mathrm{~F} \mathrm{HClO}_{4}$ and the micrometer electrode showed no detectable diffusive loss in 60 minutes with a cavity thickness of $2.6 \times 10^{-3} \mathrm{~cm}$. and the $\mathrm{H}$-cell in place. As indicated in connection with Table II, the shape of the chronopotentiograms deteriorates for large current densities. This is apparently due to inclusion within the measured potential of part of the ohmic potential difference between the working and auxiliary electrodes. This effect is discussed in greater detail in IV -4 . 
2. Thin Layer Voltammetry of the Fe(III) - Fe(II) Couple

Typical current-potential curves and peak current-sweep rate data for the $\mathrm{Fe}$ (III) - $\mathrm{Fe}$ (II) couple in $1 \mathrm{~F} \mathrm{HCl}$ are given in Figure 9 and Table III. The agreement between observed and calculated peak currents, which is quite good, demonstrates the potential usefulness of this technique for estimating the $\mathrm{n}$-values of reversible reactions. This application is particularly attractive because of the second-order dependence of the peak current on $\mathrm{n}$.

From Table III it can be seen that the anodic and cathodic peak potentials are in good agreement only for the slowest sweep rates. This trend, which is apparently due to inclusion of an ohmic potential difference within the measured potential, will be discussed further in IV -4 . 


\section{Figure 9}

\section{Single-cycle current-potential curves for $\mathrm{Fe}$ (II) and $\mathrm{Fe}$ (III) in $1 \mathrm{~F} \mathrm{HCl}$}
A. Oxidation of $\mathrm{Fe}$ (II)
B. Reduction of $\mathrm{Fe}$ (III)

Experimental conditions: Solution was $1.0 \times 10^{-3} \mathrm{~F}$ $\mathrm{Fe}$ (II) in $1 \mathrm{~F} \mathrm{HCl}$; thin layer volume was 1.4 microliter $\left(\ell=44.2\right.$ microns); sweep rate was $4.0 \frac{\text { millivolt. }}{\text { second }}$ 
$-55-$

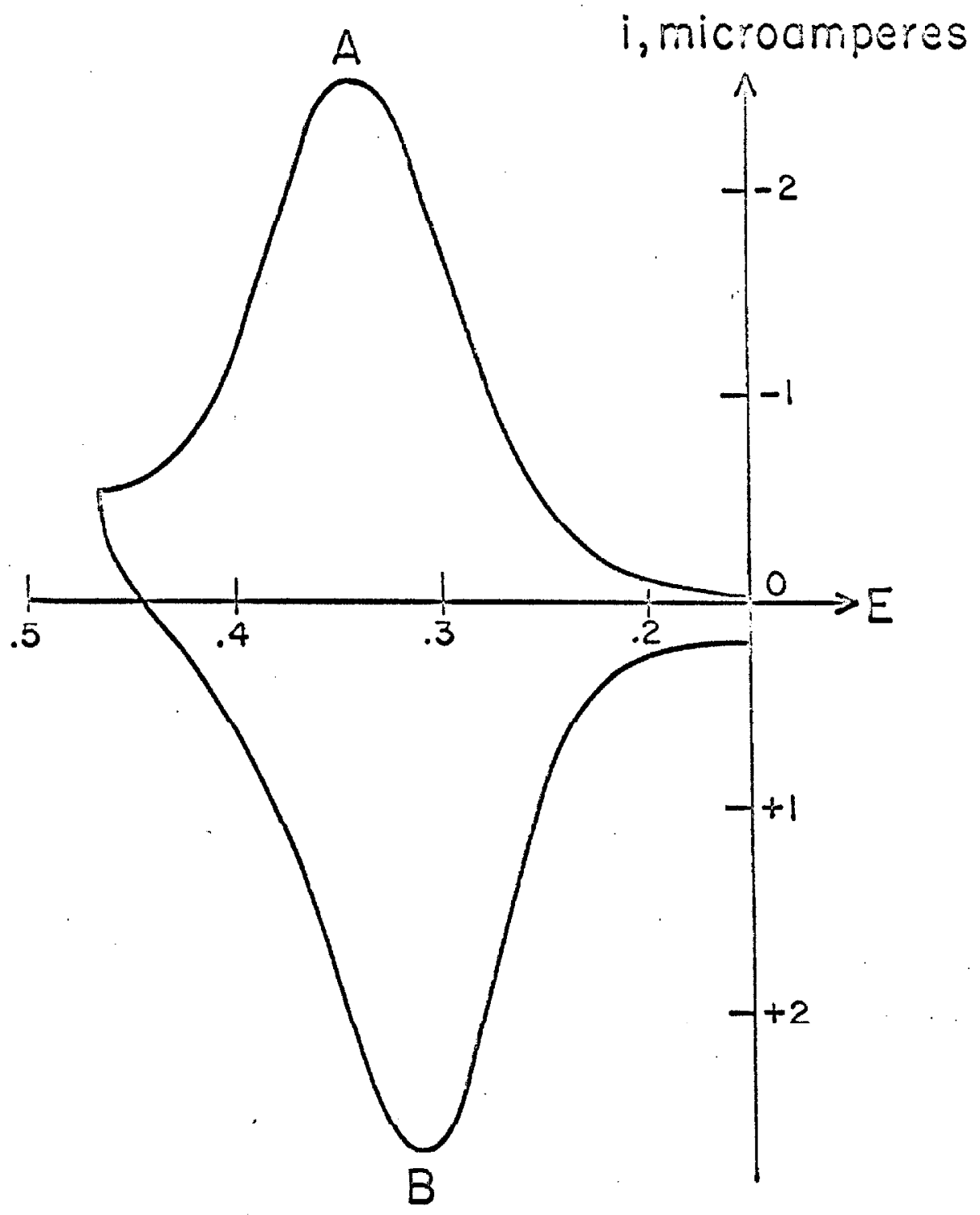




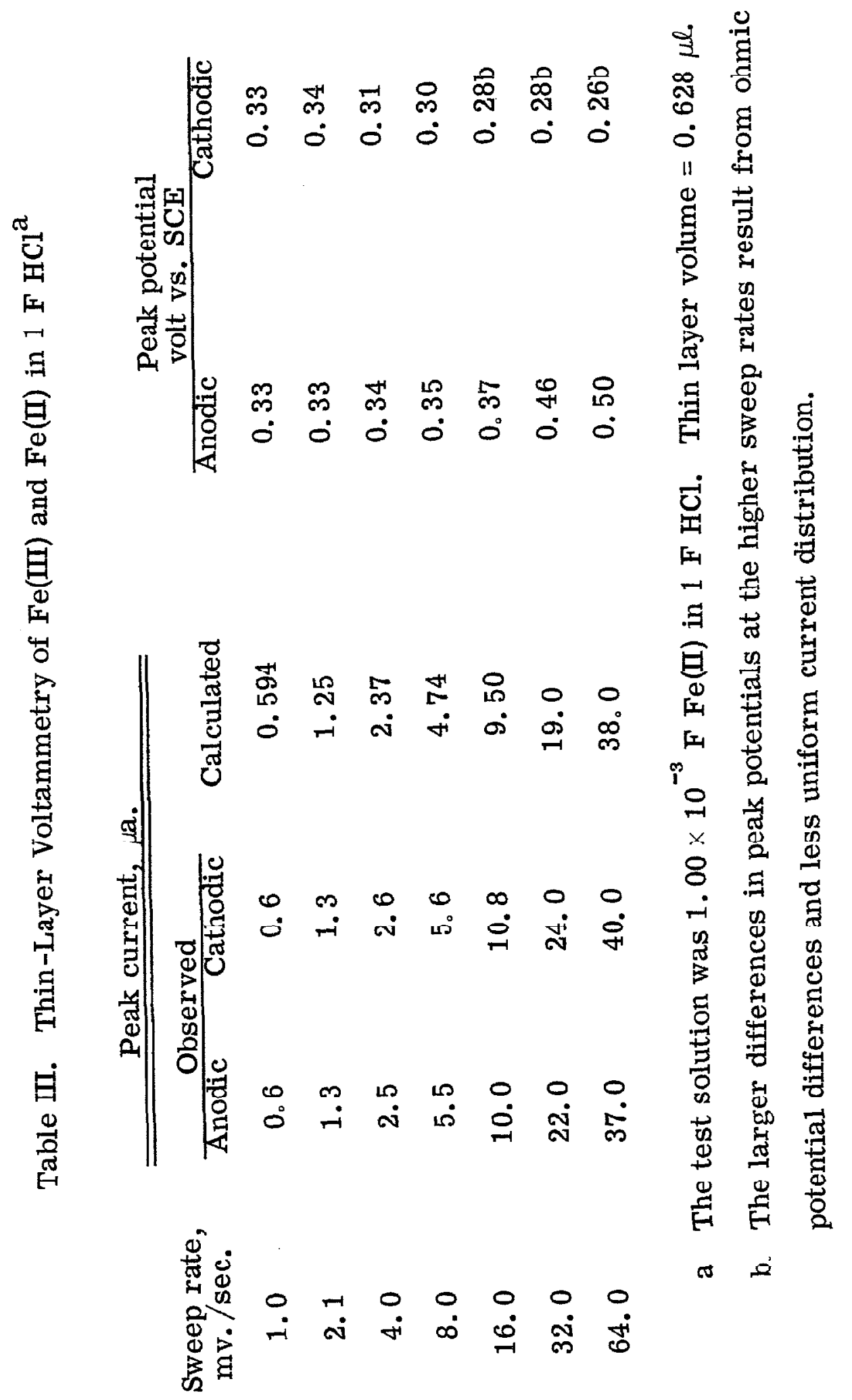




\section{Thin Layer Chronocoulometry of the $\mathrm{Fe}$ (III) - $\mathrm{Fe}$ (II) Couple}

The current integrals $Q$ obtained for reduction of $\mathrm{Fe}(\mathrm{III})$ in $1 \mathrm{~F} \mathrm{HClO}_{4}$ using the chronocoulometric measuring technique were in agreement with those calculated from Equation 14, as expected. However, the comparatively large potentiostatic currents required for chronocoulometric experiments resulted in the inclusion of comparatively large ohmic potential differences in the potential-control circuit, with the result that the time $\tau_{\min }$ required for $\mathrm{Q}$ to become constant was lengthened by an amount which increased with the bulk concentration of the reactant. 


\section{Ohmic Potential-Difference Effects}

Ohmic potential differences were unavoidably included in the measuring circuit as the result of two closely related causes. First, as is clear from Figures 5 and 0 , at least part of the ohmic potential difference between the working and auxiliary electrodes was included in the measured electrode potential. This effect was minimized by employing $\mathrm{H}$-cells with separate compartments for the reference and auxiliary electrodes (Figure 7.) A second source of ohmic potential difference in the measuring circuit was non-uniformity of the current density. The way in which non-uniform current density originated can be pictured as follows (Figure 10): the solution in the cavity acted as a resistor $\mathrm{R}(\mathrm{y}, \mathrm{z}, \mathrm{t})$ toward charge flowing from the point of entry into the thin layer cavity to points elsewhere in the cavity; charge flowing from the point of entry 0 to a point $A$ near 0 encountered less resistance than charge flowing to some point B more distant from 0; thus, the current density at A was greater than at B.

In potentiostatic experiments (for instance, voltammetry and chronocoulometry) the potential $\mathrm{E}$ experienced by the reactant at the electrode surface was not uniformly equal to $\mathrm{E}$ (applied) along the surface but instead varied according to

$$
E=E(\text { applied })+i[R(y, z, t)+R]
$$

In chronopotentiometric experiments the measured potential 
Figure 10

Schematic diagram of the micrometer electrode cavity (not to scale)

Points $0, \mathrm{~A}$ and $\mathrm{B}$ are described in the text. 


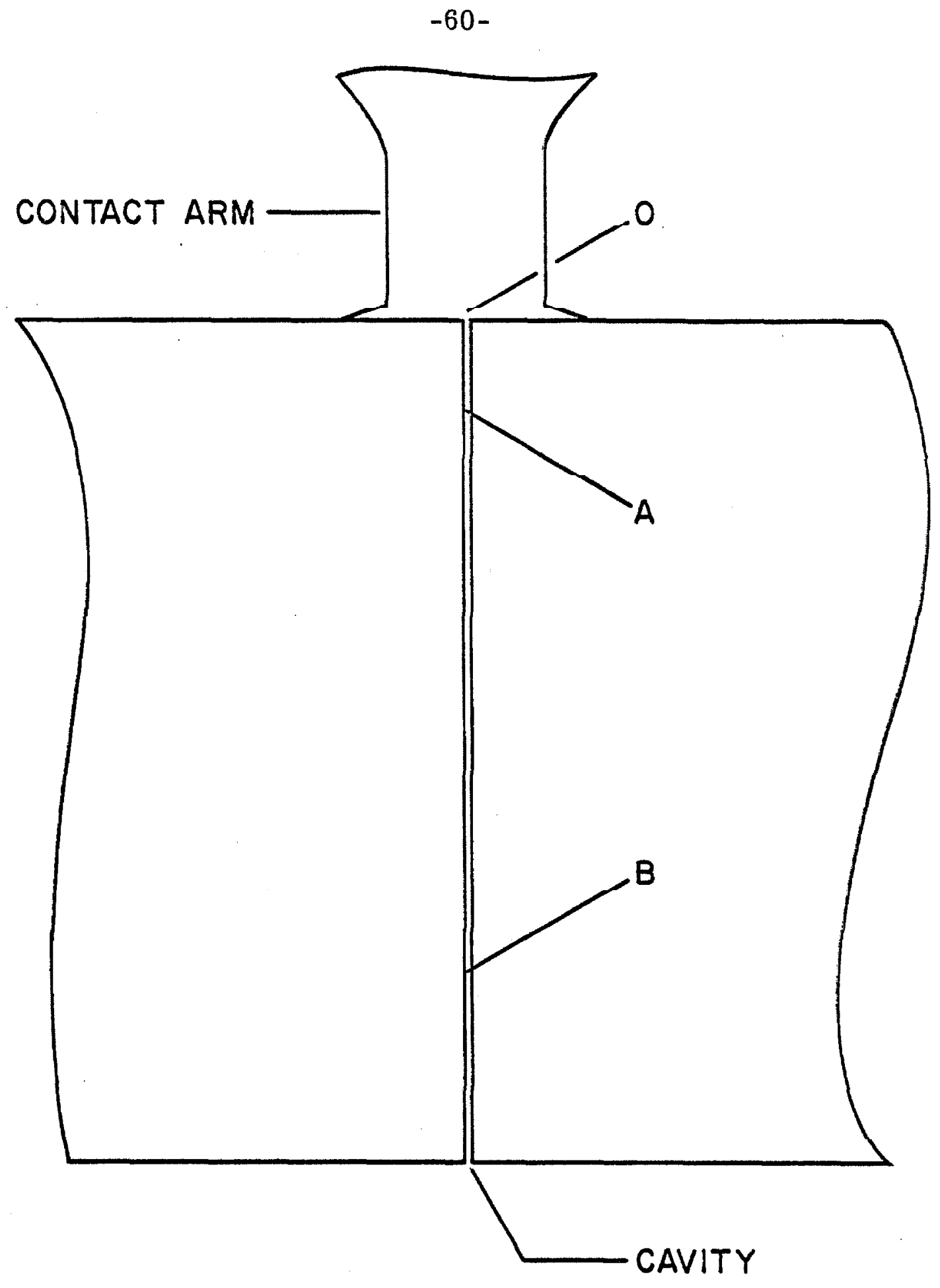


$E$ (meas.) was not equal to $\mathrm{E}$ (cell) but instead

$$
E \text { (meas.) }=E \text { (cell) }-i[R(y, z, t)+R]
$$

The departure from ideal behavior observed for large current densities is illustrated for the reduction of $\mathrm{Fe}$ (III) in Figures 11, 12, and 13. In linear potential sweep voltammetry ohmic potential differences decreased the peak current below its expected value and caused it to occur at potentials different from $E^{0}$ (Figure 11). In chronocoulometry, the effect was to lengthen the time required for the current integral to become constant (Figure 12). As Figure 13 shows, when i $R(y, z, t)$ was sufficiently large the galvanostatic reduction of $\mathrm{Fe}$ (III) was interrupted by an interfering reaction (solvent reduction) with the result that the transition time could not be determined from the chronopotentiometric curve.

In experimental applications of thin layer techniques, such as those described in Part V, it is generally possible to make the ohmic potential differences included within the measuring circuit very small by placing rcasonable limits on the magnitude of the applied current. 


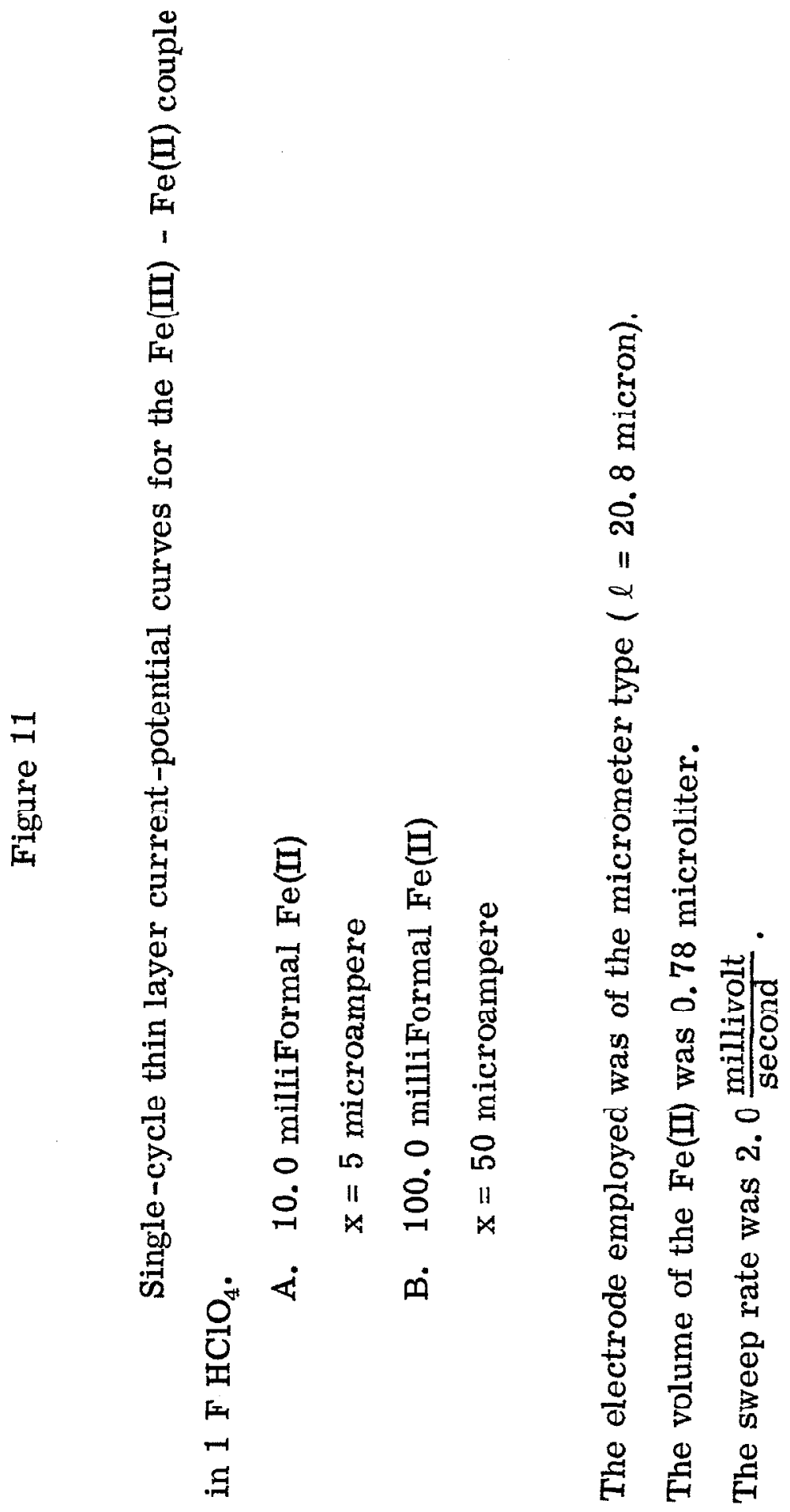




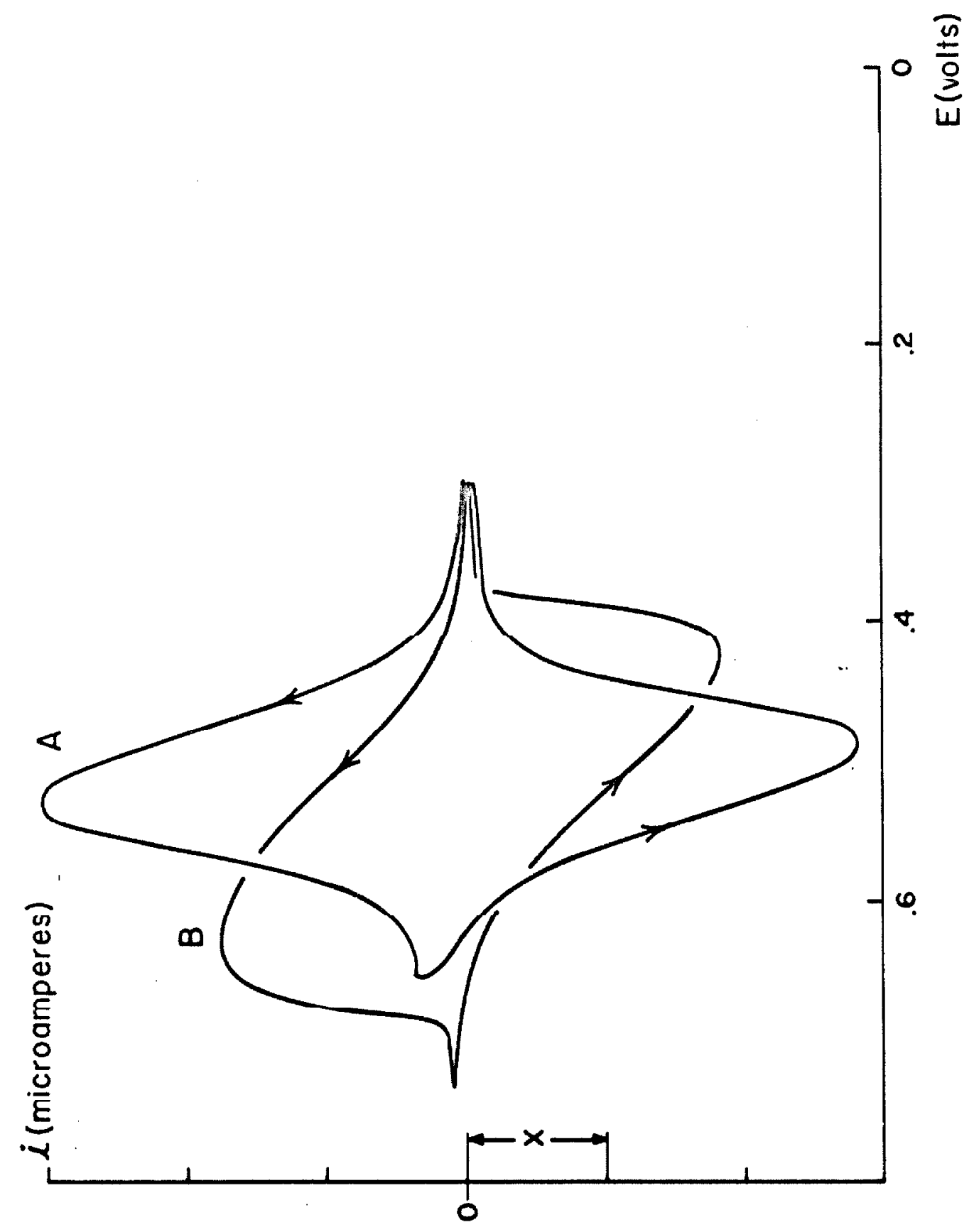


$-64-$

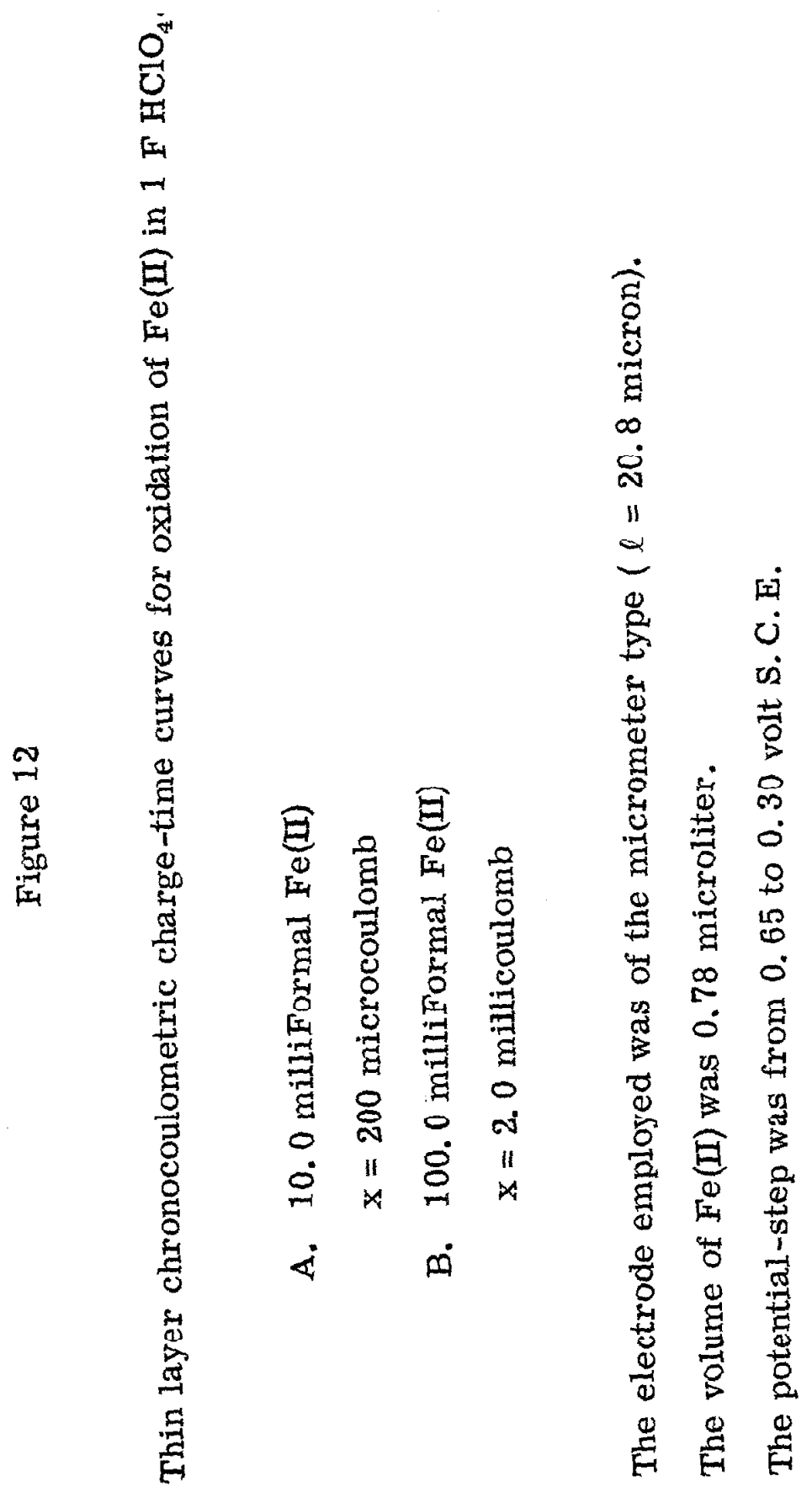




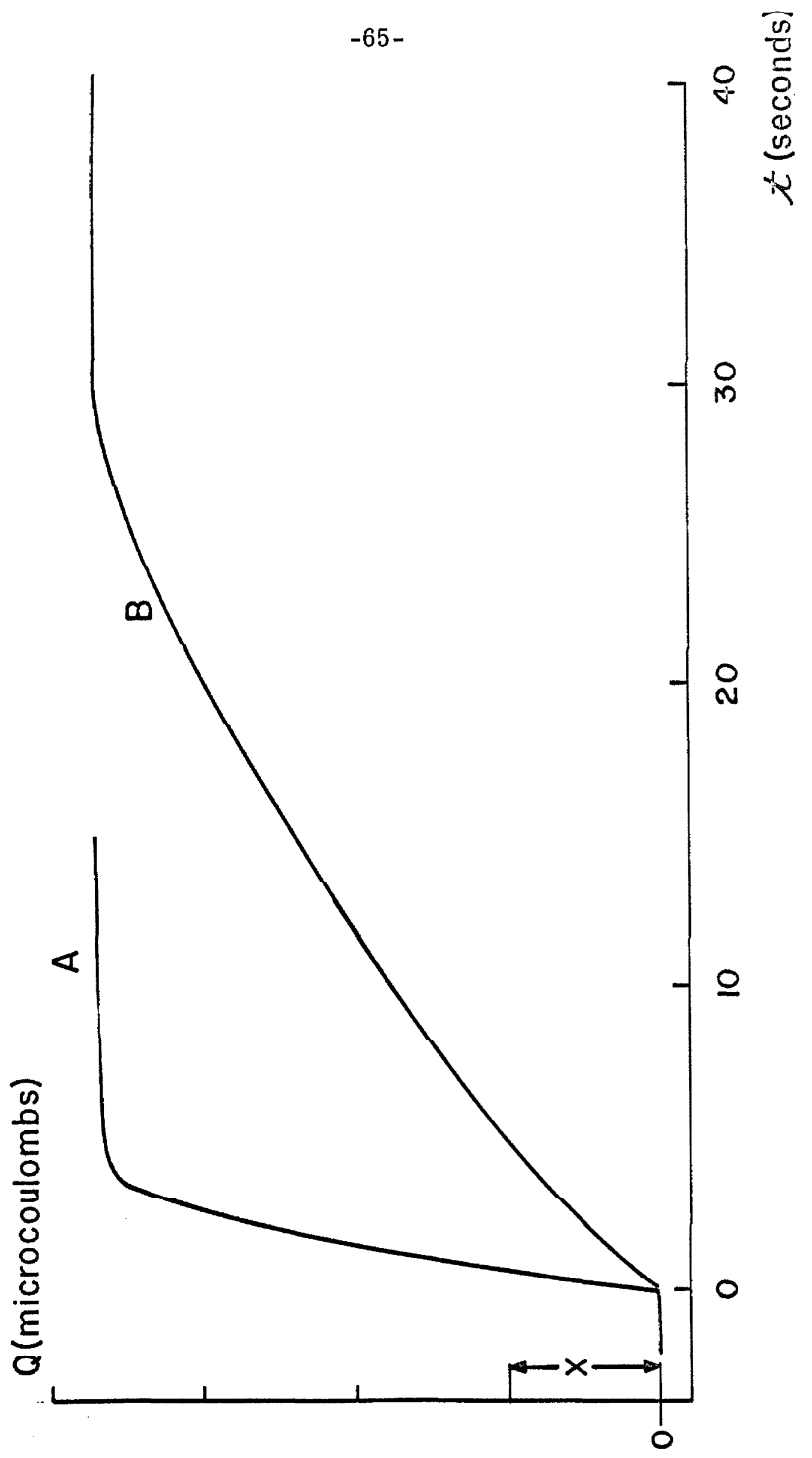



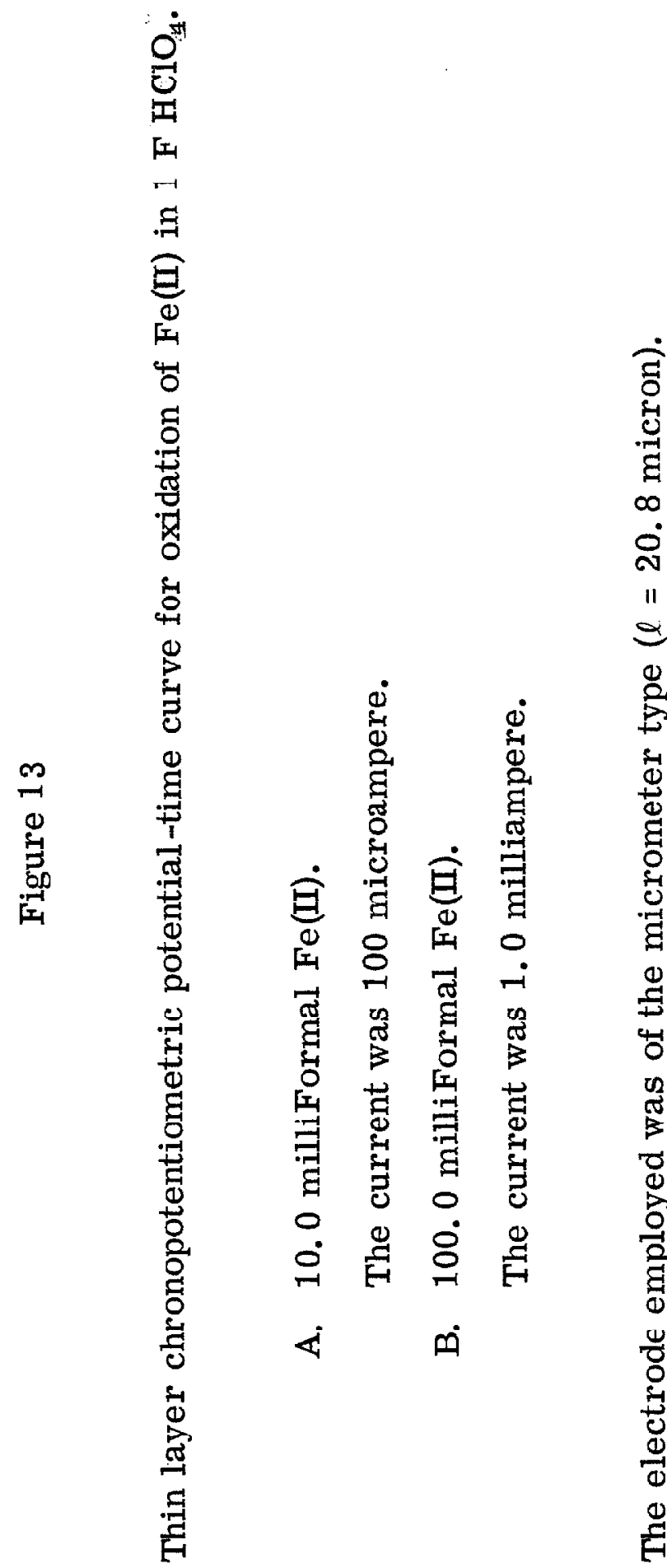

b

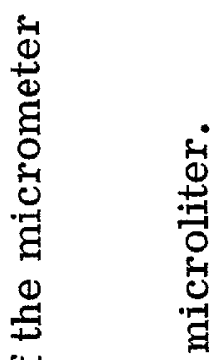

प्र

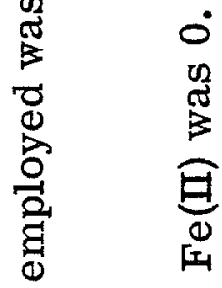

षั

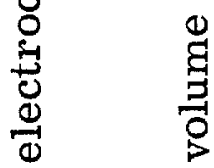

Е 


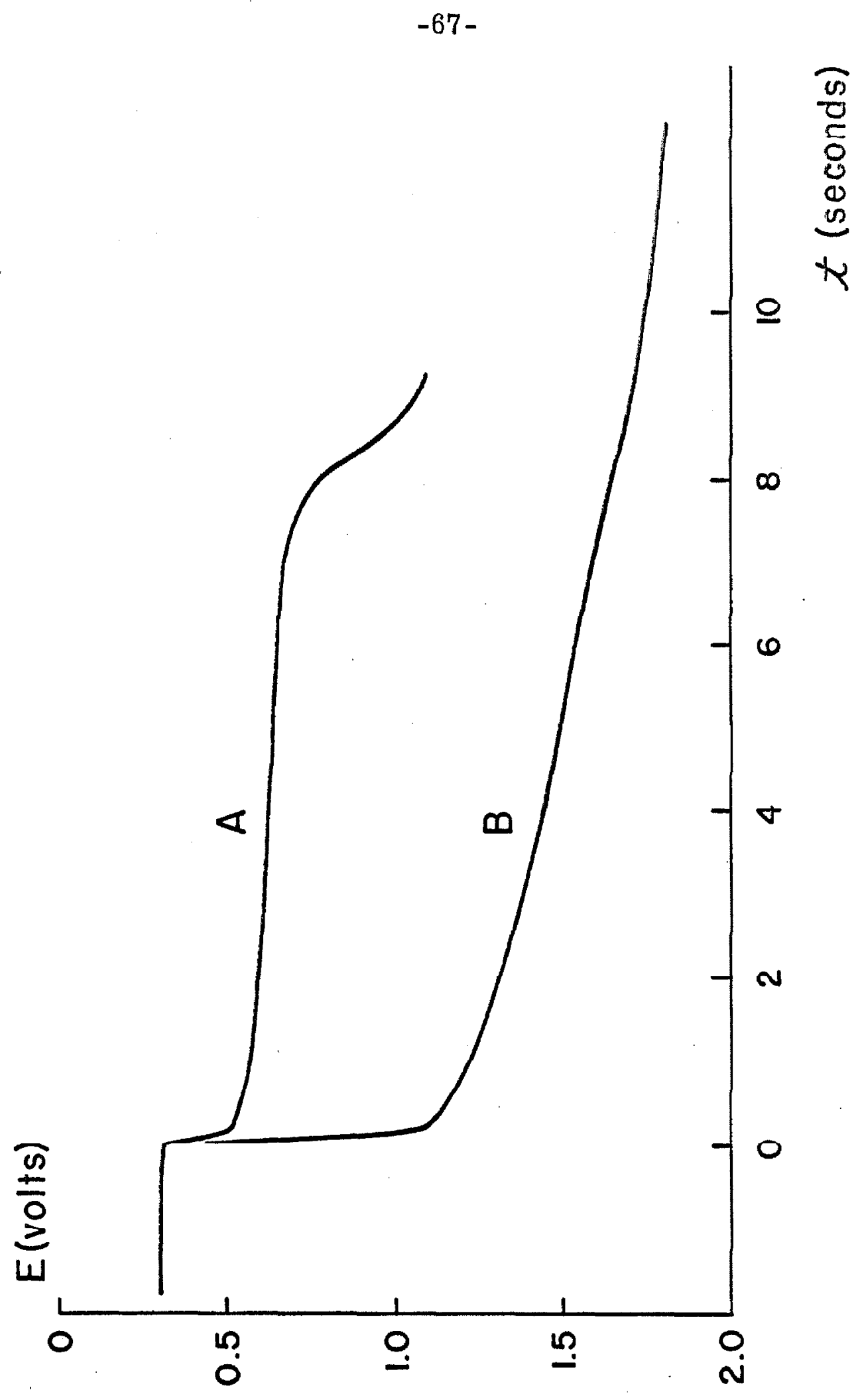




\section{Examples}

Experiments which demonstrate the suitability of the thin layer approach for study of systems where reactant adsorption can occur, and for elucidation of the stoichiometry of complicated reactions are reported in this section.

1. Determination of Reactants Adsorlued on Platinum Electrodes.

(i) A Study of the Iodide-Iodine Couple at Platinum Electrodes $(12,13)$

The electrochemical behavior of iodine and iodide ion at platinum electrodes has been treated in some detail in a number of recent papers $(14,15,16)$. Extensive adsorption of both iodide and iodine was shown to occur and it was demonstrated

12 A. T. Hubbard and F. C. Anson, J. Electruanal. Cliem. 9, 163 (1965).

13 A. T. Hubbard, R. A. Osteryoung, and F. C. Anson, Anal. Chem. , 38, 692 (1966).

14 R. A. Osteryoung, Anal. Chem., 35, 1100 (1963).

15 R. A. Osteryoung, G. Lauer, and F. C. Anson, J. Electrochem. Soc., 110, 926 (1963).

${ }^{16}$ R. A. Osteryoung and F. C. Anson, Anal. Chem., 36 975 (1964). 
that although the adsorbed iodine was electroactive--i.e., could be reduced near the reversible iodide-iodine potential-the adsorbed iodide ion was not. Among the data prescnted (16) was a brief set of experiments involving the technique of chronopotentiometry in thin layers of solution. The apparently contradictory results of these earlier experiments, coupled with the particular suitability of thin layer techniques for studies involving adsorbed reactants, prompted the additional experiments described in this paper.

\section{Experimental}

The electrode used was of the micrometer type. Ten-to fifty-micron layers of solution were confined between the faces of the micrometer which were equipotential. The diameter of each electrode face was 0.250 inches, giving an area of each face of $0.3175 \mathrm{~cm}^{2}$

Solutions were prepared from reagent-grade chemicals. Iodine solutions were prepared as follows: Solid iodine was added to deaerated $1 \mathrm{~F} \mathrm{H}_{8} \mathrm{SO}_{4}$ and saturation allowed to occur; the resulting solutions were electrolyzed with a large platinum gauze electrode controlled at +0.55 volt to remove possible traces of iodide and then diluted with deaerated $1 \mathrm{~F} \mathrm{H}_{2} \mathrm{SO}_{1}$ to approximately the desired concentrations and their titer determined immediately before use by titration with standard thiosulfate solution. Standard iodide solutions were prepared 
determinately in air-free $1 \mathrm{~F} \mathrm{H}_{2} \mathrm{SO}_{4}$.

$1 \mathrm{~F} \mathrm{H}_{2} \mathrm{SO}_{4}$ was used as the rinse solution and supporting electrolyte. All solutions were air -free and the experiments were performed with the thin layer cell mounted in a polyethylene tent which was continuously being flushed with prepurified nitrogen.

At various points in the experiments it was necessary to pipet microliter quantities of standard solutions into the thin layer cell. An example of the special pipets that were constructed for this purpose is shown in Figure 14. The solution to be pipeted was contained inside a length of glass tubing having an inside diameter of about $0.02 \mathrm{~cm}$. Calibration of the pipets was achieved by weighing the water delivered by the pipets, by recording thin layer chronopotentiograms on standard solutions delivered by the pipets, and by measuring the volume delivered by the pipets into a micrometer electrode whose geometry was already accurately known. Calibrations made by these three independent methods agreed within $1 \%$.

The contents of the pipets were delivered by expelling the solution with nitrogen pressure onto one electrode face with the micrometer opened to provide a gap of several millimeters. The micrometer was then closed to leave a layer thickness calculated to provide a gap volume corresponding exactly to the volume of liquid added. Visual inspection of the crevice was used to confirm that the liquid just filled the gap. In cases 
Figure 14.

Micropipet used for precise additions of solutions to the thin layer electrode. 
$-72-$

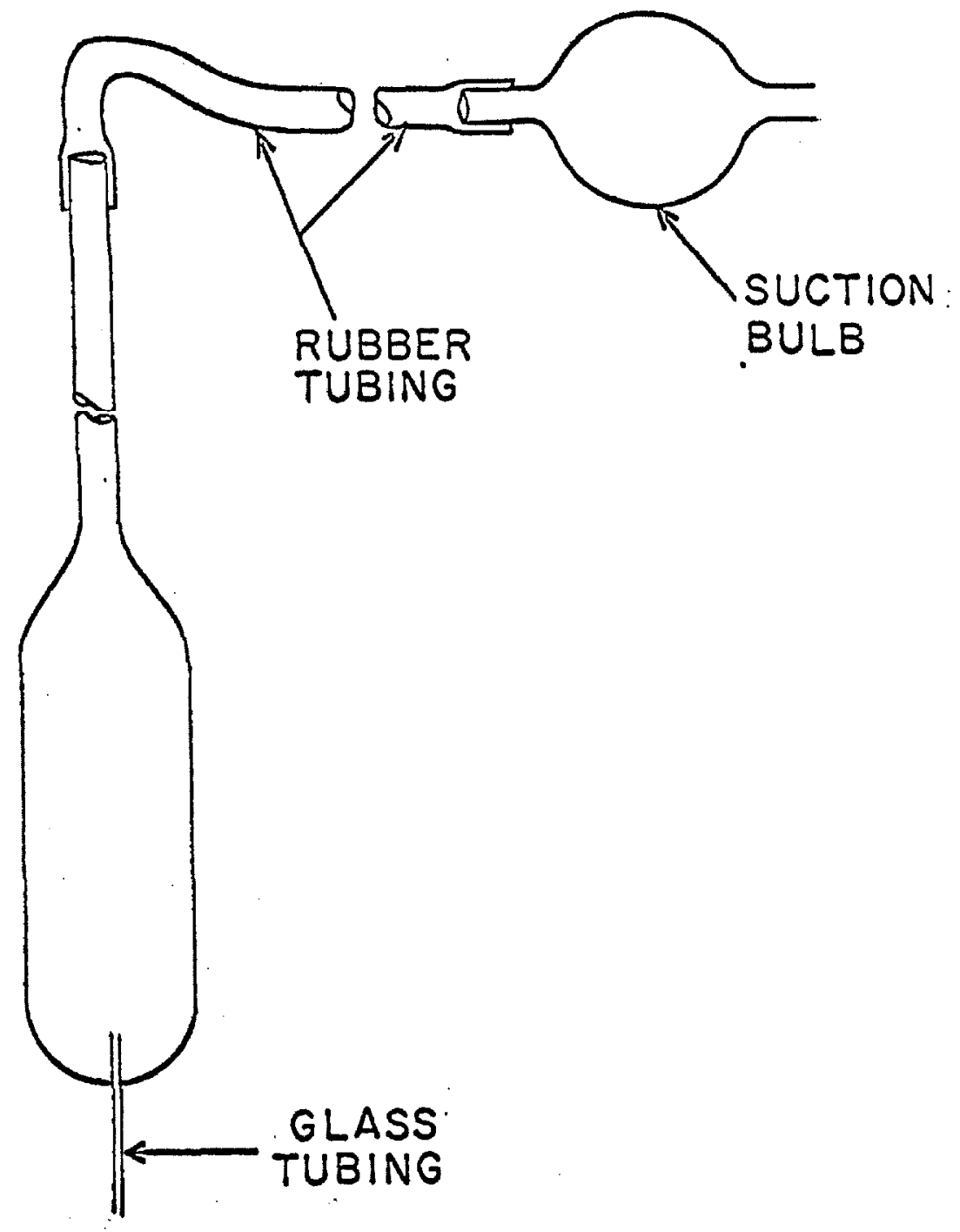


where some of the liquid had been squeezed o'd (due, possibly, to insufficicnt drying of the clectrode faces before addition of the test solution aliquot), or if the crevice was not completely full of solution, the run was discontinued and the electrode recleaned, rewashed, and refilled.

\section{Electrode Pretreatment}

It has been shown (15) that the iodide and iodine adsorbed on platinum electrodes can be removed by oxidation of the electrode in $1 \mathrm{~F} \mathrm{H}_{2} \mathrm{SO}_{4}$. The cleaning procedure used in the present experiments consisted of the following steps: The micrometer was opened to a gap of a few millimeters and the electrodes were oxidized potentiostatically at a potential of 1.2 volts. During this electrolysis pure, deaerated $1 \mathrm{~F} \mathrm{H}_{2} \mathrm{SO}_{4}$ was continuously flowing through the gap between the electrodes. The electrodes were reduced by imposing a potential of 0.4 volt with a potentiostat for several minutes. The cycle was repeated several times.

Careful inspection of anodic chronopotentiograms obtained with electrodes that had been treated with iodide or iodine confirmed that the procedure described was effective in removing adsorbed iodide and iodine. Figure 15 shows chronopotentiograms for the oxidation of an electrode cleaned as described and for oxidation of a cleaned electrode in $1 \mathrm{~F} \mathrm{H}_{\mathrm{z}} \mathrm{SO}_{4}$ after it had been bathed in $2 \mathrm{mM}$ iodide solution and washed free of unadsorbed iodide. With the clean electrode, the first indication of a potential halt occurred at about +0.7 volt, whereas 
the corresponding potential for the iodide-coated electrode was about +1.06 volts; that is, the presence of adsorbed iodide (or of iodine, which behaved similarly) caused a 360 millivolt suppression of the potential at which chronopotentiometric oxidation of the electrode occurrcd.

A second feature to be noted is the sharp potential inflection which occurred at about 1.25 volts when the electrode had bccn iodide- (or iodine-) coated but not when the electrode had been previously freed of iodide (or iodine). This potential inflection was quite sensitive to the presence of iodide or iodine on the electrode and was useful in these experiments as a convenient verification of the absence of these species on the electrode after cleaning: The inflection was observed with all electrodes known to contain adsorbed iodide or iodine and disappeared only after the electrode was subjected to the cleaning procedure described.

The cleaning procedure led to some increase in the roughness of the electrode surface as it was repeatedly oxidized and reduced. The amounts of measured adsorbed iodide and lodine are reported on the basis of the apparent geometric electrode area and will, therefore, depend somewhat on the electrode history. It was observed that the adsorption values decreased by about $20 \%$ if the cleaned electrode surfaces were bathed briefly with aqua regia (which would tend to dissolve finely divided platinum) and reduced just before an experiment. 
$-75-$

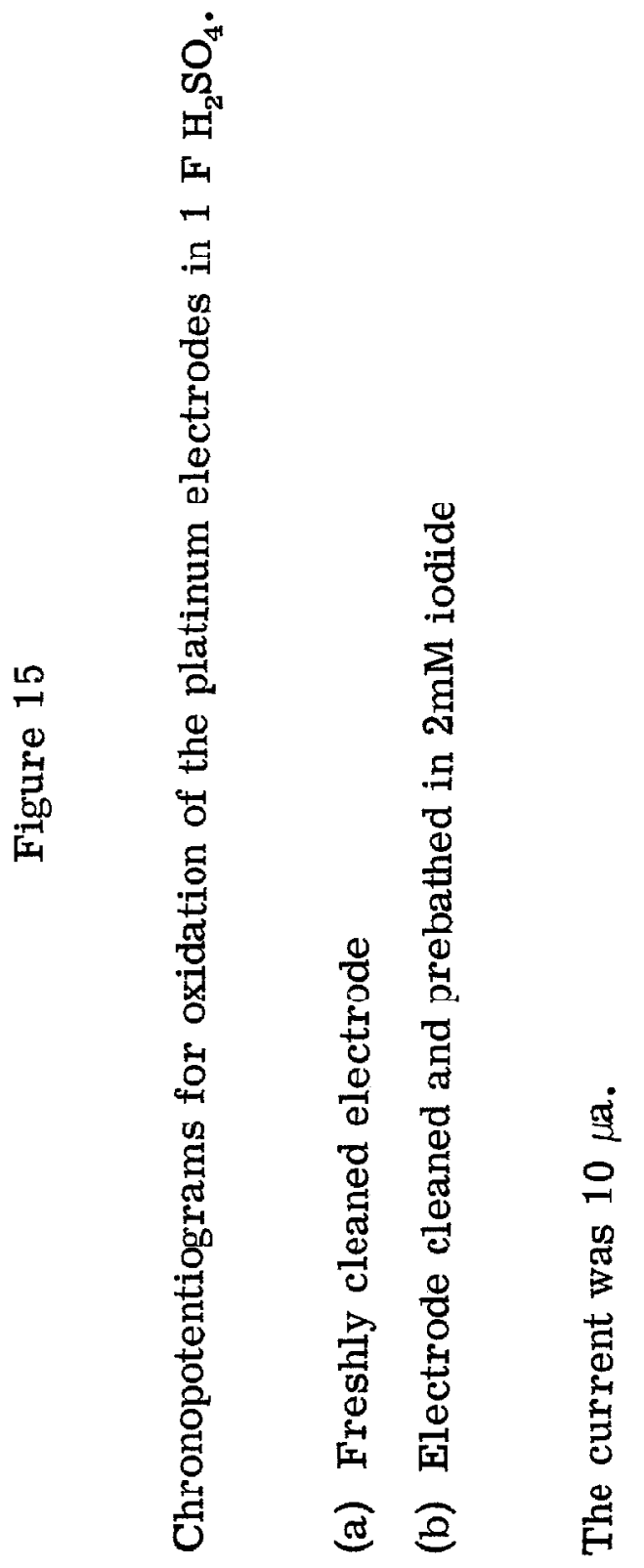


$-7 \dot{6}-$

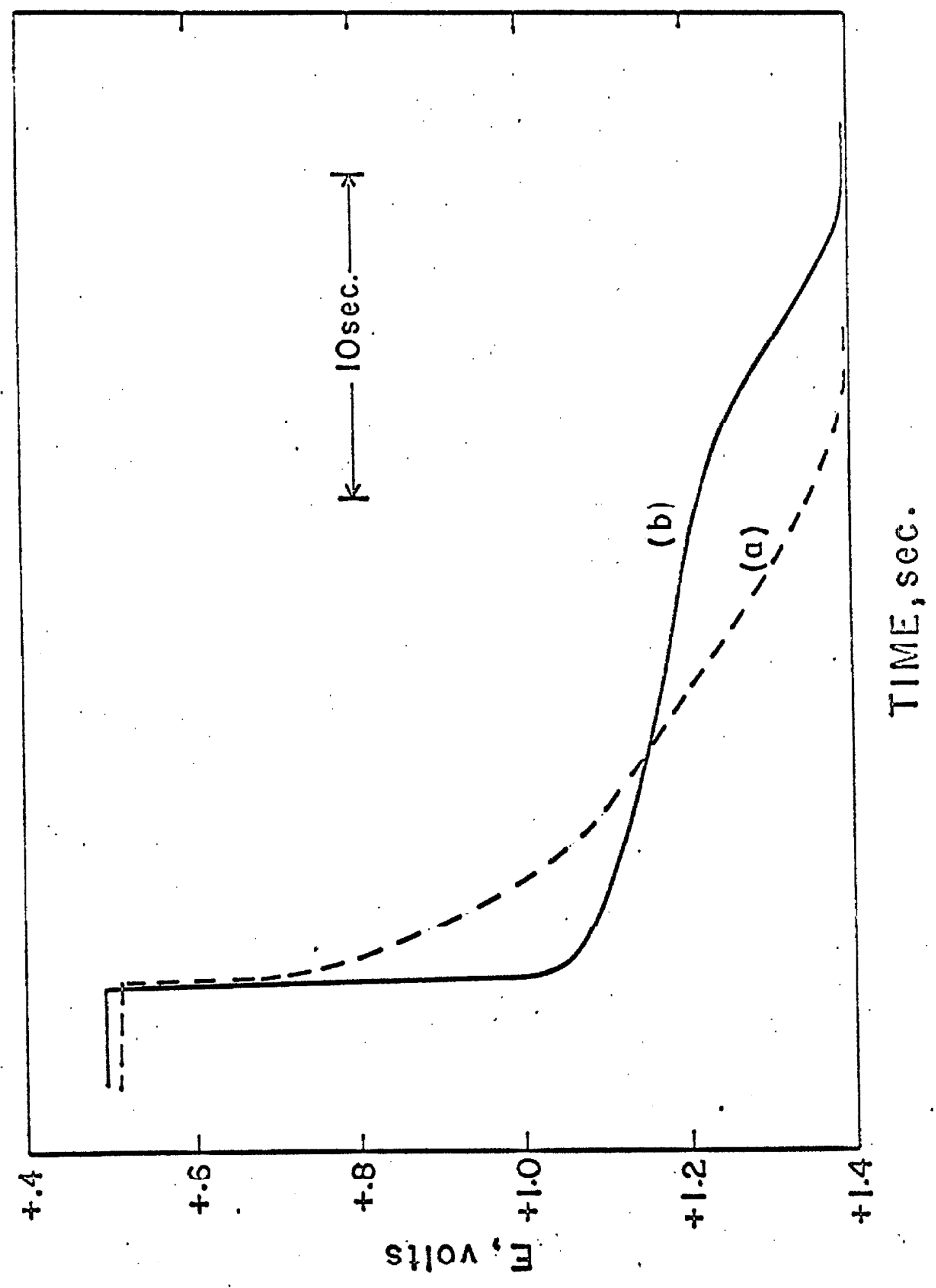




\section{Results}

\section{Determination of Electroactive}

Adsor.bed Iodine.

When a reactant is adsorbed in an electroactive state on platinum and the micrometer electrode surfaces are bathed in an excess of the reactant solution before the micrometer gap is closed to squeeze out all of the solution except for that contained in the thin layer volume, the equations for the transition time and potentiostatic current integral will not be those that are obeyed in the absence of adsorption (Equations 14 and 18). Instead, the following equations will apply

$$
\begin{aligned}
& T=\frac{\mathrm{nF}}{\dot{\mathrm{i}}}\left(\mathrm{VC}^{0}+\mathrm{A} \Gamma\right) \\
& \mathrm{Q}=\mathrm{nF}\left(\mathrm{VC}^{\circ}+\mathrm{A} \Gamma\right)
\end{aligned}
$$

$\Gamma$ is the amount of adsorbed reactant in moles $/ \mathrm{cm}^{2}$ Thus the charge in excess of that calculated from Faraday's Law (Equations 14 and 18) that is obtained in a thin layer experiment corresponds to the quantity of electroactive adsorbed reactant.

The data in Table IV were obtained by thin layer

chronopotentiometry and demonstrate the adsorption of $9.4 \times 10^{-10}$ moles $/ \mathrm{cm}^{2}{ }^{2}$ of electroactive iodine from a $1.14 \times 10^{-3} \mathrm{M}$ iodine solution. 


\section{Nonelectroactive Adsorbed Iodide}

Experiment 2 in Table IV demonstrates the absence of any electroactive adsorbed iodide from a $1.0 \times 10^{-3} \mathrm{M}$ iodide solution. Inasmuch as there is ample independent evidence that iodide ion is adsorbed on platinum $(15,17,18,19)$ the behavior of iodide in Experiment 2 must be ascribed to the fact that adsorbed iodide is not electroactive.

\section{Determination of Nonelectroactive}

Adsorbed Iodide.

If a small volume of a standard solution of a reactant that is adsorbed only in a nonelectroactive state is pipeted into the thin layer cell with cleaned platinum electrodes, the total charge obtained will be smaller than that calculated from Faraday's law by an amount corresponding to the adsorbed nonelectroactive reactant. The transition time or charge

17 N. Balashova, Zh. Fiz. Khim. 32, 2266 (1958).

18 N. Balashova, Z. Physik Chem. (Leipzig), 207, 340 (1957).

19 N. Balashova, N. S. Merkulova, Proc. 4th Soviet Conf. Electrochem., 1956, p. 48. 


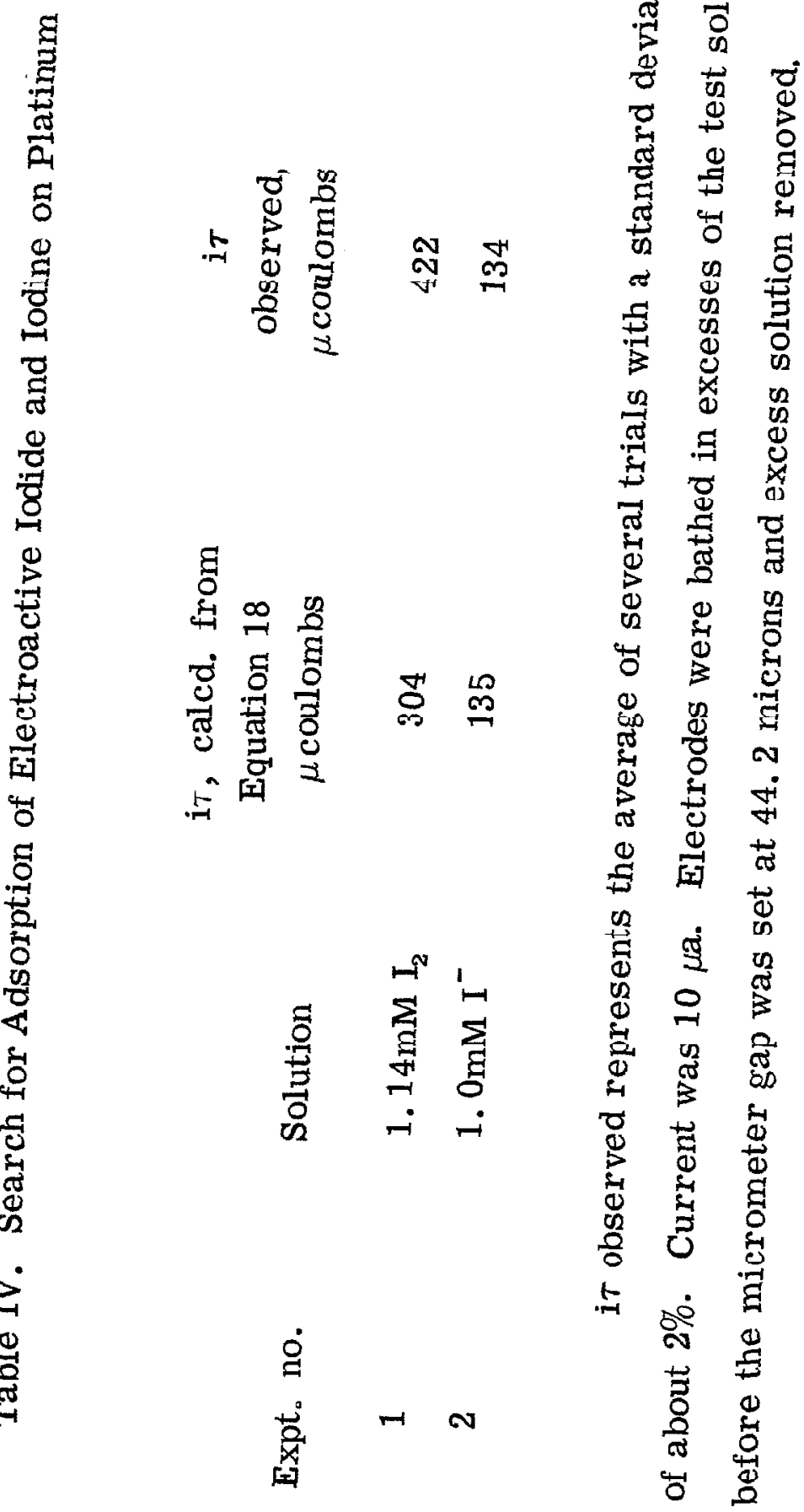


will be given by

$$
\begin{aligned}
& \tau=\frac{\mathrm{nF}}{\dot{\mathrm{i}}}\left(\mathrm{VC}^{\circ}-\mathrm{A} \Gamma\right) \\
& \mathrm{Q}=\mathrm{nF}\left(\mathrm{VC}^{\circ}-\mathrm{A} \Gamma\right)
\end{aligned}
$$

where $\Gamma$ is the amount of reactant adsorbed in moles $/ \mathrm{cm}^{2}$

Such pipet experiments were carried out with iodide solutions. A typical set of data is presented in Table V. The values of $\Gamma$ in Table $V$ were calculated from Equation 25 and indicate that $14-18 \times 10^{-10}$ moles per $\mathrm{cm}^{2}$. of iodide ion were removed from the solution by adsorption on the platinum electrode surfaces and that the adsorbed iodide was not oxidizable at the potential where the unadsorbed iodide was rapidly oxidized. Note that Experiments 5 and 6 demonstrate that Equation 14 was obeyed with electrodes that had been presaturated with iodide or iodine.

Experiment 5 in Table $\mathrm{V}$ also shows that the adsorbed iodide was not removed by copious washing with iodide-free $1 \mathrm{~F} \mathrm{H}_{2} \mathrm{SO}_{4}$ because such washing was performed as part of this experiment.

Oxidation of Adsorbed Iodide.

Experiments confirming the presence of about $2 \times 10^{-y}$ moles per $\mathrm{cm}^{2}$ of non-electroactive adsorbed iodide ion on platinum electrodes were performed by taking advantage of the following facts: 
实

U त क $H+H+H$

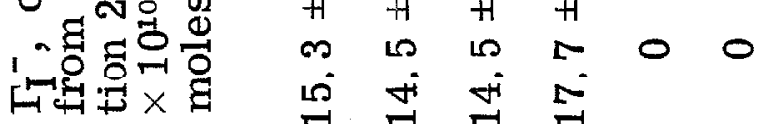

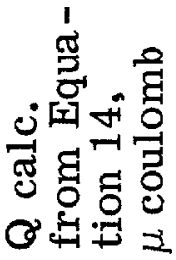

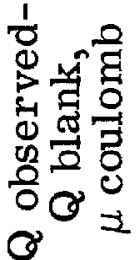
सी 䆑寻 $\sigma^{\circ}=$

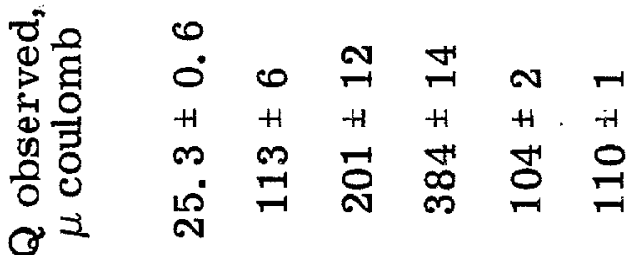
$\frac{0}{8}+\frac{n}{3}$

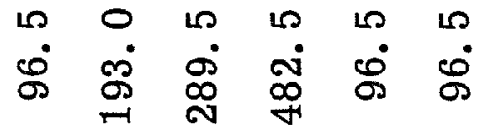
$\begin{array}{ll}H & 0 \\ + & \\ \infty & \\ \infty & \\ 0 & \\ H & \\ \text { N } & \end{array}$ N $+$ 尓 
Previous experiments (16) have demonstrated that adsorbed iodide can be oxidatively desorbed from platinum electrodes by adjusting the electrode potential to +1.2 volts in $1 \mathrm{~F} \mathrm{H}_{2} \mathrm{SO}_{4}$. At this potential the iodide was oxidized to iodate and extensive oxidation of the electrode occurred. The reduction of iodate to iodine at the oxidized thin layer electrode in $1 \mathrm{~F} \mathrm{H}_{2} \mathrm{SO}_{4}$ occurred at about 0.80 volt as is shown in the linear-potential sweep current-potential curve in Figure 16. The iodate reduction occurred before much reduction of platinum oxide (or oxygen) commenced.

Accordingly, if the thin layer electrode surfaces were saturated with respect to iodide adsorption, washed free of unadsorbed iodide, the cell filled with $1 \mathrm{~F} \mathrm{H}_{2} \mathrm{SO}_{4}$ and the electrodes potentiostated briefly at 1.2 volts, the resulting solution in the cavity should have contained an amount of dissolved iodate ion equivalent to the initially adsorbed nonelectroactive iodide. This iodate could be determined with fair accuracy by constantpotential coulometry at 0.7 volt as shown in Figure 17 and Table VI.

The cathodic charge corresponding to iodate reduction will be given by

$$
\mathrm{Q}=\mathrm{nFAT}_{\mathrm{I}}^{-}
$$




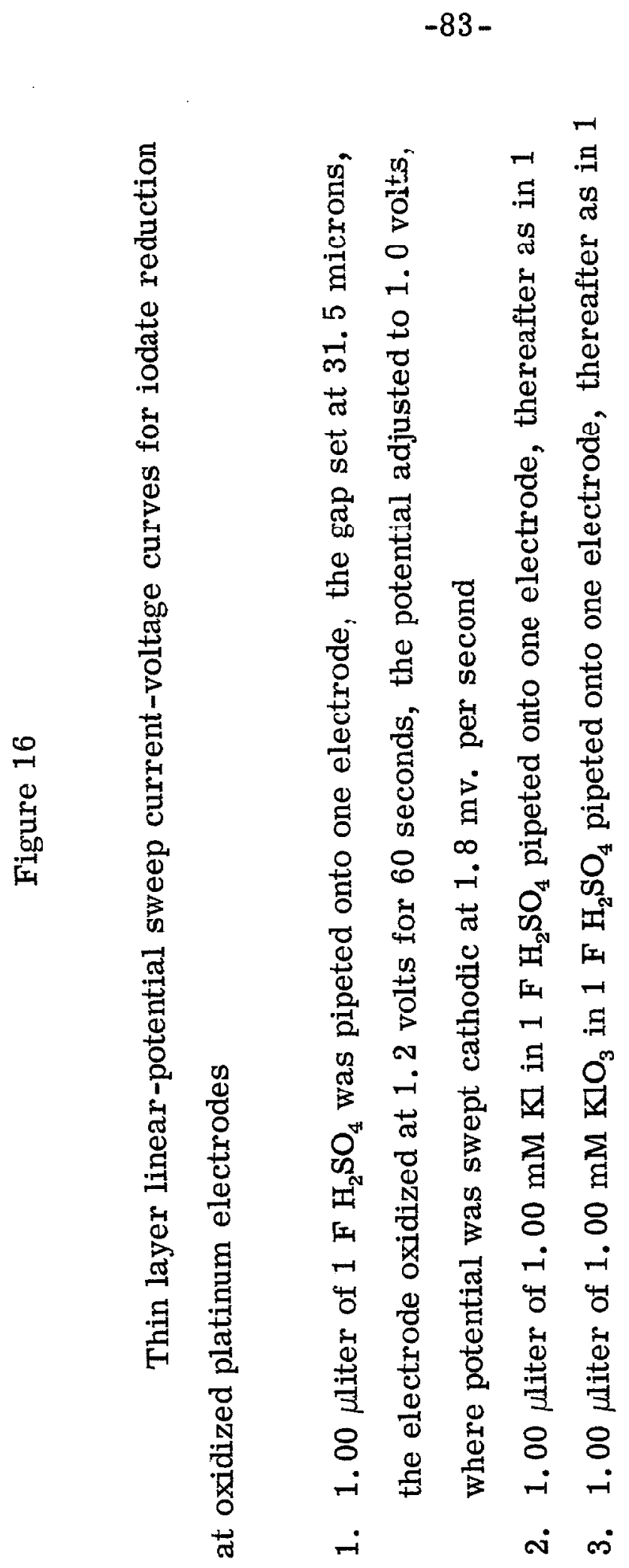


$-84-$

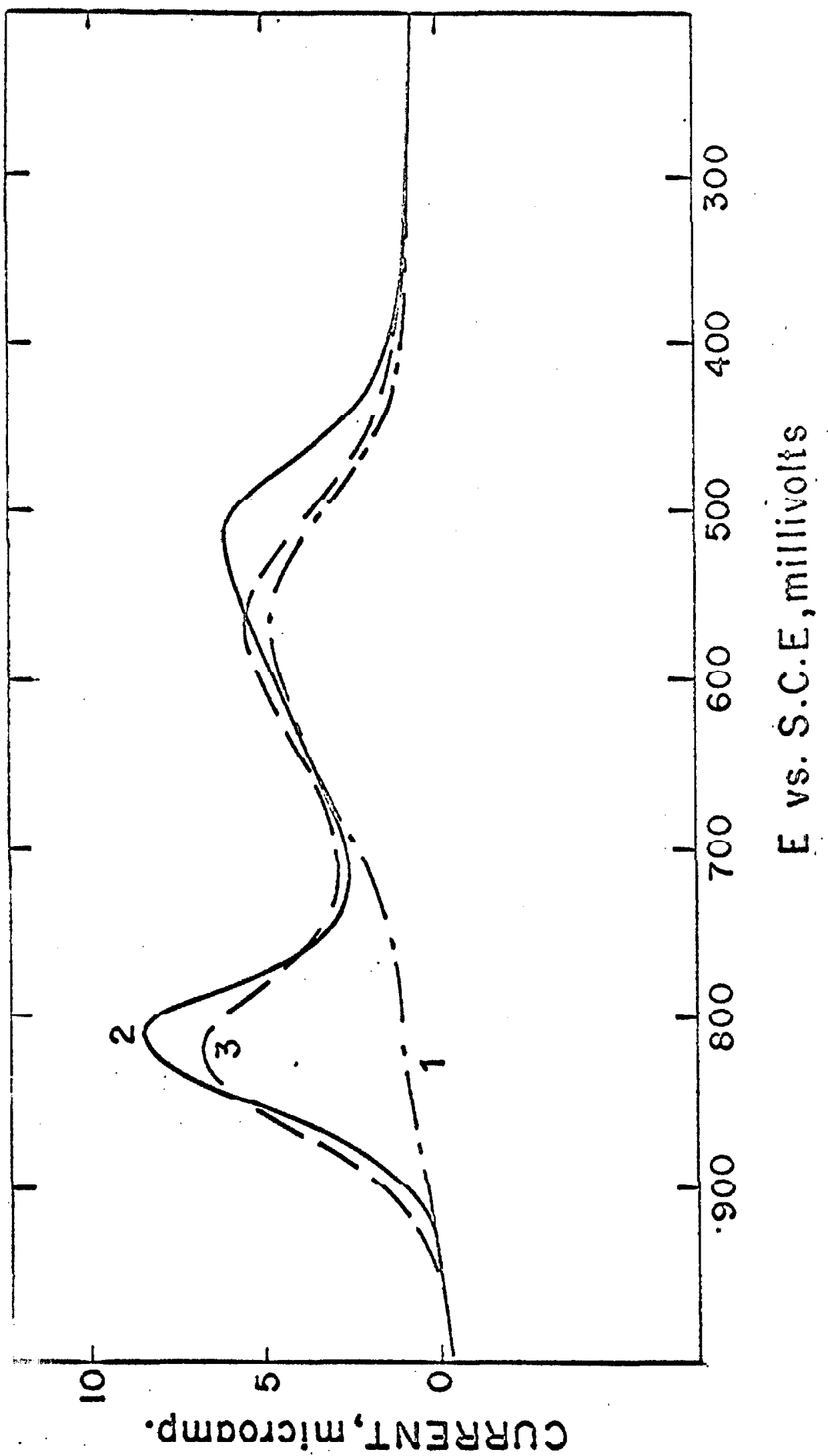




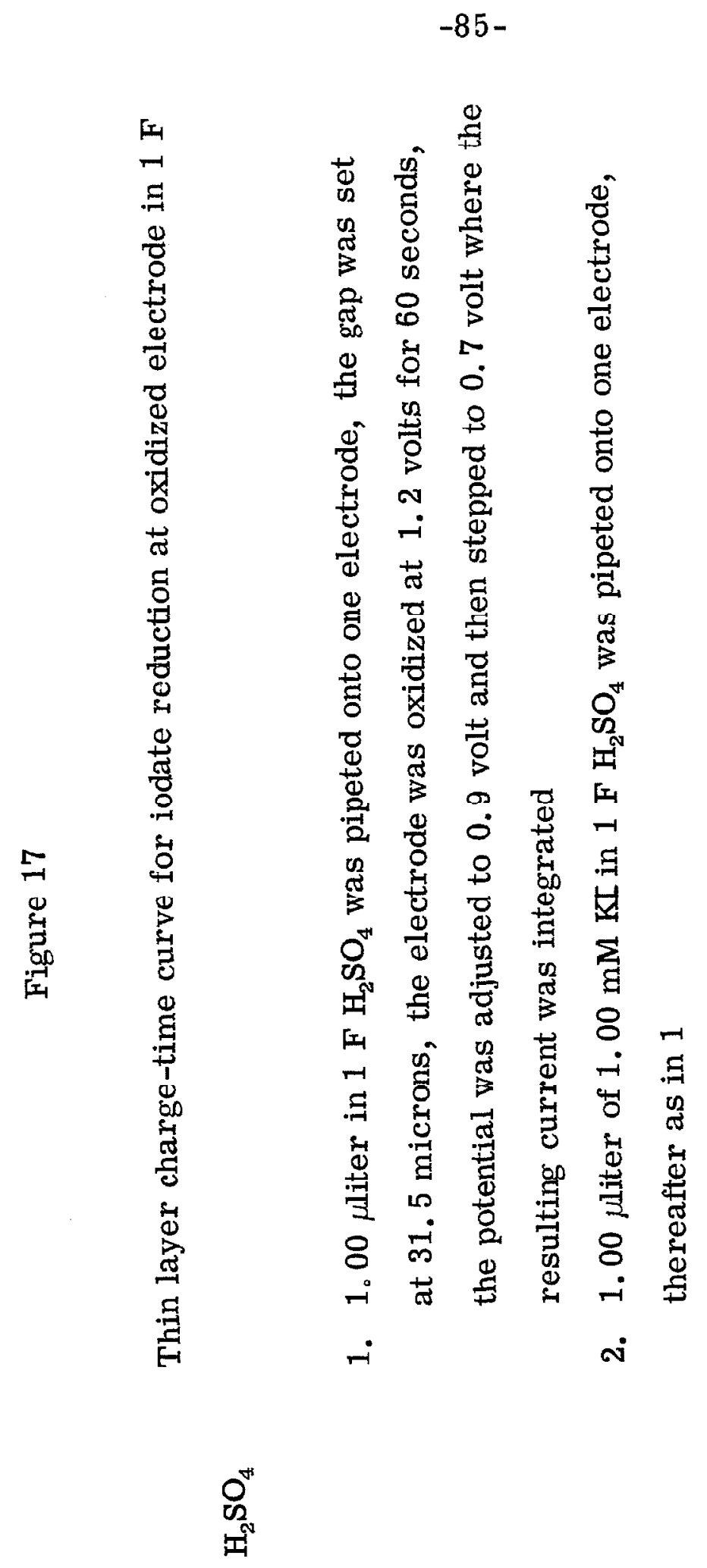


$-86-$

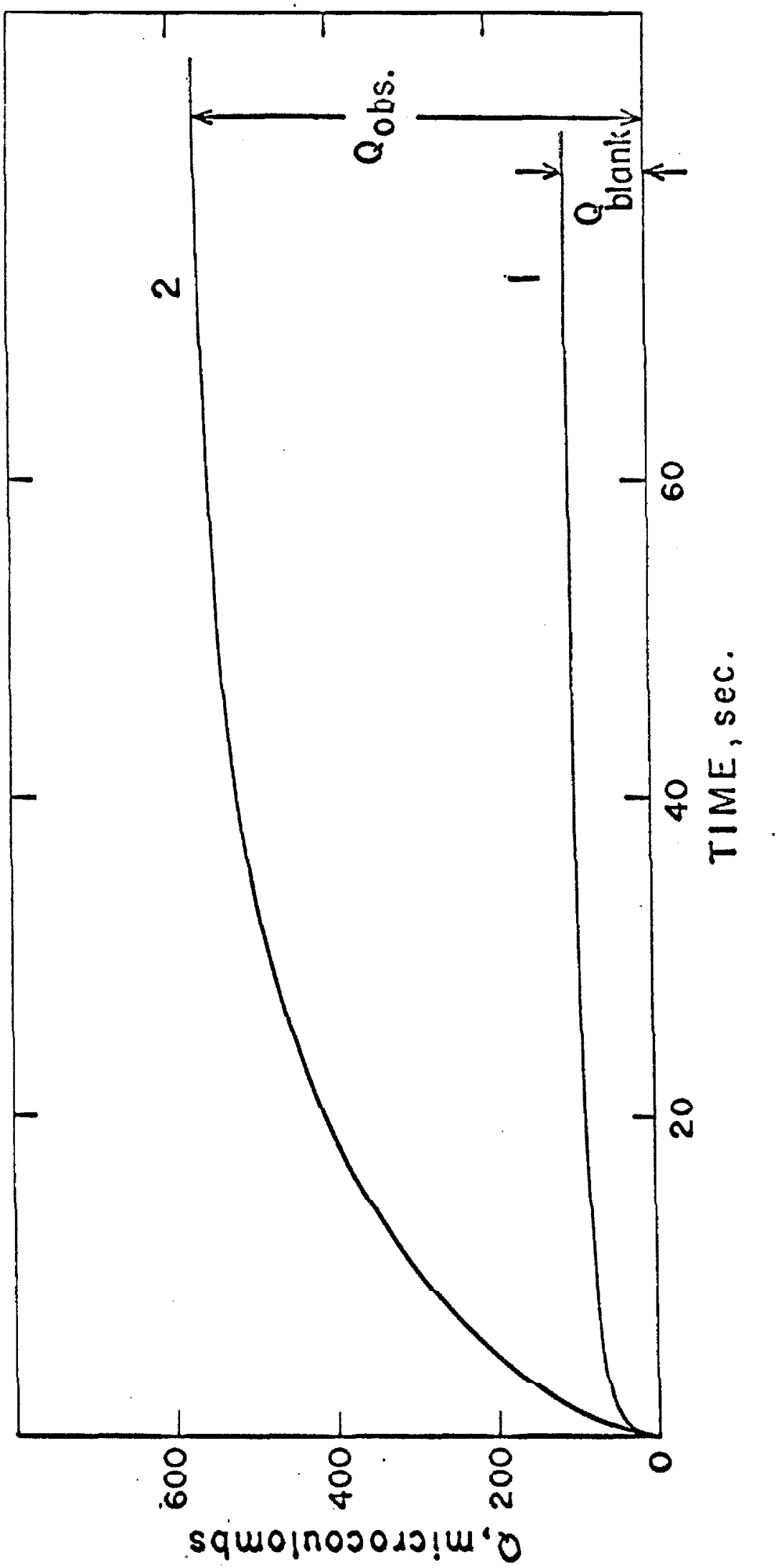


Table VI. Determination of Iodate with Oxidized Electrodes

\begin{tabular}{|c|c|c|c|c|c|}
\hline $\begin{array}{c}\text { Expt. } \\
\text { no. }\end{array}$ & $\begin{array}{l}\text { Starting } \\
\text { reagent }\end{array}$ & $\begin{array}{l}\text { Q observed, } \\
\mu \text { coulomb }\end{array}$ & $\begin{array}{l}\mathrm{Q} \text { blank, } \\
\mu \text { coulomb }\end{array}$ & $\begin{array}{c}\text { Qobs }-\mathrm{Q} \text { bl }= \\
\mathrm{Q} \text { iodate } \\
\mu \text { coulomb }\end{array}$ & $\begin{array}{l}\mathrm{Q} \text { iodate, } \\
\text { calcd. } \\
\text { from Equa- } \\
\text { tion } 14, \\
\mu \text { coulomb }\end{array}$ \\
\hline 1 & Iodide & $\begin{array}{r}570 \\
575 \\
600 \\
610 \\
\text { av. } \frac{589}{5819}\end{array}$ & $105 \pm 6$ & $484 \pm 25$ & 482.5 \\
\hline 2 & Iodate & $\begin{array}{r}605 \\
605 \\
580 \\
540 \\
500 \\
\text { av. } 566 \pm 49\end{array}$ & $105 \pm 6$ & $461 \pm 54$ & 482.5 \\
\hline
\end{tabular}

Experimental conditions: $1.00 \mu$ liter of $1.00 \mathrm{mM} \mathrm{KI}$ (Expt. 1) or $1.00 \mathrm{mM} \mathrm{KIO}_{3}$ (Expt. 2) were pipeted onto the cleaned electrode. The micrometer was set to give a gap of 31.5 microns (which just contained the solution) and the electrodes were oxidized potentiostatically at 1.2 volts for 60 seconds. The potential was adjusted to +0.9 volt and then stepped from +0.9 to +0.7 volt where the current was integrated. $\mathrm{Q}_{\text {blank }}$ was obtained by oxidizing cleaned electrodes in $1 \mathrm{~F} \mathrm{H}_{2} \mathrm{SO}_{4}$ at 1.2 volts, adjusting the potential to 0.9 volt, and stepping the potential to 0.7 volt where the current was integrated. 
where $n=5$ and $\Gamma_{I}$ - is the amount of iodide initially adsorbed. The values of $\mathrm{T}_{\mathrm{I}}{ }^{-}$calculated from Equation 26 are shown in Table VII and are close to the values obtained from the direct micropipet experiments with iodine (Table V). The presence of nonelectroactive adsorbed iodide is thus clearly established.

Determination of Nonelectroactive Adsorbed Iodine.

Although the titer of iodide-free solutions of iodine was difficult to maintain because of the volatility of the iodine, it was possible to repeat the micropipet experiments (as summarized in Table $\mathrm{V}$ for iodide) with iodine solutions by titrating the solution with thiosulfate just before it was used. These experiments were performed chronopotentiometrically and the results, summarized in Table VIII, show that extensive adsorption of iodine in a nonclectroactive form took placc, just as was truc of iodide ion. This nonelectroactive iodine was not previously detected because the techniques employed $(14,15,16)$ measured only the electroactive adsorbed iodine which was present (Table IV) if the electrode was exposed to sufficient iodine to saturate its surface with both nonelectroactive and electroactive iodine.

The presence of nonelectroactive adsorbed iodine could be confirmed in the same way that was used for iodide: oxidative desorption and determination as iodate. Table IX contains the results of these experiments. 
Table VII. Determination of Nonelectroactive Adsorbed

Iodide as Iodate

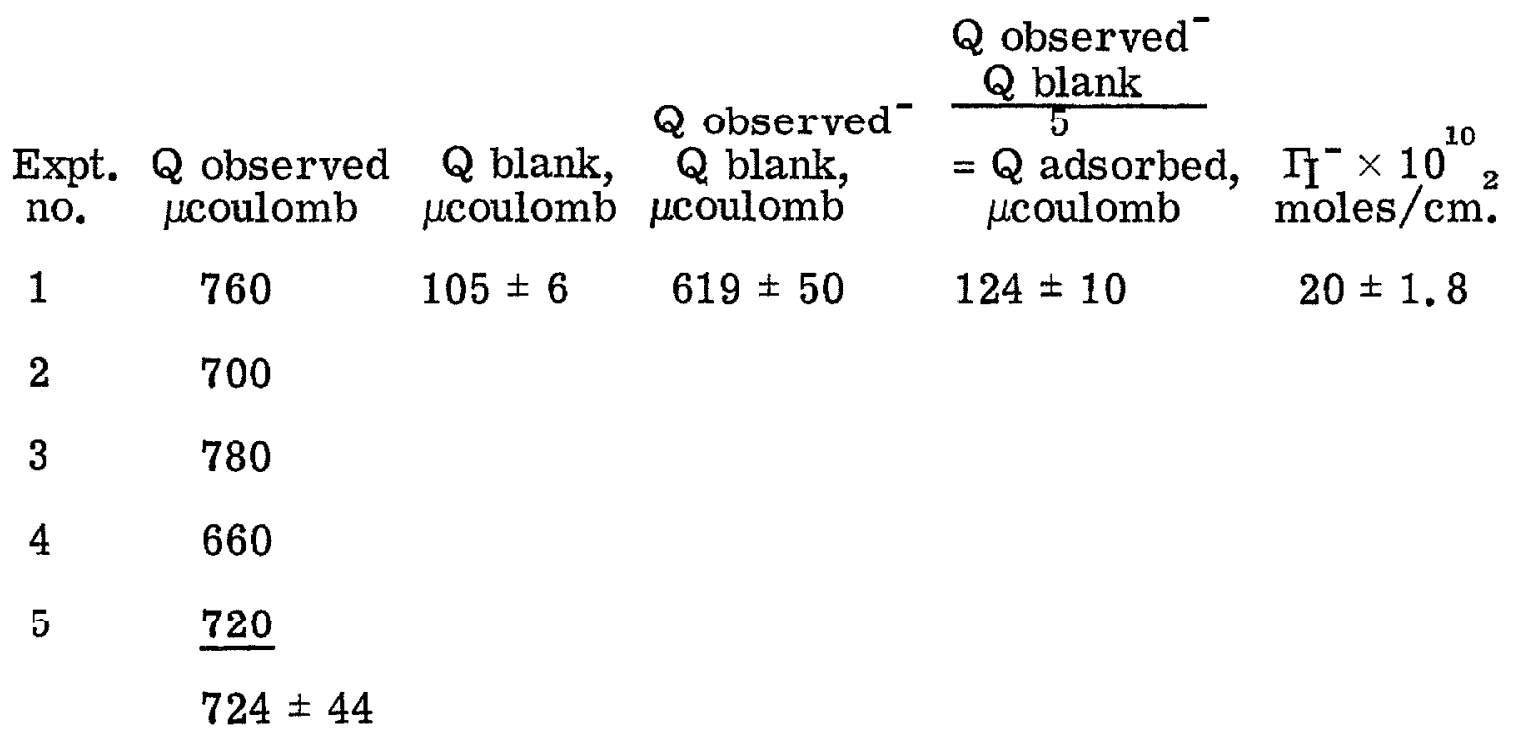

Experimental conditions: the electrodes were rinsed with excess $1.00 \mathrm{mM} \mathrm{KI}$, washed with excess $1 \mathrm{~F} \mathrm{H}_{2} \mathrm{SO}_{4}$, and the micrometer set to give a gap of 44.2 microns. The electrode was then potentiostatically oxidized at 1.2 volts for 60 seconds, the potential was adjusted to 0.9 volt and then stepped to 0.7 volt where the current was integrated. $\mathrm{Q}$ blank was obtained by oxidizing cleaned electrodes in $1 \mathrm{~F} \mathrm{H}_{2} \mathrm{SO}_{4}$ at 1.2 volts, adjusting the potential to 0.9 volt, and stepping the potential to 0.7 volt where the current was integrated. 


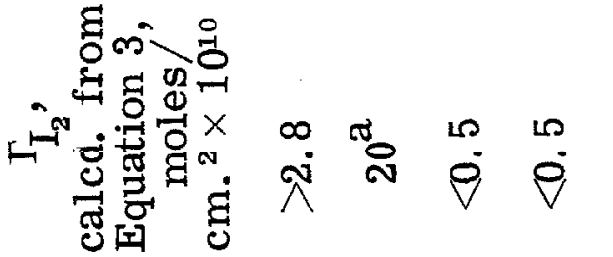

$\underset{H}{\mathbb{E}}$

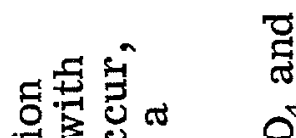

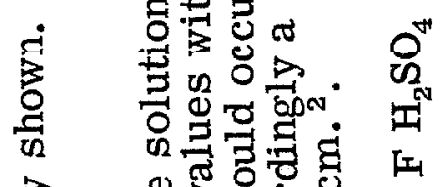

○.

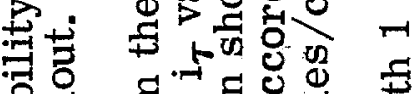

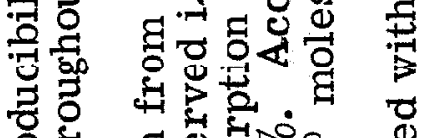

焉

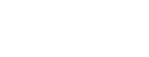

3

No $x$

를

엉영

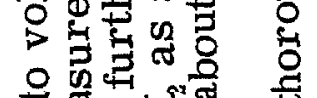

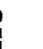

$\rightarrow$

赵

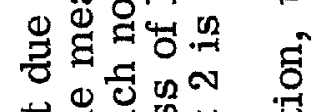

द्वृㅁํㅇ

$\rightarrow 0$

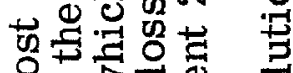

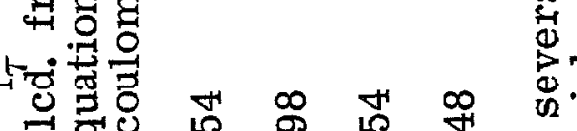

궁요

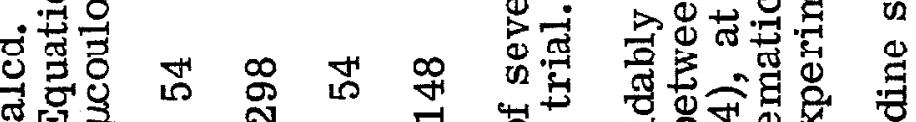

总

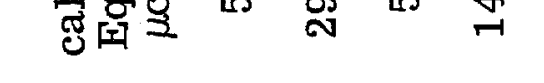

宩

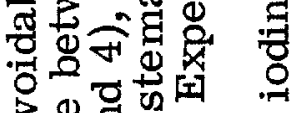

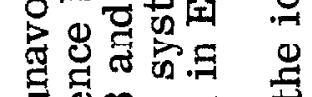

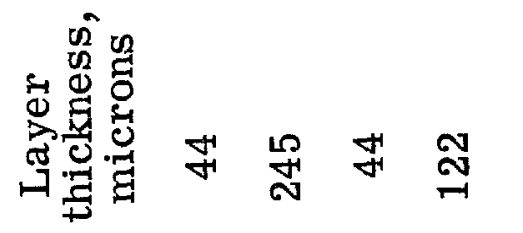

80 空

屯ิ

ف요

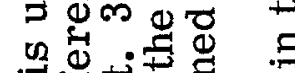

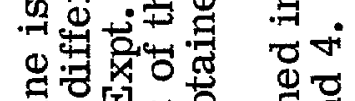

요

㝴需

긍 뫼릉응

을 的

茨 웡

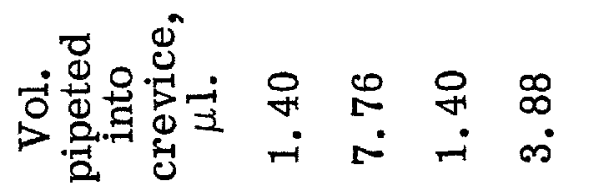

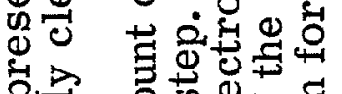

तี

两

車

$\frac{0}{0}$

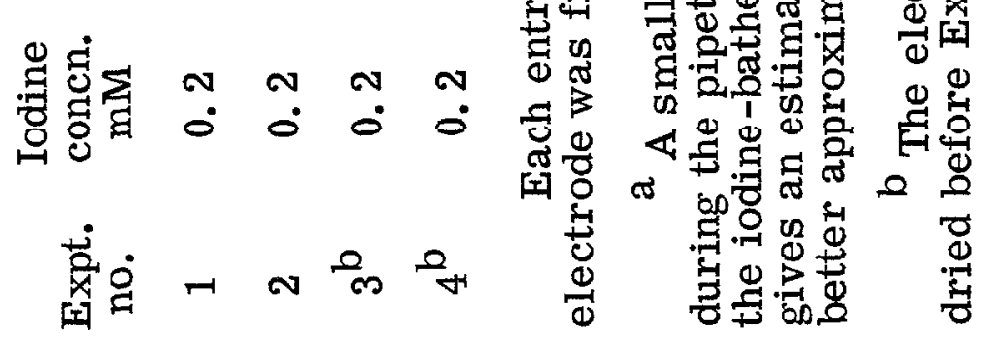

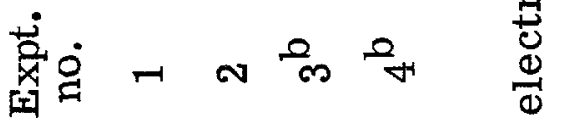


Table IX. Determination of Nonelectroactive Adsorbed Iodine

\begin{tabular}{|c|c|c|c|c|c|}
\hline $\begin{array}{l}\text { Expt. } \\
\text { no. }\end{array}$ & $\begin{array}{l}\text { Q observed, } \\
\text { بcoulomb }\end{array}$ & $\begin{array}{l}\text { Q blank, } \\
\mu \text { coulomb }\end{array}$ & $\begin{array}{l}\text { Q observed } \\
\text { Q blank, } \\
\mu \text { coulomb }\end{array}$ & $\begin{array}{l}\frac{Q \text { observed }-Q}{5} \\
=Q \text { adsorbed, } \\
\mu \text { coulomb }\end{array}$ & $\begin{array}{l}\text { olank } \\
\Gamma \times 10^{10} \\
\text { moles } / \mathrm{cm}^{2}\end{array}$ \\
\hline 1 & 1040 & $105 \pm 6$ & $971 \pm 86$ & $194 \pm 18$ & $16 \pm 1.6$ \\
\hline 2 & 1060 & & & & \\
\hline 3 & 1000 & & & & \\
\hline 4 & 1060 & & & & \\
\hline \multirow[t]{2}{*}{5} & $\underline{1020}$ & & & & \\
\hline & $1076 \pm 80$ & & & & \\
\hline
\end{tabular}

Experimental conditions: the electrodes were rinsed with excess of a saturated iodine solution in $1 \mathrm{~F} \mathrm{H}_{2} \mathrm{SO}_{4}$, washed with excess $1 \mathrm{~F} \mathrm{H}_{2} \mathrm{SO}_{4}$ and the micrometer set to give a gap of 44.2 microns. The electrode was then potentiostatically oxidized at 1.2 volts for 60 seconds, the potential was adjusted to 0.9 volt, and then stepped to 0.7 volt where the current was integrated. $Q$ blank was obtained by oxidizing cleaned electrodes in $1 \mathrm{~F} \mathrm{H}_{2} \mathrm{SO}_{4}$ at 1.2 volts, adjusting the potential to 0.9 volt, and stepping the potential to 0.7 volt where the current was integrated. 
Error in a Recent Paper.

In a recent paper (16), in which some preliminary thin layer chronopotentiometric experiments with iodide-free iodine solutions were described, the amount of iodine to which the electrode surfaces were actually exposed was not known because the addition of solutions to the cell was not performed with micropipets. However, the fact that a cathodic transition time was observed after the electrode was filled makes it clear that the electrode surfaces must have been saturated with nonelectroactive iodine. In those experiments it was observed that if some iodine was reduced and then the direction of the current was reversed the anodic transition lime was shorler than the callodic electrolysis time unless the electrodes were bathed in an iodide solution and rinsed prior to the addition of the iodine solution. It has been possible to reproduce that result in the present experiments only will incompletely reduced electrodes. So long as the cleaned electrodes were very thoroughly reduced (potentiostating at 0.35 volt for 3-4 minutes) prior to being filled with the iodine solution, the cathodic electrolysis time and anodic transition time were equal. It seems likely that the behavior reported in the earlier paper (10) was the result of incomplete reduction of the electrode inasmuch as potentiostatically controlled reduction was not employed. The present experiments simply demonstrate that iodide is not adsorbed on an electrode which has already been saturated with adsorbed iodine. 


\section{Conclusions}

Several new conclusions result from the data presented in this study. First is the fact that al saluraliun ca. $2 \times 10^{-9}$ $\mathrm{mole} / \mathrm{cm}^{2}$. of iodine is adsorbed in a nonelectroactive state on platinum electrodes. An additional $1 \times 10^{-9} \mathrm{~mole} / \mathrm{cm}^{2}$ of lodine is also adsorbed in an electroactive state. Inasmuch as the sum of the two forms of adsorbed iodine is considerably greater than the amount of iodine adsorption measured in the previous radiotracer experiments in which an electrode was immersed in a radio-iodine solution, washed and counted $(9,16,17$, 18), it seems highly probable that only the electroinactive iodine remains on an electrode that is extensively washed with $1 \mathrm{~F} \mathrm{H}_{2} \mathrm{SO}_{4}$. The radiotracer experiments were thus not measuring the same iodine as were the electrochemical experiments (thin layer experiments excepted) and the rough correspondence between the amount of adsorbed iodine found by the two techniques $(14,15)$ was accidental. This point of view makes it easier to understand the fact that extensive iodine adsorption can be demonstrated with radio-iodine on a platinum electrode which gives no cathodic transition time when used in an ordinary chronopotentiometric experiment in $1 \mathrm{~F} \mathrm{H}_{2} \mathrm{SO}_{4}$. (16).

The present thin layer experiments provide the first direct electrochemical estimate of the extent of iodide adsorption on platinum electrodes--ca. $1.2 \times 10^{-9} \mathrm{~mole} / \mathrm{cm}^{2}$. at saturation (Tablc V). This valuc corrcøponds to the approximate value 
reported previously on the basis of radio-iodine experiments (17). The electroinactivity of the adsorbed iodide is confirmed by all of the experiments presented here. The data in Tables IV, V, and VI show that the adsorption of iodide on the electrode eliminates the further adsorption of nonelectroactive iodine and iodide. The adsorption of nonelectroactive lodine is also shown to eliminate further adsorption of iodide (Table V). Electroactive iodine adsorption, however, continues to occur on both iodide-and iodinecoated electrode surfaces.

The common practice of activating platinum electrodes toward adsorption of reactants--e.g., by platinization--in an attempt to increase the rate of an electrode reaction may be precisely the wrong approach for reactants which mimic the behavior of the iodide-iodine couple.

Conversations with Dr. R. A. Osteryoung assisted with the progress of this study. 


\section{(ii). A Study of the $\mathrm{CoY}^{-}-\mathrm{CoY}^{-2}$ and $\mathrm{FeY}^{-}-\mathrm{FeY}^{-2}$ Couples At Platinum Electrodes (20)}

Previous studies in these laboratories in which diffusion chronopotentiometry was employed as the measuring technique $(21,22)$ produced evidence that both $\mathrm{CoY}^{-}$and $\mathrm{CoY}^{-2}\left(\mathrm{H}_{4} \mathrm{Y}=\mathrm{e}-\right.$ thylenediaminetetracetic acid) are extensively adsorbed on bright platinum electrodes. Quantitative measurement of the amount of each complex adsorbed was not attempted because of the poor definition of the waves and the possibility that the data contained some contribution from oxide film formation or supporting electrolyte reduction. When bromide or iodide ion was added to the solutions the adsorption of the cobalt complexes appeared to be prevented, presumably because of the preferential adsorption of the halides.

The thin layer electrochemical technique has been applied to the $\mathrm{CoY}^{-}-\mathrm{CoY}^{-2}$ couple to check the earlier results and to provide a quantitative measure of the extent of the adsorption. The iron complexes $\mathrm{FeY}^{-}$and $\mathrm{FeY}^{-2}$ were also examined for possible adsorption.

20 A. T. Hubbard and F. C. Anson, Anal. Chem., 38, 1601! (1966).

21 F. C. Anson, Anal. Chem. , 36, 521 (1964).

22 F. C. Anson, J. Electrochem. Soc., 110, 436 (1963). 
Experimental

A micrometer thin layer electrode was employed. The total geometric area of the electrode cavity was $0.635 \mathrm{~cm}^{2}$. The electrode was cleaned by alternate potentiostatic oxidation (1.2 volts vs. SCE) and reduction ( 0.0 volts vs. SCE) while a stream of oxygen-free $1 \mathrm{~F} \mathrm{H}_{2} \mathrm{SO}_{4}$ was flowing across the electrode faces. After the cleaning cycle the electrode was maintained at 0.4 volt vs. SCE for several minutes until any residual current decayed to less than one microampere.

Both linear potential sweep and chronocoulometric (potentialstep with current integration) techniques were employed. All solutions were deaerated with prepurified nitrogen and the electrode was enclosed in a nitrogen-filled polyethylene tent during measurements.

Reagents.

A $0.1 \mathrm{~F}$ solution of $\mathrm{CoY}^{-2}$ was prepared by mixing equimolar quantities of $\mathrm{CoSO}_{4} \cdot 7 \mathrm{H}_{2} \mathrm{O}$ and $\mathrm{Na}_{2} \mathrm{H}_{2} \mathrm{Y} \cdot 2 \mathrm{H}_{2} \mathrm{O}$ in a $1 \mathrm{~F} \mathrm{pH} 7$ phosphate buffer solution.

Crystalline $\mathrm{NaCoY} \cdot 4 \mathrm{H}_{2} \mathrm{O}(23)$ was prepared as follows:

An aqueous solution of $\mathrm{Ba}(\mathrm{CoY})_{2} \cdot 4 \mathrm{H}_{2} \mathrm{O}$, prepared according

23 J. L. Hoard and H. A. Weakliem, J. Am. Chem. Soc., 81, 549 (1959). 
to the published procedure (24), was treated with a slight excess of $\mathrm{Na}_{2} \mathrm{SO}_{4}$, the resulting $\mathrm{BaSO}_{4}$ removed by filtration, and the filtrate added to a large volume of anhydrous ethanol. The resulting precipitate was recrystallized from an aqueous solution to give large violet crystals which were dried for 24 hours at $50^{\circ}$ C. Purity of the crystals was confirmed by thin layer electrochemical analysis of weighed portions.

Attempts to prepare pure $\mathrm{NH}_{4} \mathrm{FeY} \cdot \mathrm{H}_{2} \mathrm{O}$ by the published procedure (25) were unsuccessful. However, NaFeY $\cdot 3 \mathrm{H}_{2} \mathrm{O}$ was successfully obtained by the following modified procedure: A fresh precipitate of $\mathrm{Fe}(\mathrm{OH})_{3}$ was prepared by adding excess aqueous ammonia to a solution of ferric sulfate. The precipitate was thoroughly washed by decantation and then treated with slightly less than the stoichiometric quantity of ethylene-diaminetetraacetic acid, $\mathrm{H}_{4} \mathrm{Y}$, and the $\mathrm{pH}$ of the mixture adjusted to about 8.5 with $\mathrm{NaOH}$. The remaining $\mathrm{Fe}\left(\mathrm{OH}_{3}\right)$ was removed by filtration and the filtrate adjusted to $\mathrm{pH} 5$ by addition of perchloric acid; the volume was reduced slowly on the steam bath until crystals began to form. Such solutions yielded large brown-colored crystals of $\mathrm{NaFeY} \cdot 3 \mathrm{H}_{2} \mathrm{O}$ which were

${ }^{24}$ T. Moeller, (ed.), Inorganic Syntheses, 5 , 186 McGrawHill Book Co., N. Y., 1957.

25 H. Brintzinger, et. al., Z. . An. Chem., 251, 285 (1943). 
collected by filtration, washed with ethanol and ether, and air dried. Purity of the crystals was confirmed by thin layer electrochemical analysis of weighed portions.

Solutions of $\mathrm{FeY}^{-2}$ were prepared by potentiostatic reduction of $\mathrm{FeY}^{-}$at a large platinum gauze electrode in the absence of oxygen.

Other chemicals were reagent grade and were used without further purification. The water was triply distilled; the second distillation was from alkaline permanganate.

The special micropipets employed have been previously described.

\section{Results and Discussion $\mathrm{CoY}^{-}$and $\mathrm{CoY}^{-2}$.}

The single-cycle thin layer current-potential curve for reduction of $\mathrm{CoY}^{-}$and subsequent oxidation of $\mathrm{CoY}^{-2}$ in $1 \mathrm{~F} \mathrm{NaClO}_{4}$ supporting electrolyte is shown in Figure 18, Curve A. The great irreversibility of this couple observed in the earlier studies $(21,22)$ persists even under thin layer conditions.

Addition of iodide ion to the solution causes the electrode rcactions to become morc ncarly reversible, as shown in curve $B$ in Figure 18. This effect is believed to result from the preferential adsorption of iodide ion on the electrode which causes desorption of the cobalt complexes which, when adsorbed, interfere with the electrode reactions $(21,22)$. This ability of iodide ion both to desorb 


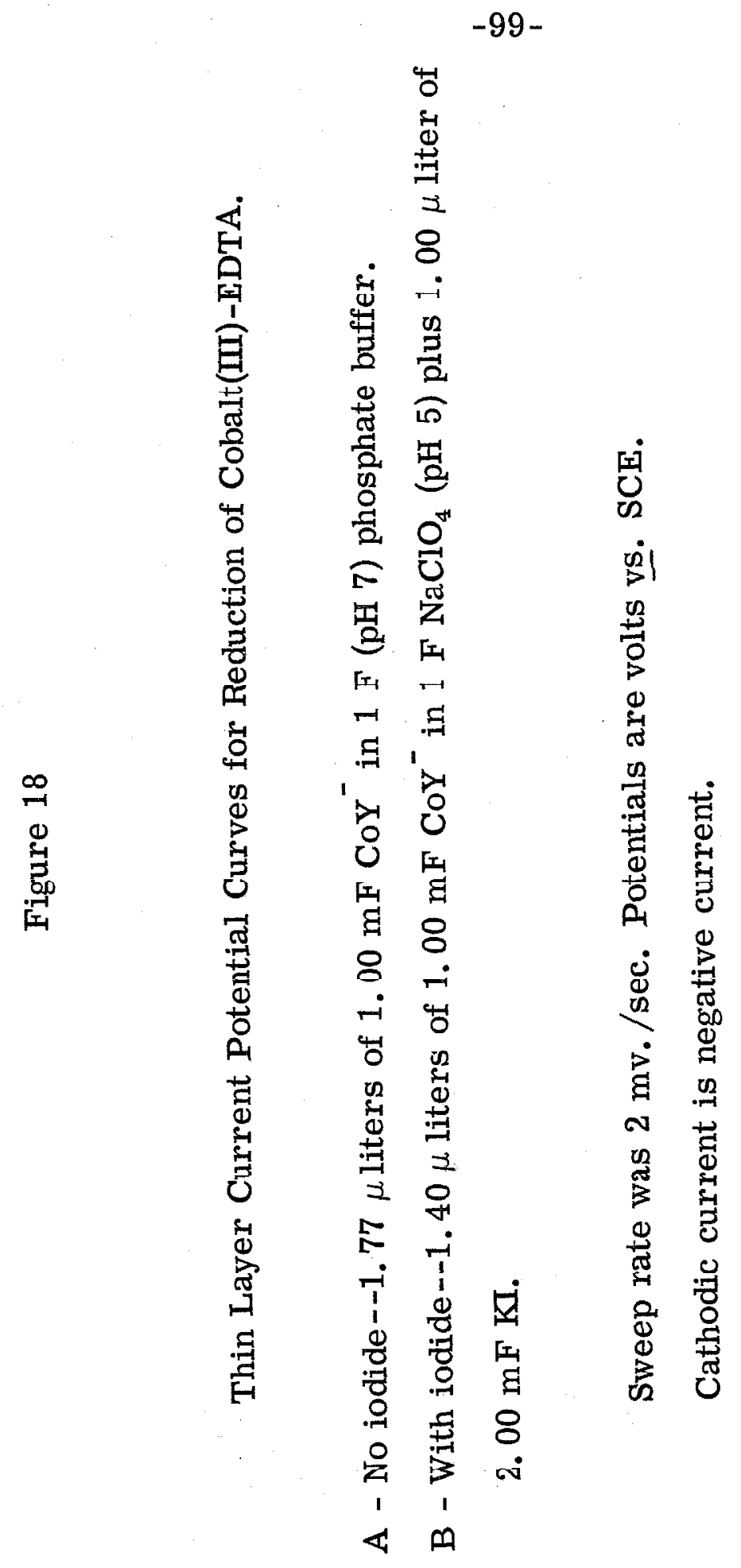


$-100-$

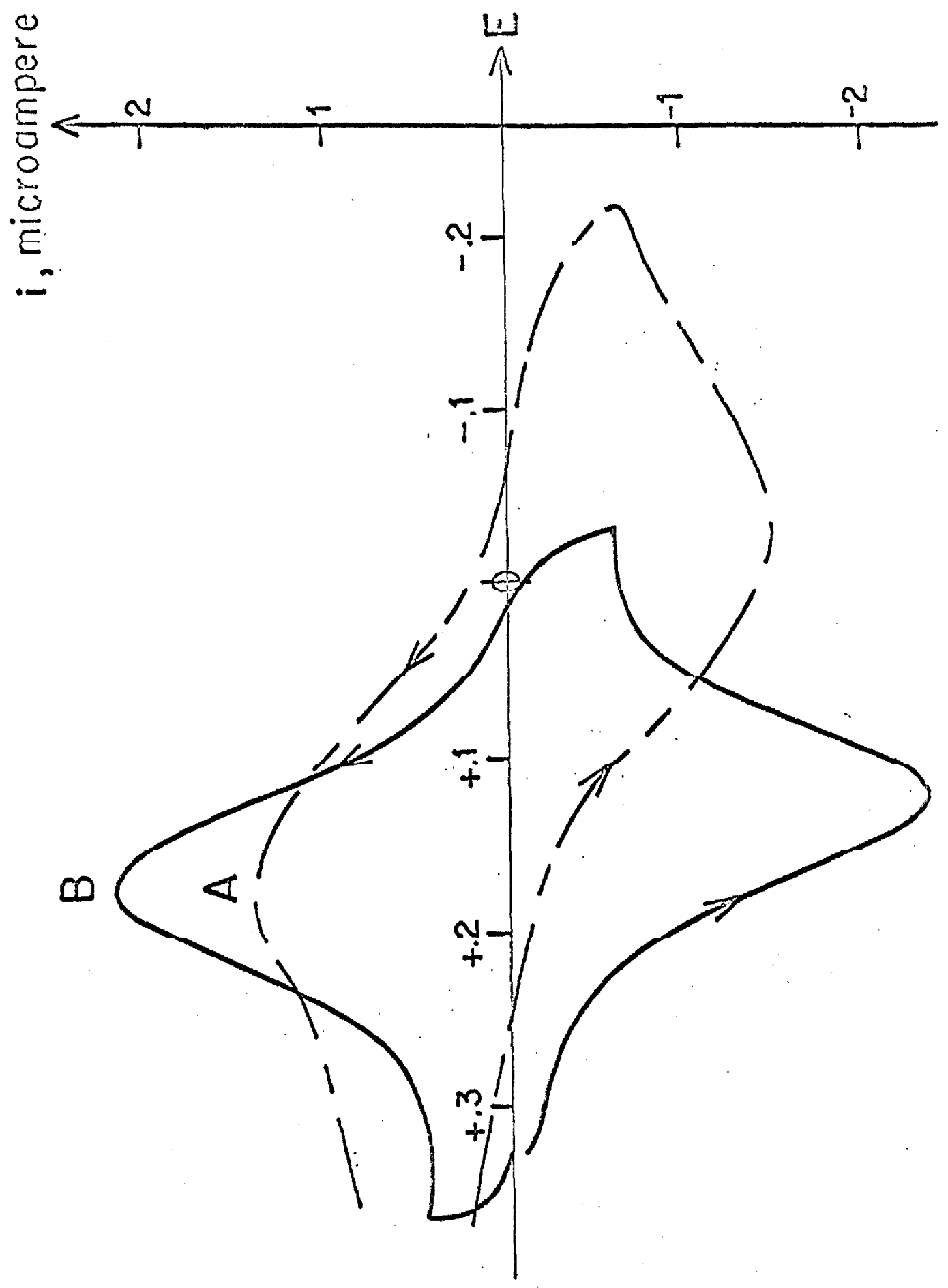


the cobalt complexes and to render the electrode reactions more reversible was exploited to measure the extent of adsorption of the cobalt complexes. To do this the following procedure was employed: The cleaned electrode was rinsed and filled with an exact volume of a solution containing $1 \mathrm{~F}$ phosphate buffer $(\mathrm{pH}=7)$ and millimolar $\mathrm{CoY}^{-}$or $\mathrm{CoY}^{-2}$. The gap was then opened to a width of 2-3 millimeters (the cobalt solution adhered, without loss, to one of the electrode faces at this point) and an exact amount of a 2 milliformal $\mathrm{KI}$ solution was pipeted onto the face of one electrode where it adhered. The gap was then set to contain the total volume of solution added. Connection was made to the capillary-tipped salt bridge and the total amount of $\mathrm{CoY}^{-}$or $\mathrm{CoY}^{-2}$ in the crevice was determined by the chronocoulometric technique.

The amount of adsorbed $\mathrm{CoY}^{-}$or $\mathrm{CoY}^{-2}$ was calculated from Equation 23

$$
\mathrm{Q}=\mathrm{nFVC} \mathrm{C}^{0}+\mathrm{nFAT}
$$

The experimental results are summarized in Table $\mathrm{X}$. Substantial adsorption of both $\mathrm{CoY}^{-}$and $\mathrm{CoY}^{-2}$ was found (Experiment numbers 1 and 3 ) in agreement with the previous chronopotentiometric evidence $(21,22)$. Because both the adsorbed $\mathrm{CoY}^{-}$and $\mathrm{CoY}^{-2}$ had to be desorbed by iodide in order to be measured in these experiments, it was necessary to show that iodide, in the concentration range used, desorbed the cobalt complexes completely. That this was the case was demonstrated by Experiment 


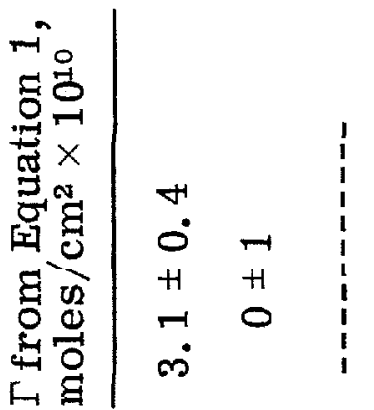

2

్ㅗㄹ

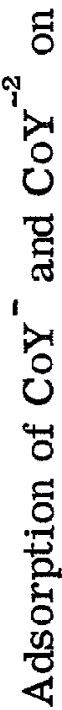

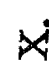

$\frac{0}{0}$
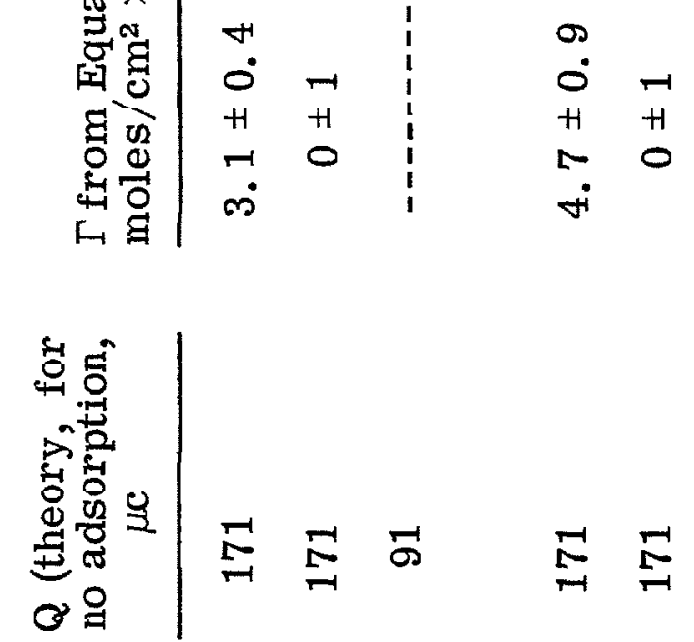

苨

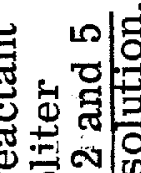

\&

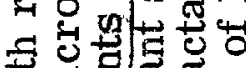

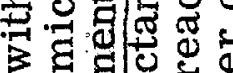
उN E

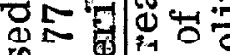

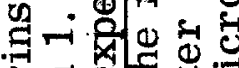

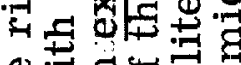

ه 등

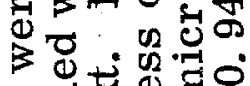

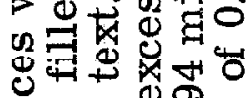

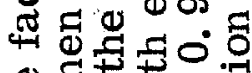

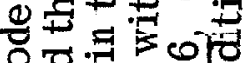

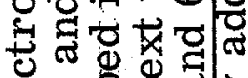

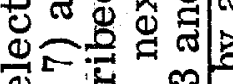

屯. II

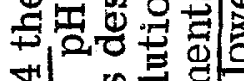

열

.

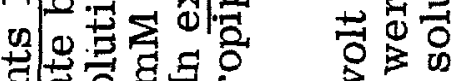

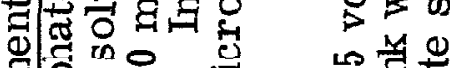

태용

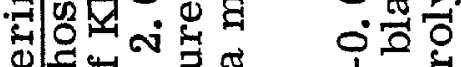

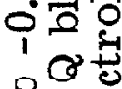

()

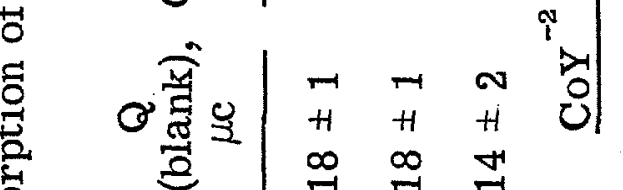

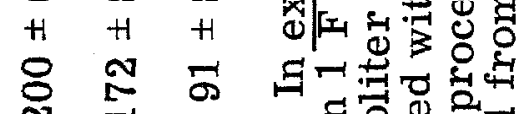

. . न्द

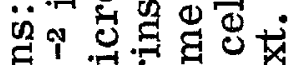

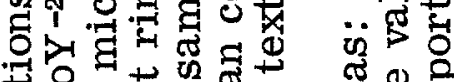

『ి

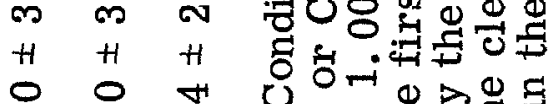

Q

in 0

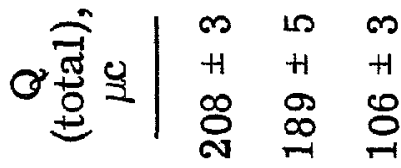

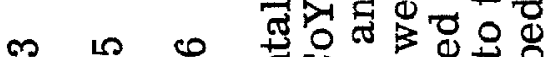

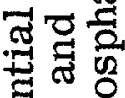

H H H

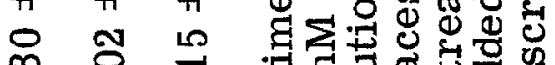

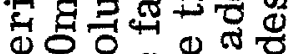

ثั่ ณำ

एवं

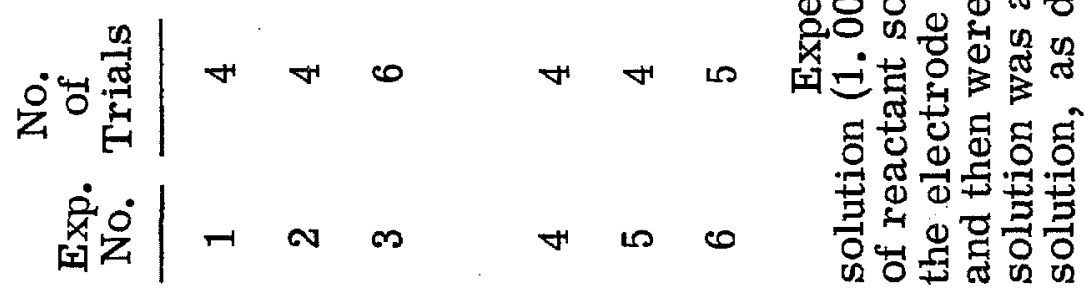

0

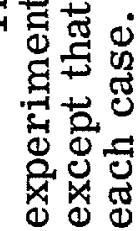


numbers 3 and 6 in Table $X$. In these experiments an exactly measured volume of the cobalt complex was pipeted into the cleaned cell, the gap closed to this volume to allow the cobalt complex to be adsorbed, the gap opened and an exactly measured aliquot of iodide was added, and the amount of cobalt complex in the cell determined in the usual way. The fact that all of the cobalt complex initially added was recovered in this process demonstrates that the iodide left none adsorbed and unreactive.

The values of $\Gamma$ reported here are, however, somewhat smaller than the previous chronopotentiometric data suggest. No values for $\Gamma$ were calculated in the previous study, but if any of the usual approximate models (26) are applied to the data, values of $25-90 \times 10^{-10} \mathrm{moles} / \mathrm{cm} .{ }^{2}$ for $\Gamma$ result, and it seems likely that the chronopotentiometric transition times were seriously lengthened by the overlap of $\mathrm{CoY}^{-}$reduction with supporting electrolyte reduction in the iodide-free solutions. We regard the thin layer values for $\Gamma$ as the most reliable because they could be obtained in iodide-containing solutions in which the reduction and oxidation of $\mathrm{CoY}^{-}$and $\mathrm{CoY}^{-2}$ are well separated from the background reactions.

26 S. V. Tafwawadi, and A. J. Bard, Anal. Chem. 36, 2 (1964). 


\section{$\mathrm{FeY}^{-}$and $\mathrm{FeY}^{-2}$.}

In contrast with the corresponding cobalt complexes, $\mathrm{FeY}^{-}$ and $\mathrm{FeY}^{-2}$ behaved reversibly at platinum electrodes in the absence of any added iodide inn. A typical thin layer currentpotential curve for this couple is shown in Figures 19. The peak currents (3.39 microamperes-cathodic and 3.37 microamperesanndic) agree well with each other and with the theoretical values of 3.33 microampere (Equation 5).

The possibility of adsorption of $\mathrm{FeY}^{-}$or $\mathrm{FeY}^{-2}$ was examined with the chronocoulometric technique in thin layers, and the results are summarized in Table XI. The data show that neither $\mathrm{FeY}^{-}$nor $\mathrm{FeY}^{-2}$ are adsorbed on the platinum electrodes. Similar experiments in which the electrodes werc maintained at potentials between +0.6 and +0.1 volt vs. SCE during the washing and filling steps gave identical behavior. There is thus a clear difference in bchavior between the cobalt and the iron chelates of EDTA.

\section{Conclusions.}

The ability of the thin layer technique to provide quantitative adsorption data for systems which thwart most other electrochemical techniques is clearly demonstrated by the $\mathrm{CoY}^{-}-\mathrm{CoY}^{-2}$ couple. The idea of trapping an adsorbale within the thin layer by prewashing and then desorbing it by addition of a preferentially adsorbed substance (for example, iodide ion) may prove of general utility 
$-105-$

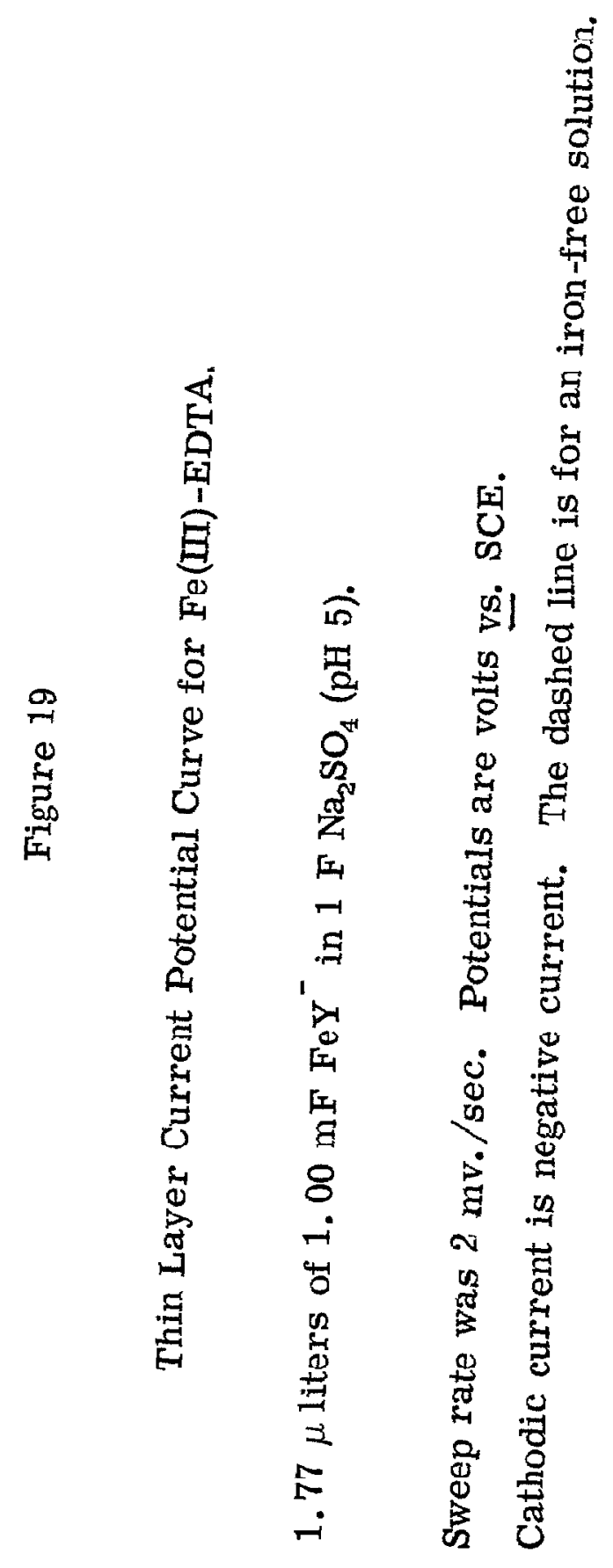


$-106-$

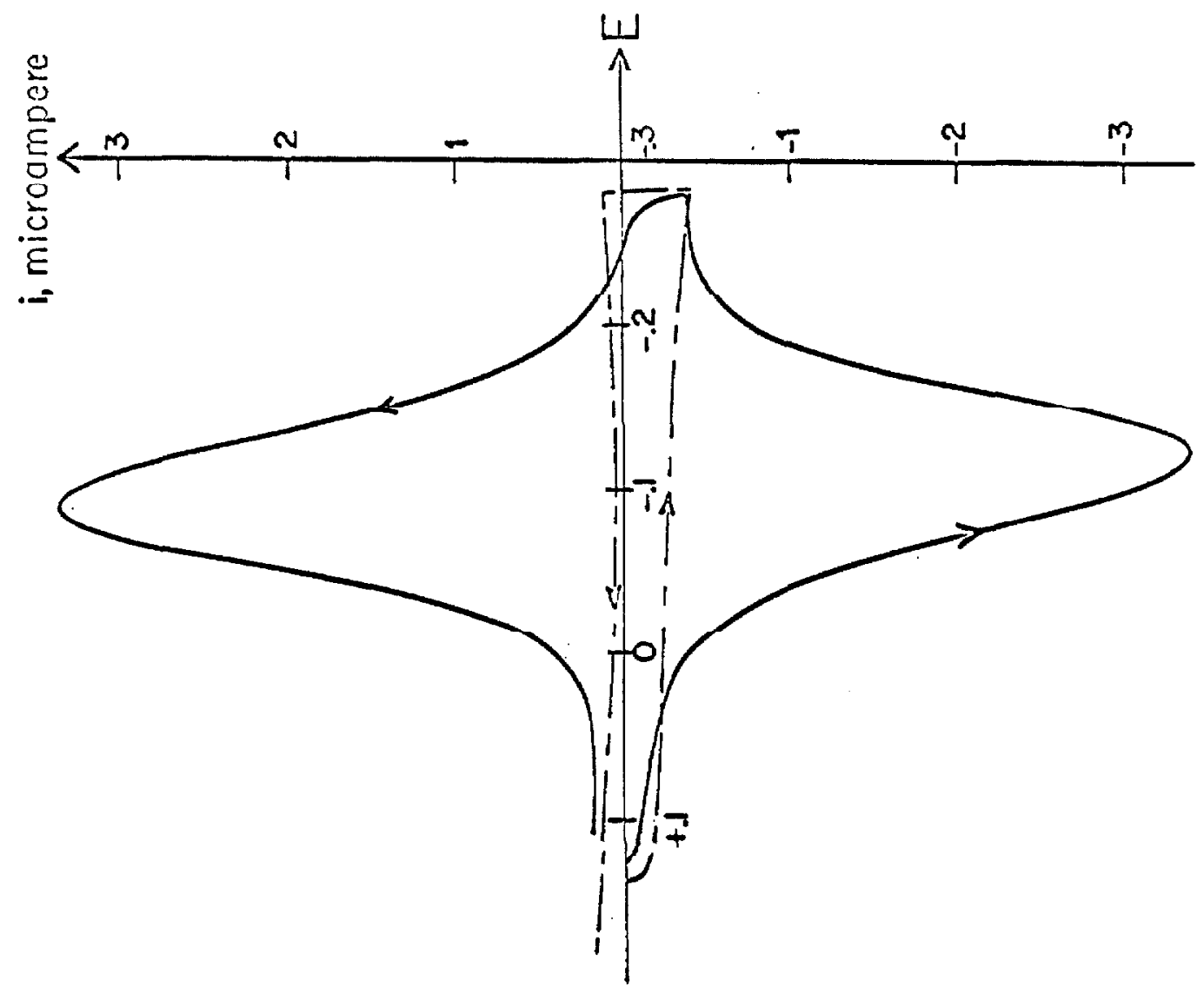


$-107-$

अ

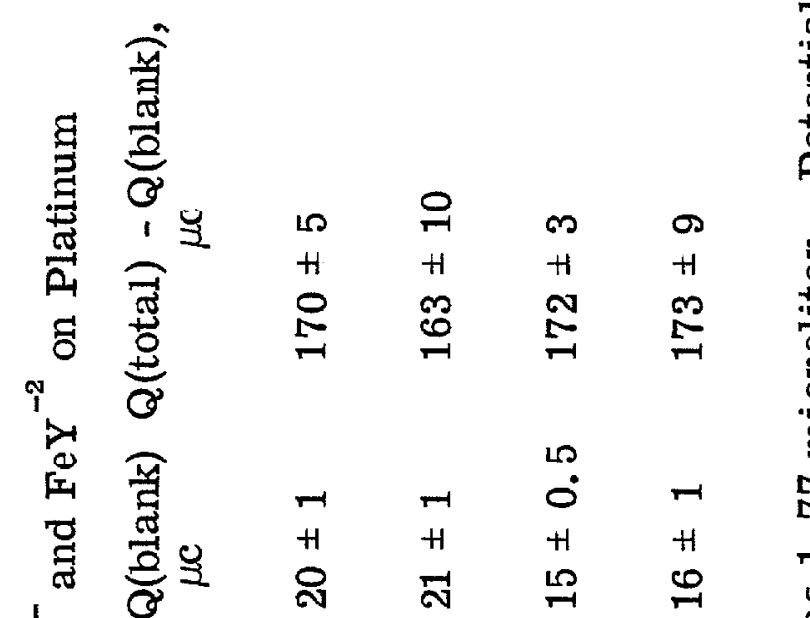

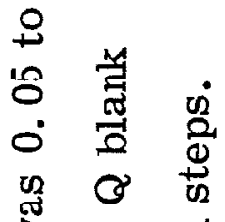

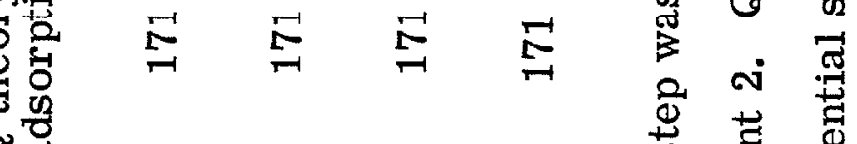

兽

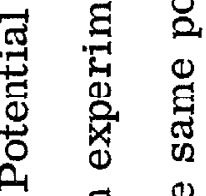

$\Xi \stackrel{\Xi}{ \pm}$

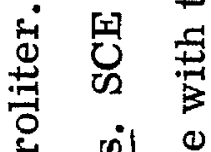

i) $\stackrel{0}{5}$

$\stackrel{5}{\circ} \stackrel{0}{\circ}$

$\approx>E$

- 00

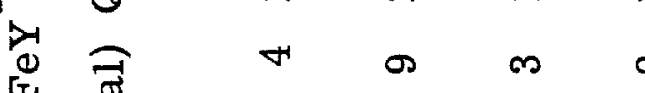

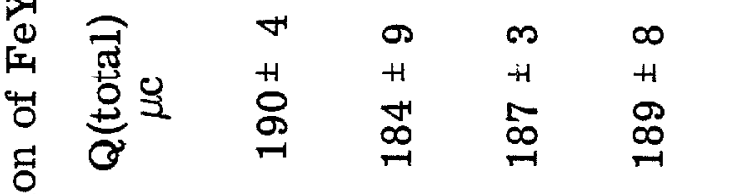

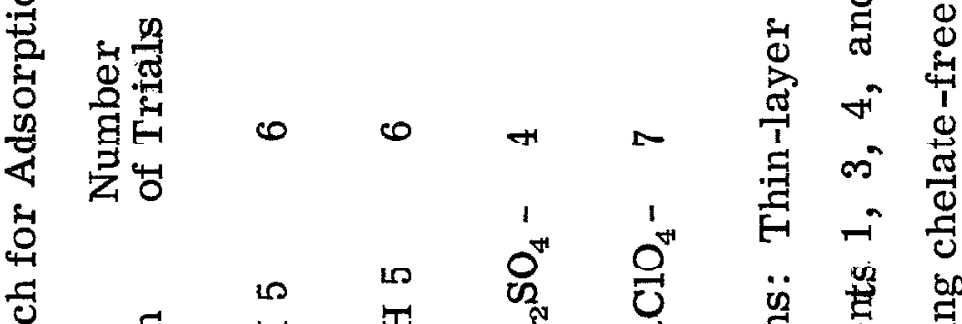

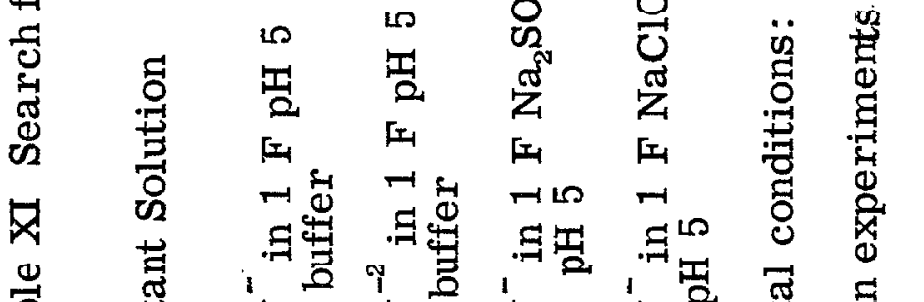

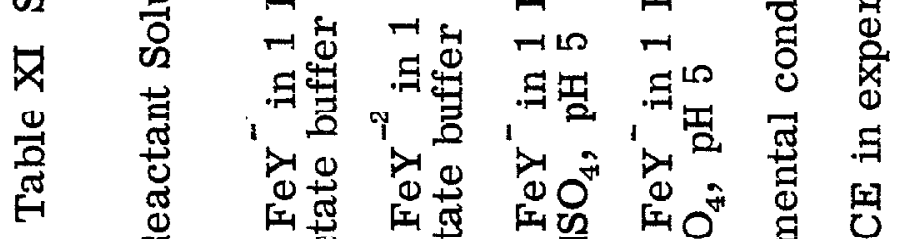

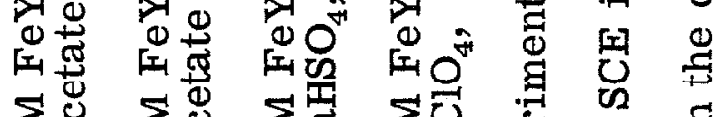

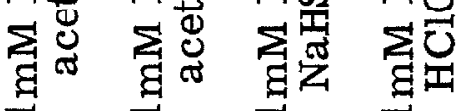

字

- $\rightarrow$ -

造

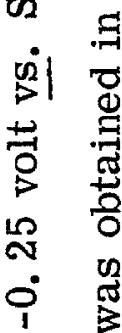


$-108-$

in studies of systems in which the adsorbed reactant inlerferes with, or completely prevents, the reaction of unadsorbed reactant. 
2. Elucidation of the Stoichiometry of Complicated Reactions - A Study of the Electrochemistry of the Chloride, Bromide and Iodide Complexes of Platinum(II) and (IV) by Means of Thin Layer Electrochemistry (27).

Although the electrochemistry of the platinum halides has not escaped previous study $(28,29,30)$, it cannot be considered to be well understood.

In the present study, the stoichiometry of the electrochemical oxidation of $\mathrm{PtCl}_{4}{ }^{-2}, \mathrm{PtBr}_{4}{ }^{-2}$ and $\mathrm{PtI}_{4}{ }^{-2}$ and of the electrochemical reduction of $\mathrm{PtCl}_{6}{ }^{-2}, \mathrm{PtBr}_{6}{ }^{-2}, \mathrm{PtI}_{6}{ }^{-2}$ and their hydrolysis products has been examined by means of thin layer electrochemical techniques. The effect of acidity and halide concentration on these reactions has been investigaled. The parlicular advantages of the llin layer approach for the study of irreversible redox couples have been pointed out in the above discussion, and these advantages have been exploited in the present study.

\section{(i). Experimental}

The micrometer thin layer electrode and associated circuitry

27 A. T. Ilubbard and F. C. Anson, Anal. Chem. 38, in press (1966).

28 A. N. Frumkin, Trans. Faraday Soc., 54, 156 (1958).

29 V. I. Kravtsov, and D. V. Sinalsov, Vcstn. Leningr. Univ., 19, Ser. Fiz. 프him. No. 2, 90 (1964).

30 J. J. Lingane, J. Electroanal. Chem., 7, 94 (1964). 
have been described above. The measurements of total charge consumed by particular electrode reactions were carried out in two different ways: When the electrode potential was potentiostatically stepped from one value (where no current flowed) to another, the resulting current was integrated by means of operational amplifiers and the integral was recorded. For the experiments in which the electrode potential was swept linearly but very slowly, the area under the resulting individual current potential peaks was evaluated graphically. When more than one current peak occurred, the areas were divided at the current minima.

Because the electrode reactions exhibited considerable irreversibility, even at the low current densities prevailing in the thin layer experiments, it was necessary to match the potential sweep rates to the reactant concentrations in order to keep the peak currents constant and small. In this way the observed peak potentials remained constant even though the concentrations of the individual components varied.

The very slow potential swecp rates $(0.125-0.5$ millivolts/ second) were obtained by means of a synchronous motor-driven potentiometer instead of the operational amplifier sweep generator proviously described (Part III). All potentials were measured versus the saturated calomel electrode.

The platinum thin layer electrodes were cleaned before each experiment by alternate, anodic (1.5 volts) and cathodic ( 0 volt), polarization in $1 \mathrm{~F} \mathrm{H}_{2} \mathrm{SO}_{4}$; after several such cycles the 
electrode was potentiostated at 0.4 volt for several minutes until any residual current decayed to less than one microampere and was then used immediately.

\section{Reagents}

$\mathrm{K}_{2} \mathrm{PtCl}_{6}$ was prepared by mixing excesses of $1 \mathrm{~F} \mathrm{KCl}$ solution with an $0.1 \mathrm{~F}$ solution of $\mathrm{H}_{2} \mathrm{PtCl}_{6}$ in $3 \mathrm{~F} \mathrm{HCl}$. The precipitated $\mathrm{K}_{2} \mathrm{PtCl}_{6}$ was washed with ice water, ethanol and anhydrous ether. Hydrolyzed solutions of $\mathrm{K}_{2} \mathrm{PtCl}_{6}$ and $\mathrm{K}_{2} \mathrm{PtBr}_{6}$ wcrc preparcd by either of the following two methods (solutions prepared by either method behaved identically): (1) Solutions of $\mathrm{K}_{2} \mathrm{PtCl}_{6}$ or $\mathrm{K}_{2} \mathrm{PtBr}_{6}$ in water were irradiated for two hours at room temperature with a mercury arc lamp (General Electric Co. No. H4AB, 100 watts) located $10 \mathrm{~cm}$. from the solution and then allowed to stand 48 hours before use. (2) Solutions of $\mathrm{K}_{2} \mathrm{PtCl}_{6}$ or $\mathrm{K}_{2} \mathrm{PtBr}_{6}$ in water were allowed to stand under nitrogen for several weeks at room temperature under ordinary laboratory illumination.

$\mathrm{K}_{4} \mathrm{PtCl}_{4}$ was prepared according to a published procedure (31) $\mathrm{K}_{2} \mathrm{PtBr}_{6}$ was prepared as follows: Several grams of $\mathrm{H}_{2} \mathrm{PtCl}_{6} \cdot 6 \mathrm{H}_{2} \mathrm{O}$ were treated with $10 \mathrm{ml}$. per gram of $48 \% \mathrm{HBr}$ and the mixture kept near $90^{\circ} \mathrm{C}$ for two hours. A slight excess of $\mathrm{KBr}$ was added and the resulting precipitate of $\mathrm{K}_{2} \mathrm{PtBr}_{6}$ was recrystallized several times from $1 \mathrm{~F} \mathrm{HBr}$.

31 J. Kleinberg (ed.), Inorganic Syntheses, 7, 240, McGrawHill Book Co., N.Y., 1963. 
Other chemicals were of reagent grade and were used without further purification.

All solutions were stored and used under an atmosphere of prepurified nitrogen. The thin layer electrode was contained in a small polyethylene tent that was continuously flushed with nitrogen.

It should be pointed out that the use of the thin layer electrode was essential in these experiments for two reasons: The electrode reactions are irreversible so that poorly defined waves are obtained at the usual current densities required in macro-electrochemical cells. In addition, platinum metal is deposited during many of the reductions. In the thin layer cell the amount of deposition during the course of each experiment is manageably small. In macro-cells, however, so much more platinum is deposited that the effective electrode area does not remain constant during an individual experiment.

$$
\text { (ii). } \mathrm{PtCl}_{4}{ }^{-2} \text { and } \mathrm{PtCl}_{6}{ }^{-2}
$$

Figure 20, curve A shows the thin layer current-potential curve that resulted when a slow linear potential sweep was applied to a solution of $\mathrm{PtCl}_{6}{ }^{-2}$ in $1 \mathrm{~F} \mathrm{HCl}$. The difference between the observed peak potential ( 0.1 volt) and the accepted standard potential --0.43 volt S. C. E. (32)--illustrates the irreversibility of the reaction. The current potential curve does not show a distinct

32 W. L. Latimer, Oxidation Potentials, 2nd ed., p. 207, N.Y.: Prentice Hall, 1952. 


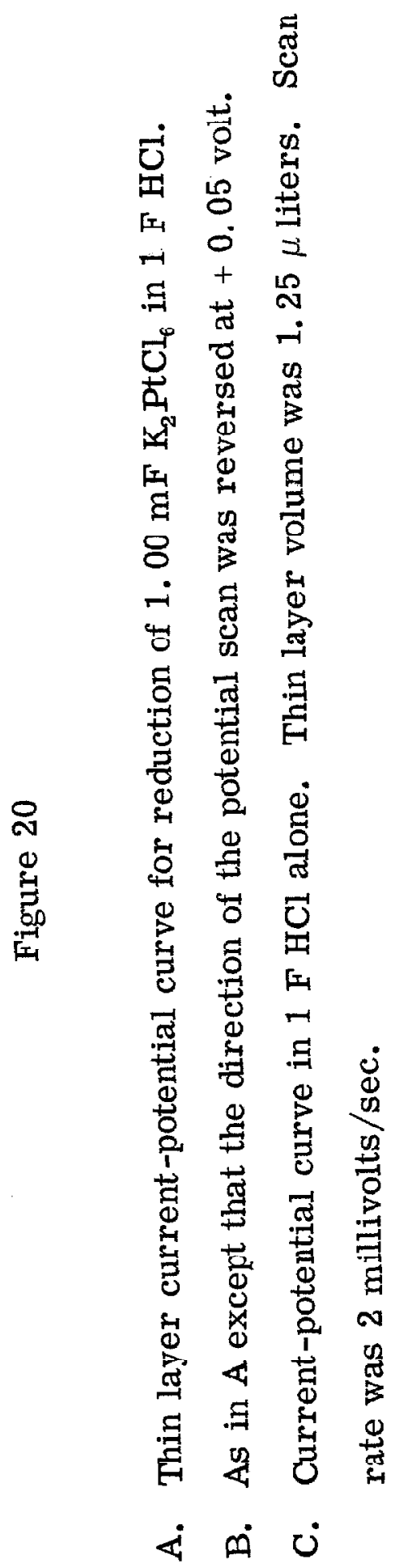


$-114-$

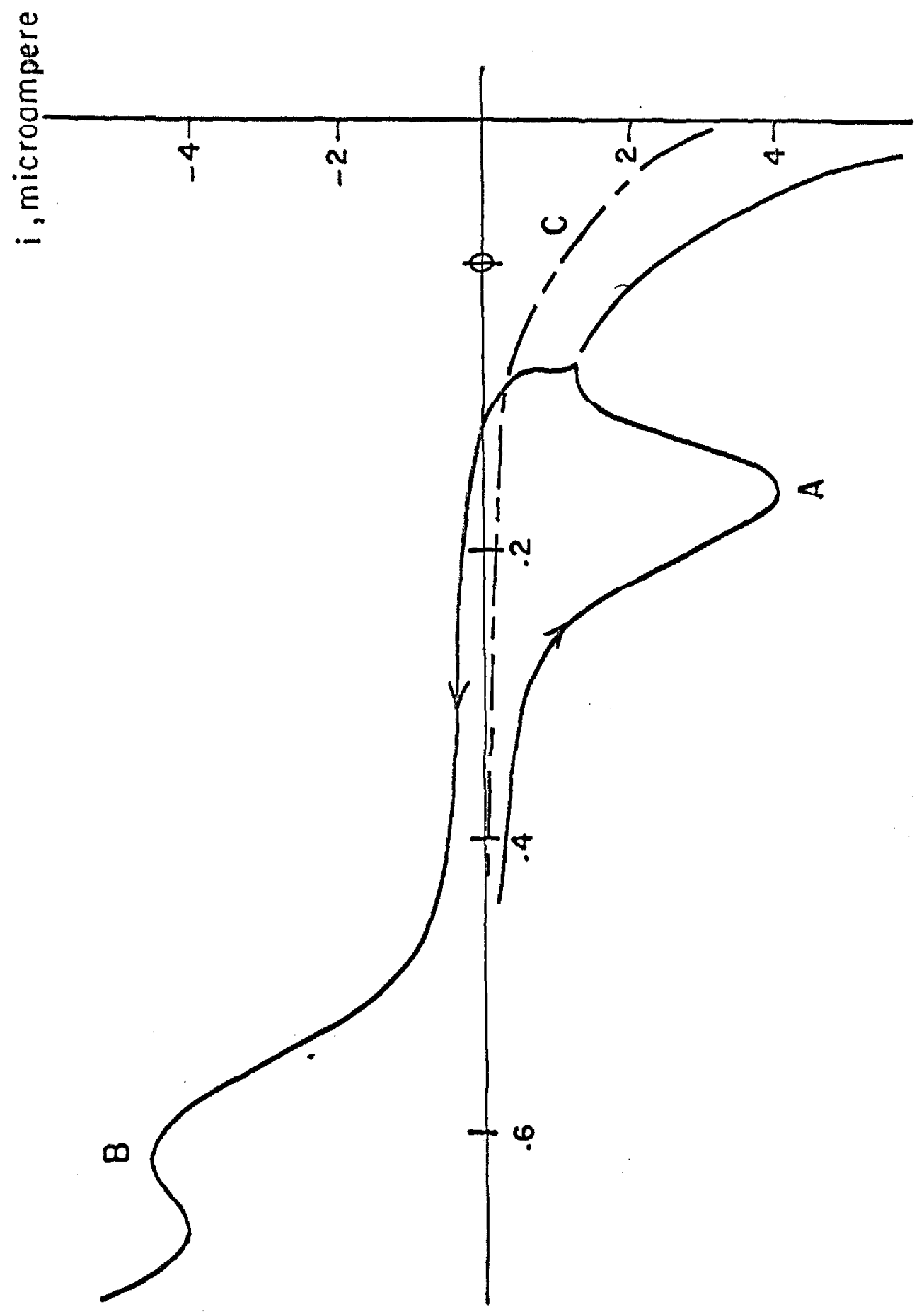


second peak for the reduction of $\mathrm{PtCl}_{4}{ }^{-2}$ because of the extreme irreversibility of this reaction. However, it is certain that $\mathrm{PtCl}_{4}{ }^{-2}$ is formed from the reduction of $\mathrm{PtCl}_{6}{ }^{-2}$ because reversal of the potential scan direction immediately after the $\mathrm{PtCl}_{6}{ }^{-2}$ reduction wave leads to an anodic current peak (Figure 20, curve B) which is identical to the peak obtained with a separate solution of pure $\mathrm{PtCl}_{4}{ }^{-2}$ (Figure 21-A).

The results of potential-step current integration experiments with $\mathrm{PtCl}_{6}{ }^{-2}$ solutions are given in Table XII. It is clear that in $1 \mathrm{~F} \mathrm{HCl}$ electrolyte under the conditions prevailing in the thin layer experiments the $n$-values are 2 for both the reduction of $\mathrm{PtCl}_{6}{ }^{-2}$ and the oxidation of $\mathrm{PtCl}_{1}{ }^{-2}$. This result is in disagreement with the proposal of Lingane (30) that Pt(III) is a stable intermediate in the reduction of $\mathrm{PtCl}_{6}{ }^{-2}$.

Figure 21b shows the thin layer current-potential curve that results when the oxidation of $\mathrm{PtCl}_{4}{ }^{-2}$ is followed by reversal of the potential scan direction. The product of the oxidation of $\mathrm{PtCl}_{1}{ }^{-2}$ is not simply $\mathrm{PtCl}_{6}{ }^{-2}$ but a mixture of at least two species. The "new" platinum (IV) complex is surely of the general type $\mathrm{Pt}(\mathrm{OH})_{\mathrm{m}} \mathrm{Cl}_{6}-\mathrm{m}^{-2}$, there being no ligands other than $\mathrm{Cl}^{-}$and $\mathrm{OH}^{-}$ (or $\mathrm{H}_{2} \mathrm{O}$ ) present in the solution. The exact identity of the species present is discussed in the following sections.

(iii). Hydrolysis of $\mathrm{PtCl}_{6}{ }^{-2}$

The hydrolysis of $\mathrm{PtCl}_{6}^{-2}$ has been studied in some detail by 
$-116-$

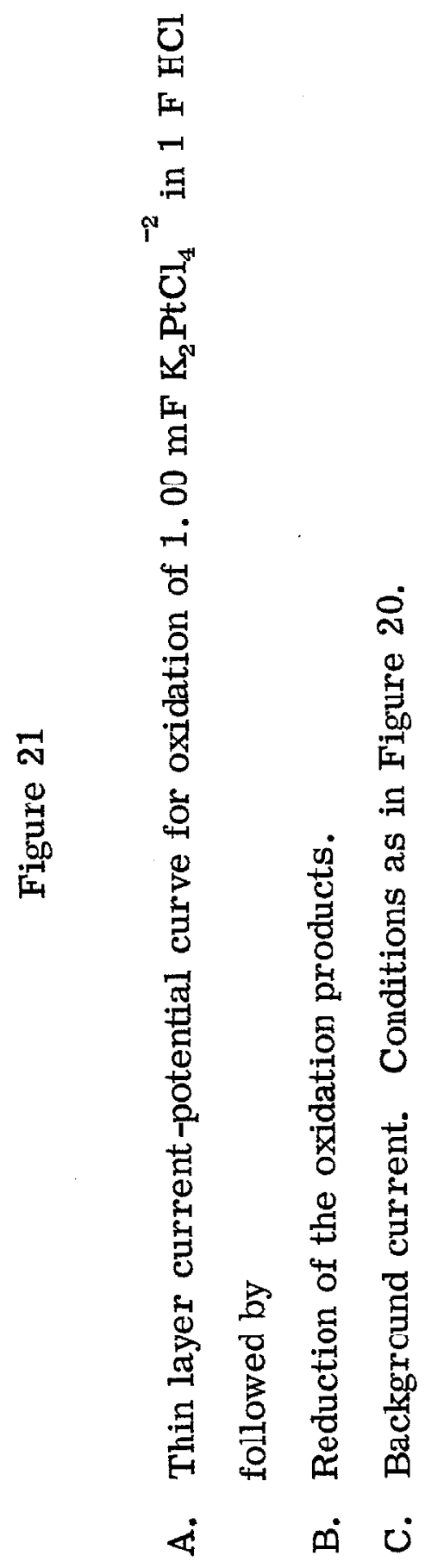


$-117-$

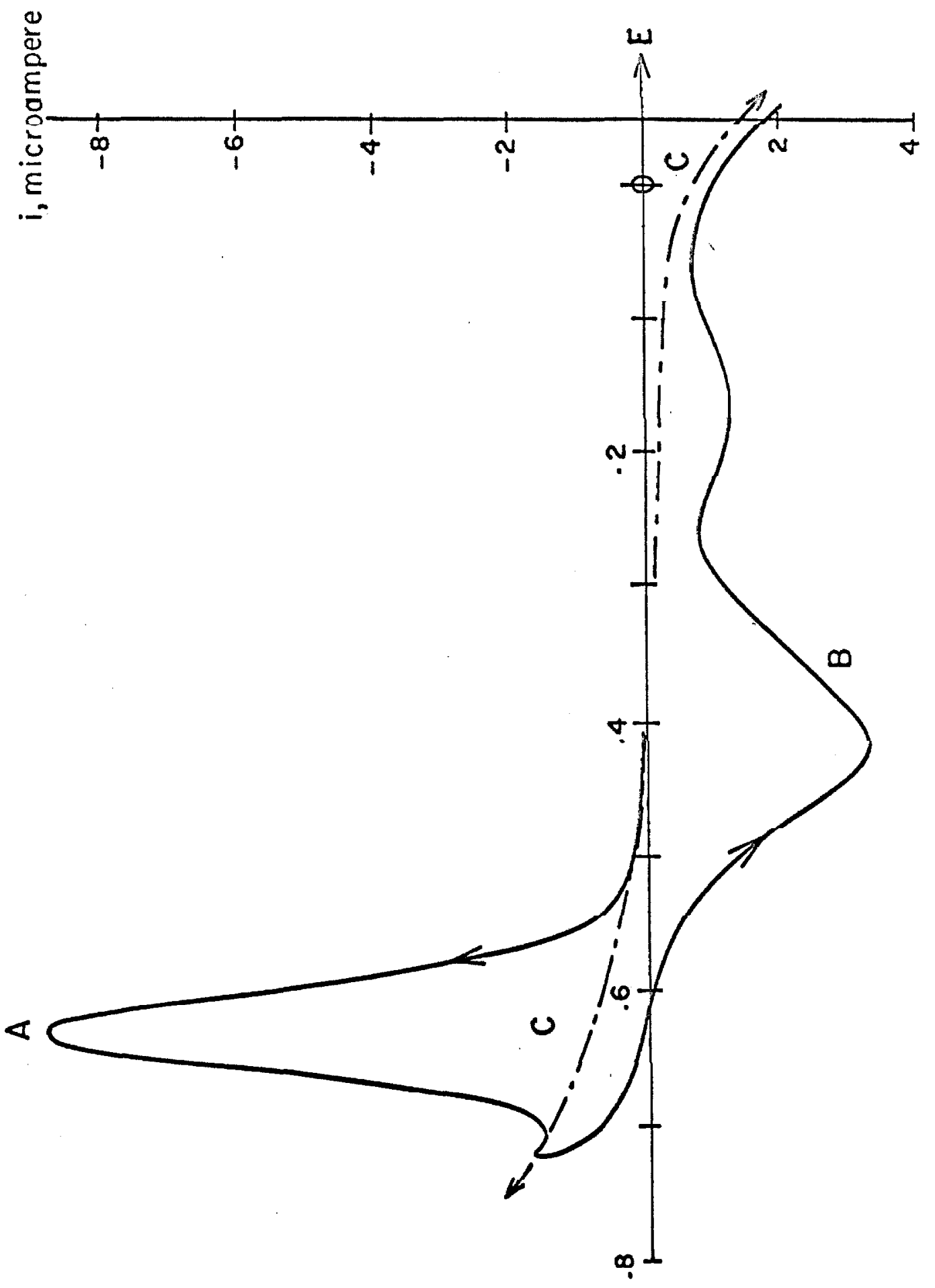




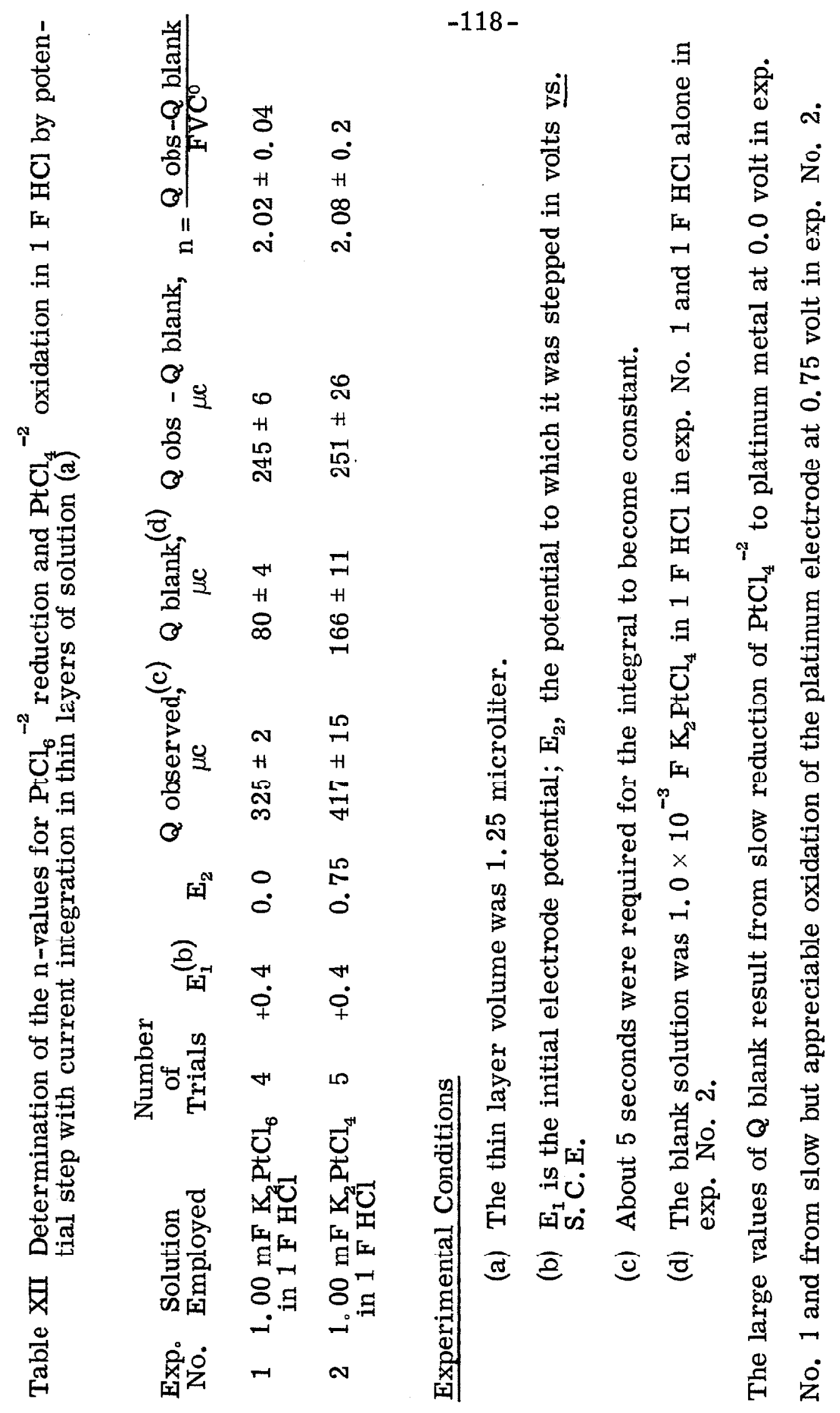


Dreyer (33) who showed that aqueous $\mathrm{K}_{2} \mathrm{PtCl}_{6}{ }^{-2}$ solutions slowly hydrolyze according to the generalized reaction

$$
\mathrm{PtCl}_{6}{ }^{-2}+\overline{\mathrm{m}} \mathrm{H}_{2} \mathrm{O} \rightarrow \sum_{\mathrm{m}=1}^{6} \mathrm{a}_{\mathrm{m}} \mathrm{Pt}(\mathrm{OH})_{\mathrm{m}} \mathrm{Cl}_{6-\mathrm{m}}{ }^{-2}+\overline{\mathrm{m}} \mathrm{H}^{+}
$$

The average extent of hydrolysis $\overline{\mathrm{m}}$, is defined according to

$$
\overline{\mathrm{m}}=\frac{1}{\mathrm{C}^{\circ}} \mathrm{m} \stackrel{6}{=} \mathrm{m} \mathrm{C}_{\mathrm{m}}=\frac{\text { moles } \mathrm{OH}^{-} \text {required in titration of }}{\text { hydrolyzed sol'n. }}
$$

where $\mathrm{C}^{\circ}$ is the total $\mathrm{Pt}$ concentration and $\mathrm{C}_{\mathrm{m}}$ is the concentration of the $\mathrm{m}^{\text {th }}$ hydrolyzed form, $\mathrm{Pt}(\mathrm{OH})_{\mathrm{m}} \mathrm{Cl}_{6-\mathrm{m}}{ }^{-2}$. The value of $\overline{\mathrm{m}}$ for any solution can be determined conveniently by titration of the partially hydrolyzed solution with standard $\mathrm{NaOH}$, taking advantage of the fact that the rate of reaction between $\mathrm{OH}^{-}$and the unhydrolyzed platinum complex is rather slow in the absence of $\mathrm{Pt}(\mathrm{II})$ compounds or intense irradiation.

In the present work hydrolyzed $\mathrm{PtCl}_{6}{ }^{-2}$ solutions of several different total $\mathrm{Pt}$ concentrations were titrated with standard $\mathrm{NaOH}$ solution to a phenolphthalein end point. The results are

${ }^{33}$ R. Dreyer, et.al., Z. phys. Chem. , 224, 199 (1963). 
summarized in Table XIII and Figure 22. The observed dependence of $\overline{\mathrm{m}}$ on the initial concentration of $\mathrm{PtCl}_{6}{ }^{-2}$ is in agreement with the experiments of Dreyer (33). This concentration dependence and the fact that the hydrolysis appears to cease could be explained either by the reaction having achieved equilibrium or by an acid and/or chloride inhibition of the kinetically controlled hydrolysis reaction. Neither Dreyer's experiments nor our own permitted a choice to be made between these two alternatives.

To study the electrochemical behavior of the hydrolyzed $\mathrm{PtCl}_{6}{ }^{-2}$ solutions aliquots were made $1 \mathrm{~F}$ in $\mathrm{NaClO}_{4}$ and subjected to slow linear potential sweep experiments in the thin layer electrode. The current-potential curves in Figure 23 resulted. The area under each peak in these current-potential curves was determined graphically.

The total area under each current-potential curve is given by Equation 14.

$\mathrm{n}$ equals 4 in Equation 14 for the reduction of $\mathrm{PtCl}_{6}{ }^{-2}$ in $\mathrm{NaClO}_{4}$ solutions. This change in $\mathrm{n}$-value when the supporting electrolyte is changed from $\mathrm{HCl}$ to $\mathrm{NaClO}_{4}$ is examined in more detail in a later section.

Equation 14 should be obeyed whether or not the electrode reactions proceed reversibly so long as the sweep rate is slow enough to insure that all of the reactant in the thin layer is consumed and the current efficiency for each reaction (after correction for any blank) is $100 \%$. 
Table XIII Determination of $\overline{\mathrm{m}}$

$\begin{array}{cccc}\begin{array}{c}\text { Initial } \mathrm{K}_{2} \mathrm{PtCl}_{6} \\ \begin{array}{c}\text { Concentration } \\ \times 10^{3} \mathrm{~F}\end{array}\end{array} & \begin{array}{c}\text { Sample, volume } \\ \mathrm{ml}\end{array} & \begin{array}{c}\text { Vol. of 0.00967 F } \\ \text { NaOH Required } \\ \text { ml }\end{array} & \overline{\mathrm{m}} \\ 1.25 & 20 & 5.60 & 2.24 \\ 2.50 & 20 & 8.91 & 1.78 \\ 5.00 & 10 & 6.49 & 1.30 \\ 10.00 & 2 & 1.84 & 0.930 \\ 20.00 & 4 & 5.70 & 0.713\end{array}$

The solutions were prepared as described in the experimental section; i.e., hydrolysis had essentially ceased before the titrations were carried out. The standard deviation in the experiments was about $1 \%$. 


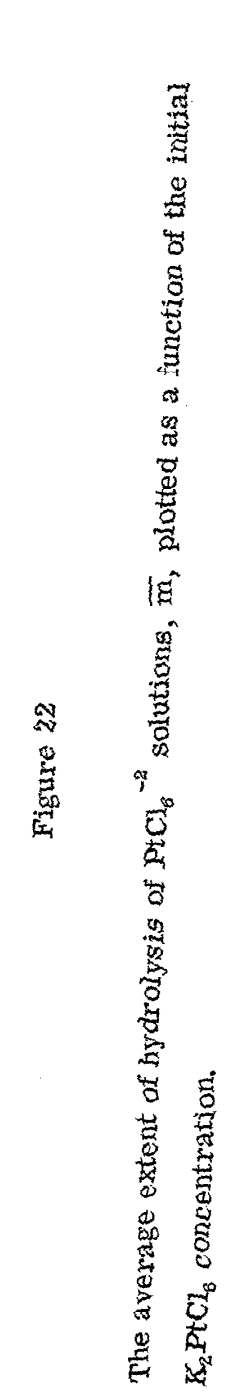


$-123-$

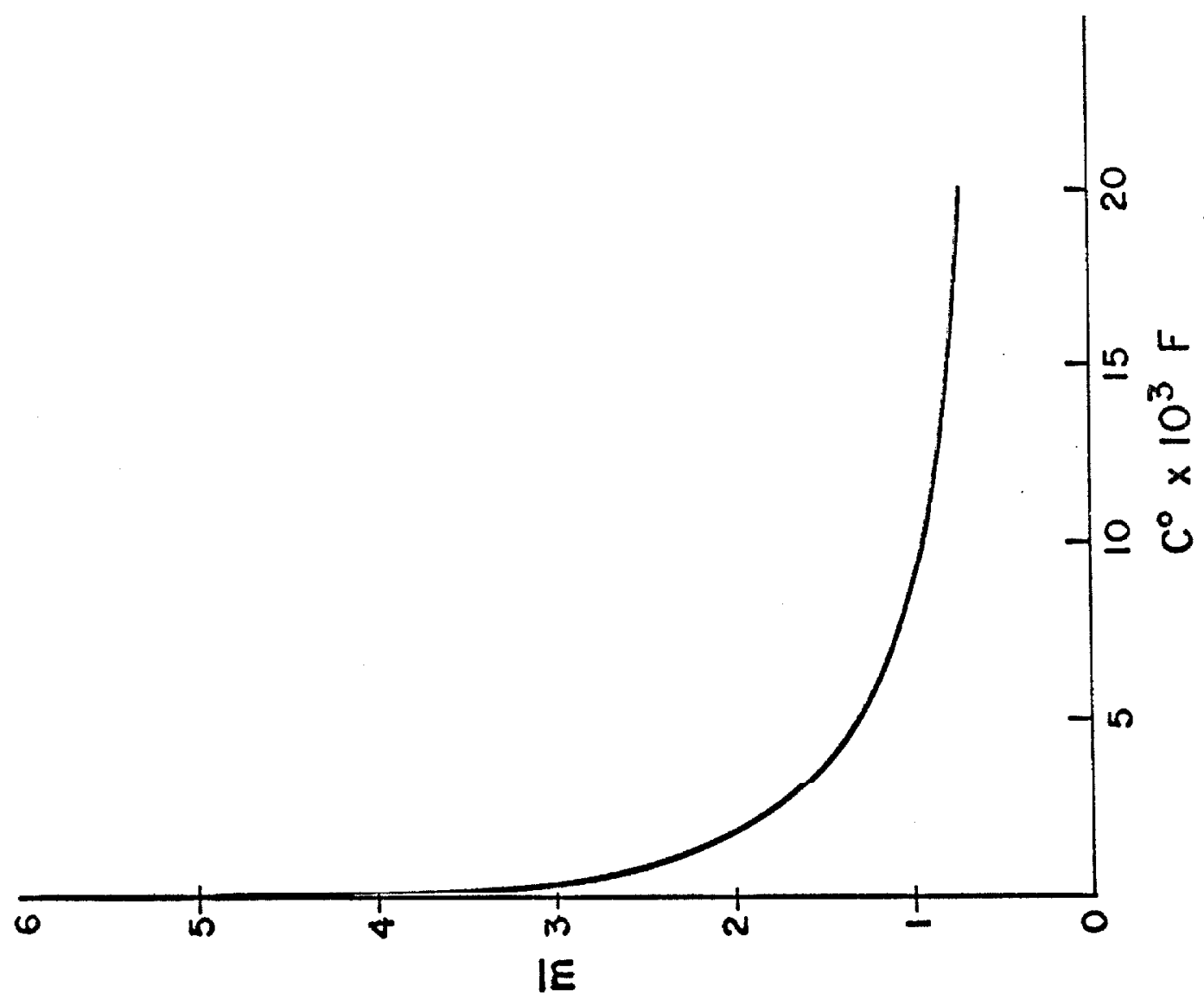




\section{Figure 23}

Cathodic thin layer current-potential curves for hydrolyzed $\mathrm{K}_{2} \mathrm{PtCl}_{6}$ solutions. The thin layer volume was 1.25 microliter.

A. A hydrolyzed solution containing $20.0 \times 10^{-3}$ F Pt(IV) was diluted to $16.0 \times 10^{-3} \mathrm{~F}$ with $5 \mathrm{~F}$ $\mathrm{NaClO}_{4}$. The sweep rate was $0.125 \mathrm{mv}$./second.

B. A hydrolyzed solution containing $10.0 \times 10^{-3}$ F Pt(IV) was diluted to $8.0 \times 10^{-3} \mathrm{~F}$ with $5 \mathrm{~F}$ $\mathrm{NaClO}_{4}$. The sweep rate was $0.25 \mathrm{mv}$. /second.

C. A hydrolyzed solution containing $5.0 \times 10^{-3} \mathrm{~F}$ $\mathrm{Pt}(\mathrm{IV})$ was diluted to $4.00 \times 10^{-3} \mathrm{~F}$ with $5 \mathrm{~F}$ $\mathrm{NaClO}_{4}$. The sweep rate was $0.50 \mathrm{mv}$. /second.

D. A hydrolyzed solution containing $2.50 \times 10^{-3} \mathrm{~F}$ $\mathrm{Pt}(\mathrm{IV})$ was diluted to $2.00 \times 10^{-3} \mathrm{~F}$ with $5 \mathrm{~F}$ $\mathrm{NaClO}_{4}$. The sweep rate was $1.00 \mathrm{mv}$./second.

E. A hydrolyzed solution containing $1.25 \times 10^{-3}$ F Pt(IV) was diluted to $1.0 \times 10^{-3} \mathrm{~F}$ with $5 \mathrm{~F}$ $\mathrm{NaClO}_{4}$. The sweep rate was $2.00 \mathrm{mv}$. /second.

F. Background current. 


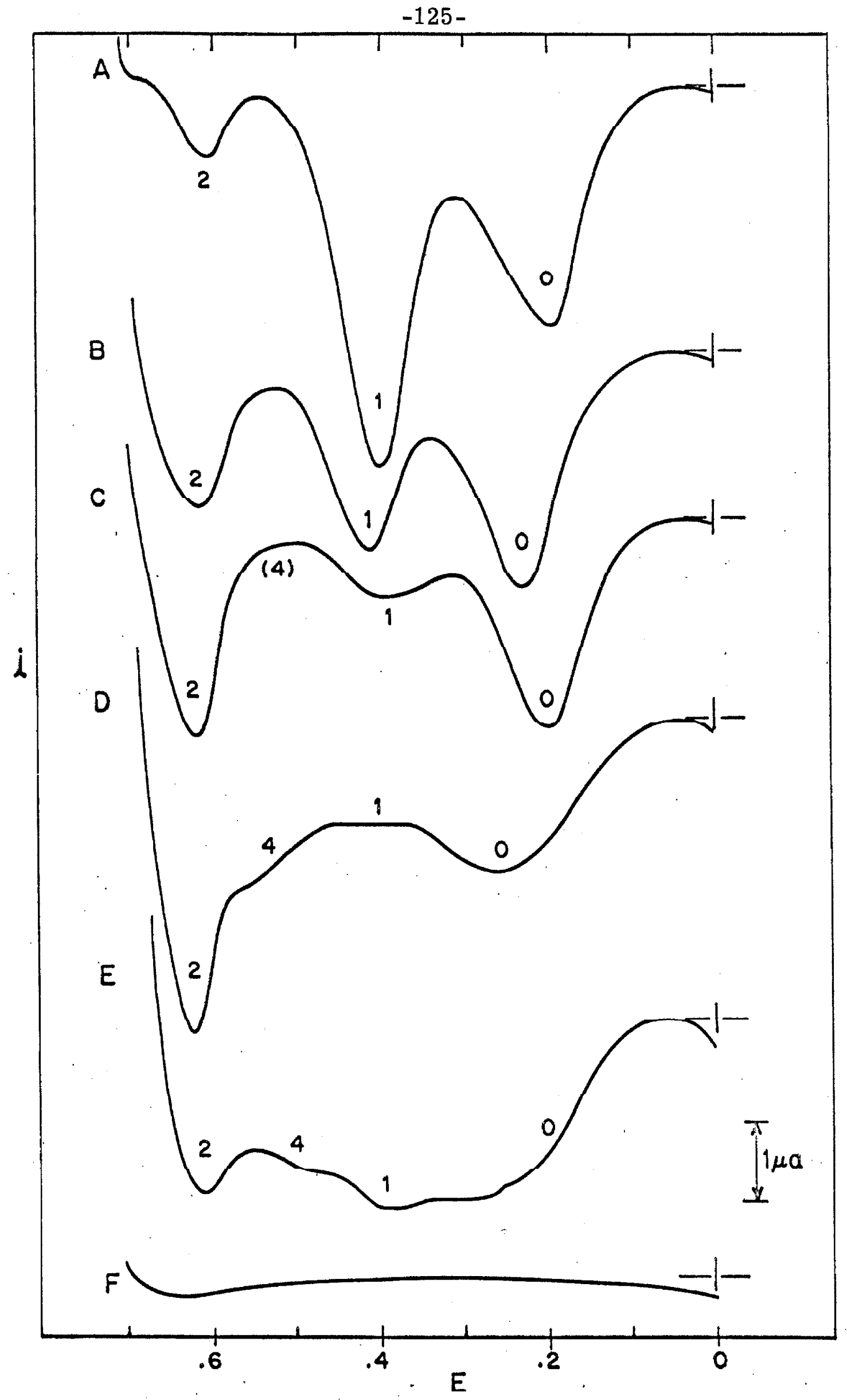


The identity of the hydrolyzed Pt(IV) species giving rise to each of the current peaks in Figure 23 was established by comparing the ratio of the area under each peak to the total area with the value of $\overline{\mathrm{m}}$ determined by the titration for the same solution. It follows from Equations 14 and 28 that

$$
\overline{\mathrm{m}}=\sum_{\mathrm{m}=0}^{6} \frac{\mathrm{mQ}_{\mathrm{m}}}{\mathrm{Q}_{\text {Total }}}
$$

where $Q_{m}$ is the area under the peak in the current-potential curve corresponding to the hydrolyzed species $\mathrm{Pt}(\mathrm{OH})_{\mathrm{m}} \mathrm{Cl}_{6-\mathrm{m}}{ }^{-2}$. The integral values of $m$ assigned to each of the observed current peaks were chosen to give the best agreement of $\bar{m}$ calculated from Equation 29 with the measured values in Table XIII. The results of this analysis are shown in Table XIV. The agreement is quite good considering the extensive overlapping of some of the peaks. The sweep rates used in Figure 23 varied from 0.125 to 2 millivolts/ sec. for the reason explained in the experimental section. At the lowest sweep rate about 90 minutes were required for the recording of the curves. This long duration of the experiment is probably responsible for the discrepancy between the total charge measured under each curve and the theoretical value calculated from Equation 14. This discrepancy was not a serious problem inasmuch as only the ratios of individual peak areas to the total area were needed for the calculation of $\overline{\mathrm{m}}$. Thus it appears that the four peaks labeled 0,1 , 2, and 4 in Figure 23 correspond respectively to the species: 


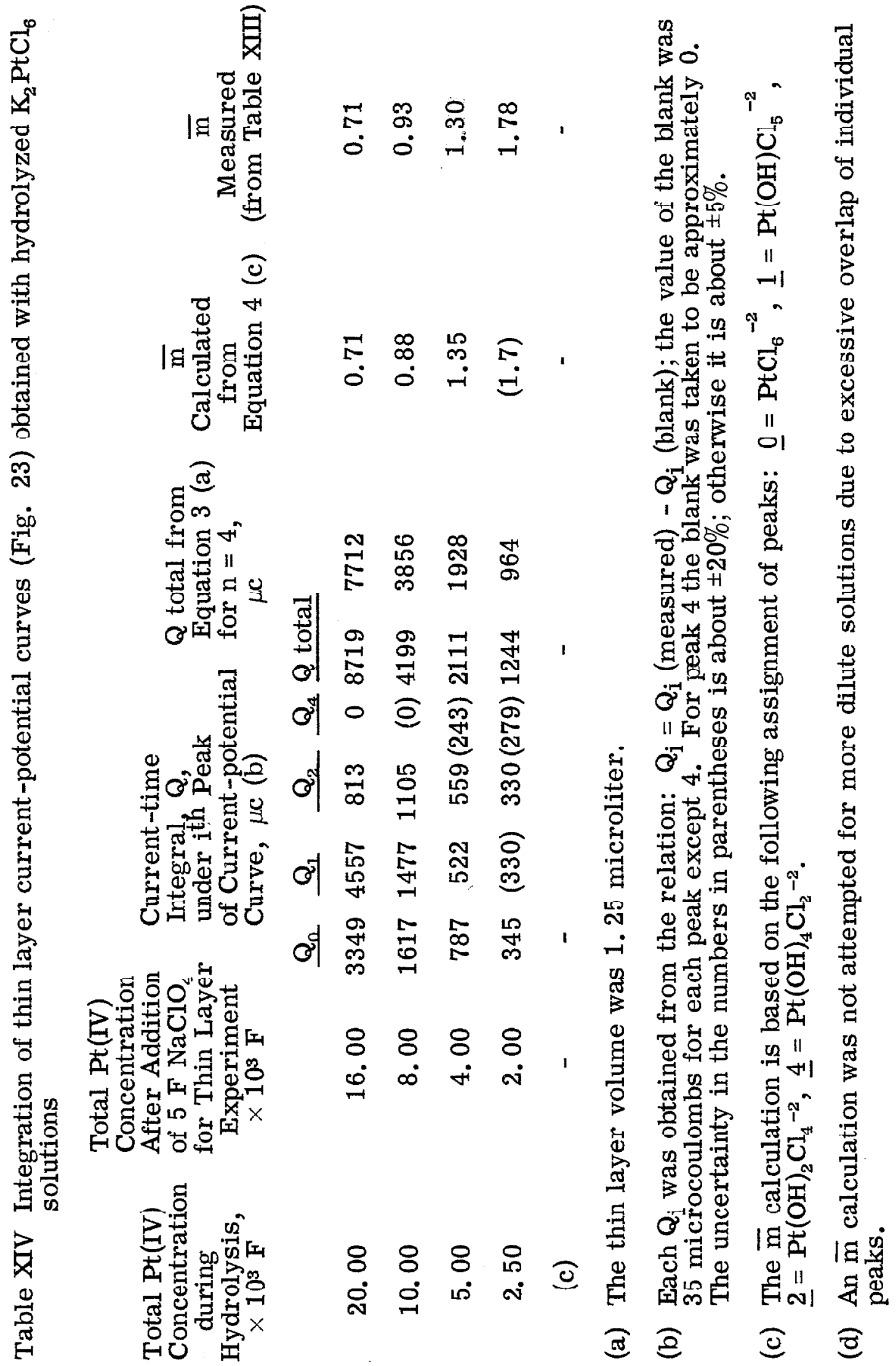


$\mathrm{PtCl}_{6}{ }^{-2}, \mathrm{PtOHCl}_{5}{ }^{-2}, \mathrm{Pt}(\mathrm{OH})_{2} \mathrm{Cl}_{4}{ }^{-2}$, and $\mathrm{Pt}(\mathrm{OH})_{4} \mathrm{Cl}_{2}{ }^{-2}$.

The reactions of these three hydroxide-containing Pt(IV) species with $1 \mathrm{~F} \mathrm{HCl}$ were investigated by making each of the fully hydrolyzed solutions $1 \mathrm{~F}$ in $\mathrm{HCl}$ and recording the resulting thin layer current-potential curves. (Approximately 10 minutes elapsed between the addition of the $\mathrm{HCl}$ and the initiation of the potential sweep.) The results are shown in Figure 24. The fact that $\mathrm{HCl}$ causes peak 0 to grow at the expense of peak 1 suggests that $\mathrm{Pt}(\mathrm{OH}) \mathrm{Cl}_{5}{ }^{-2}$ reacts rapidly with $\mathrm{HCl}$ to form $\mathrm{PtCl}_{6}{ }^{-2}$, Peak 2 occurs in $1 \mathrm{~F} \mathrm{HCl}$ at the same potential ( +0.35 volts) as the peak resulting from the reduction of the hydroxy species obtained by oxidation of $\mathrm{PtCl}_{4}{ }^{-2}$ in $1 \mathrm{~F} \mathrm{HCl}$ (Figure 21). From the relative heights of the two peaks in Figure 21 it seems likely that the oxidation of $\mathrm{PtCl}_{4}{ }^{-2}$ in $1 \mathrm{~F} \mathrm{HCl}$ proceeds according to $\mathrm{PtCl}_{4}^{-2}-2 \mathrm{e}^{-\underline{1 \mathrm{FHCl}}} \stackrel{\text { ca. }}{ } 1 / 3 \mathrm{PtCl}_{6}{ }^{-2}+$ ca. $2 / 3 \mathrm{Pt}(\mathrm{OH})_{2} \mathrm{Cl}_{4}^{-2}$

The persistence of peaks 2 and 4 in the $1 \mathrm{~F} \mathrm{HCl} \mathrm{suggests}$ that $\mathrm{Pt}(\mathrm{OH})_{2} \mathrm{Cl}_{4}{ }^{-2}$ and $\mathrm{Pt}(\mathrm{OH})_{4} \mathrm{Cl}_{2}{ }^{-2}$ are more resistant to attack by chloride than is $\mathrm{PtOHCl}_{5}{ }^{-2}$. This resistance to attack by chloride is consistent with the suggestion that the hydroxide ligands have the trans configuration in $\mathrm{Pt}(\mathrm{OH})_{2} \mathrm{Cl}_{4}{ }^{-2}$ and $\mathrm{Pt}(\mathrm{OH})_{4} \mathrm{Cl}_{2}{ }^{-2}$ (34).

34 F. Basolo and R. G. Pearson, in Progress in Inorganic Chemistry, F. A. Cotton, ed., 4, 381, Interscience, N.Y., 1962. 


\section{Figure 24}

Cathodic thin layer current-potential curves for hydrolyzed $\mathrm{K}_{2} \mathrm{PtCl}_{6}$ solutions after addition of $\mathrm{HCl}$. Thin layer volume was 1.25 microliter.

A. A hydrolyzed solution containing $20.0 \mathrm{mF} \mathrm{Pt(IV)}$ was diluted to $16.0 \mathrm{mF}$ with $5 \mathrm{~F} \mathrm{HCl}$. The sweep rate was $1.25 \mathrm{mv}$./second; $\mathrm{x}=10$ microampere.

B. A hydrolyzed solution containing $10.0 \mathrm{mF}$ Pt(IV) was diluted to $8.0 \mathrm{mF}$ with $5 \mathrm{~F} \mathrm{HCl}$. The sweep rate was $1.25 \mathrm{mv}$. /second; $\mathrm{x}=5$ microampere.

C. A hydrolyzed solution containing $5.0 \mathrm{mF}$ Pt(IV) was diluted to $4.0 \mathrm{mF}$ with $5 \mathrm{~F} \mathrm{HCl}$. The sweep rate was $1 \mathrm{mv}$./second; $\mathrm{x}=2$ microampere.

D. A hydrolyzed solution containing $2.5 \mathrm{mF}$ Pt(IV) was diluted to $2.0 \mathrm{mF}$ with $5 \mathrm{~F} \mathrm{HCl}$. The sweep rate was $2 \mathrm{mv}$./second; $\mathrm{x}=2$ microampere.

E. A hydrolyzed solution containing $1.25 \mathrm{mF}$ Pt(IV) was diluted to $1.0 \mathrm{mF}$ with $5 \mathrm{~F} \mathrm{HCl}$. The sweep rate was $1 \mathrm{mv}$./second; $\mathrm{x}=1 \mathrm{microampere}$.

F. Background current. $1 \mathrm{~F} \mathrm{HCl}$. The sweep rate was $2 \mathrm{mv} . /$ second; $\mathrm{x}=1$ microampere. 


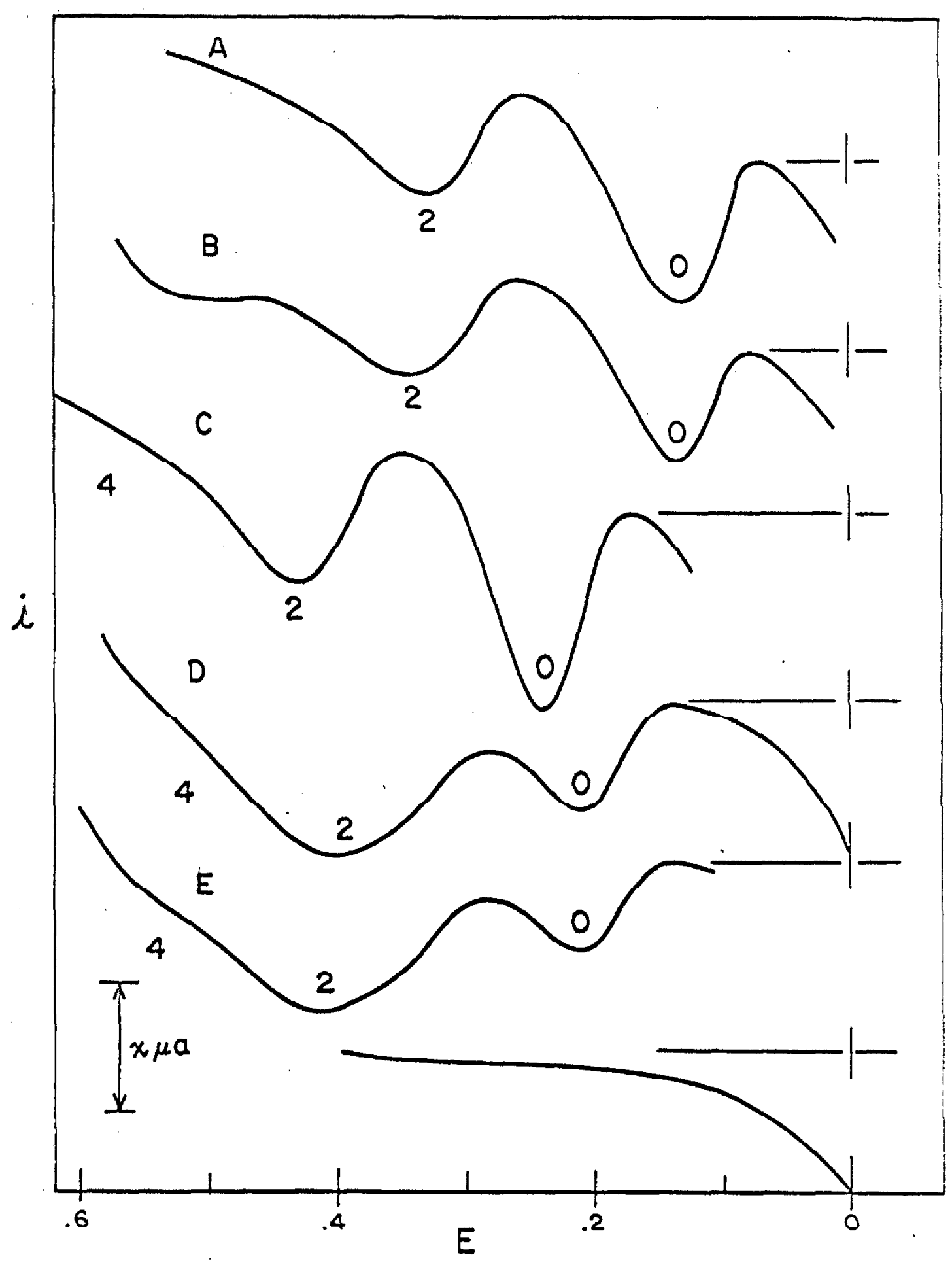


(iv). Supporting Electrolyte Effects

To further define the effect of solution $\mathrm{pH}$ and chloride concentration on the reduction of $\mathrm{PtCl}_{6}{ }^{-2}$ and its hydrolysis products, aliquots of a $1.25 \mathrm{mM}$ hydrolyzed $\mathrm{PtCl}_{6}{ }^{-2}$ solution (for which $\overline{\mathrm{m}}=$ 2.20) were made $1 \mathrm{~F}$ in $\mathrm{HCl}, \mathrm{HClO}_{4}, \mathrm{NaCl}$, or $\mathrm{NaClO}_{4}$ and the $\mathrm{n}$ values for reduction obtained by thin layer chronocoulometry. The rcsulte appear in Table XV and indicate that in $\mathrm{HCl}, \mathrm{HClO}_{4}$ or $\mathrm{NaCl}$ the reduction product is $\mathrm{Pt}(\mathrm{II})$ whereas in $\mathrm{NaClO}_{4}$ the reduction proceeds all the way to platinum metal. The $\mathrm{PtCl}_{4}{ }^{-2}$ experiments in Table XV reflect the large difference in the rate of reduction of $\mathrm{PtCl}_{4}{ }^{-2}$ when the electrolyte is changed from $\mathrm{HCl}, \mathrm{HClO}_{4}$, or $\mathrm{NaCl}$ to $\mathrm{NaClO}_{4}$. The cathodic thin layer current-potential curve obtained wilh $\mathrm{PlCl}_{4}{ }^{-2}$ in $1 \mathrm{~F} \mathrm{NaClO}_{4}$ appears in Figure 25.

The fact that a 2 electron reduction wave is observed for $\mathrm{PtCl}_{4}{ }^{-2}$ in $\mathrm{NaClO}_{4}$ but not in $\mathrm{HCl}$ is consistent with the fact that $\mathrm{PtCl}_{6}{ }^{-2}$ is reduced to $\mathrm{PtCl}_{4}{ }^{-2}$ in $\mathrm{HCl}$ but all the way to platinum metal in $\mathrm{NaClO}_{4}$.

The reasons for such a strong dependence of the $n$-values on the composition of the supporting electrolytes are not elucidated by these experiments.

$$
\text { (v). } \mathrm{PtBr}_{6}{ }^{-2} \text { and } \mathrm{PtBr}_{4}{ }^{-2}
$$

Figure 26, curve A, shows the thin layer current-potential curve obtained with a solution of $\mathrm{PtBr}_{6}{ }^{-2}$ in $1 \mathrm{~F} \mathrm{NaBr}$. As was true 


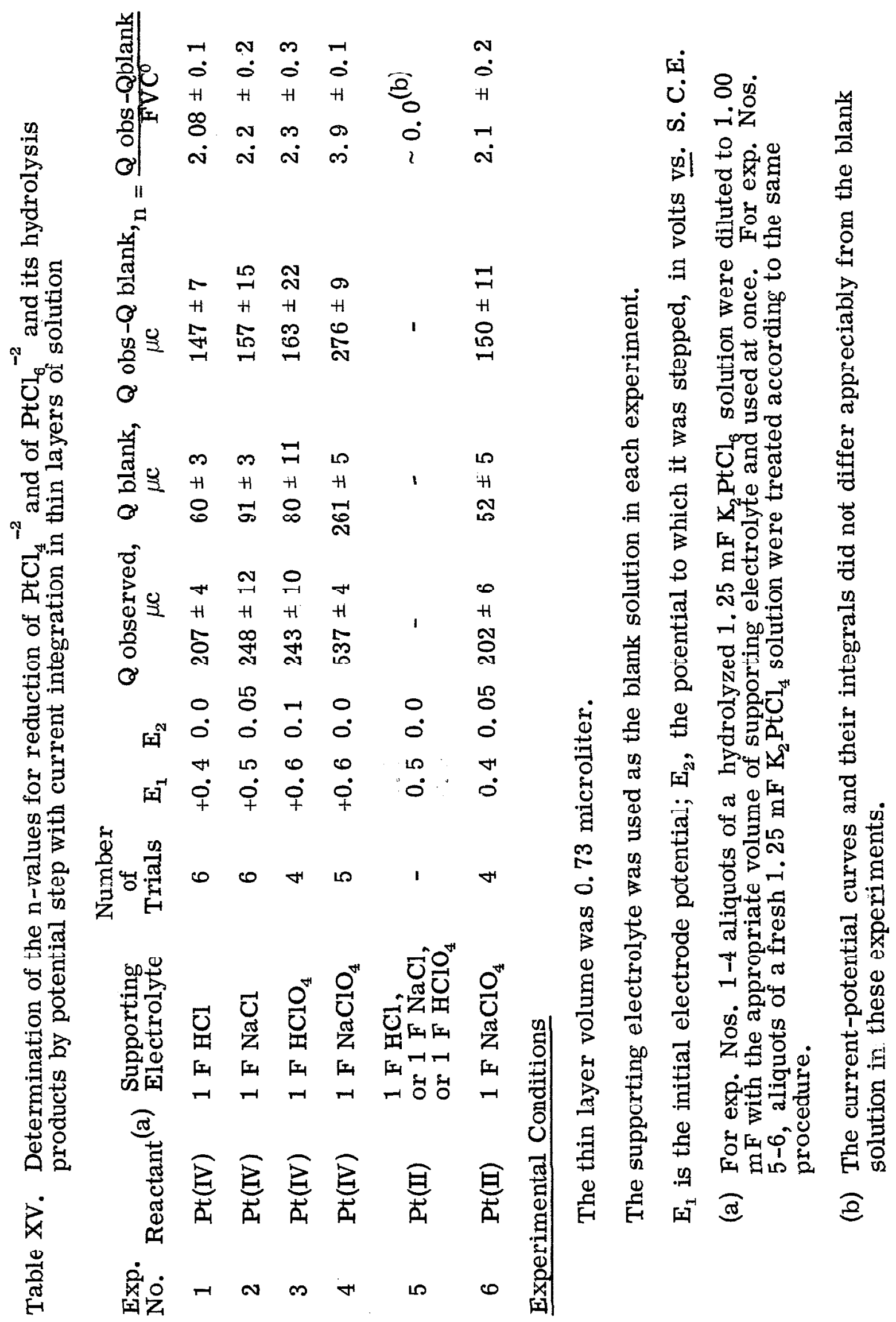


$-133-$

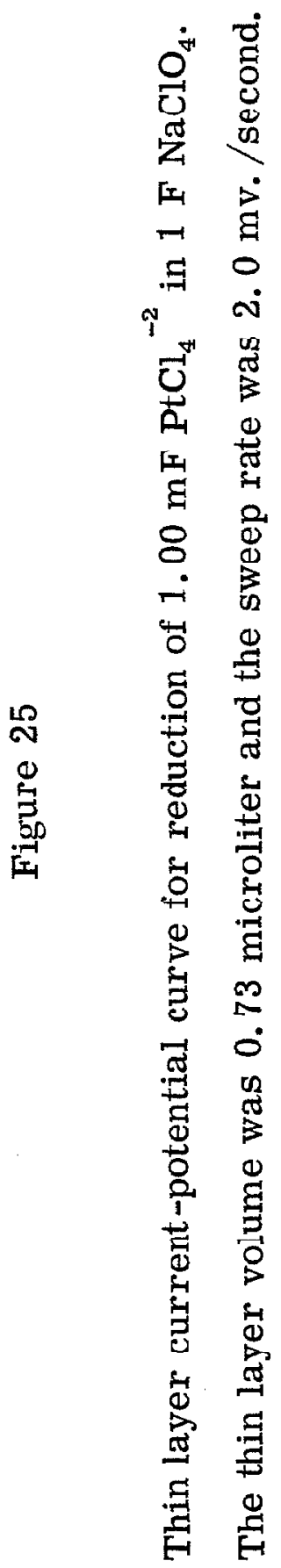


$-134-$

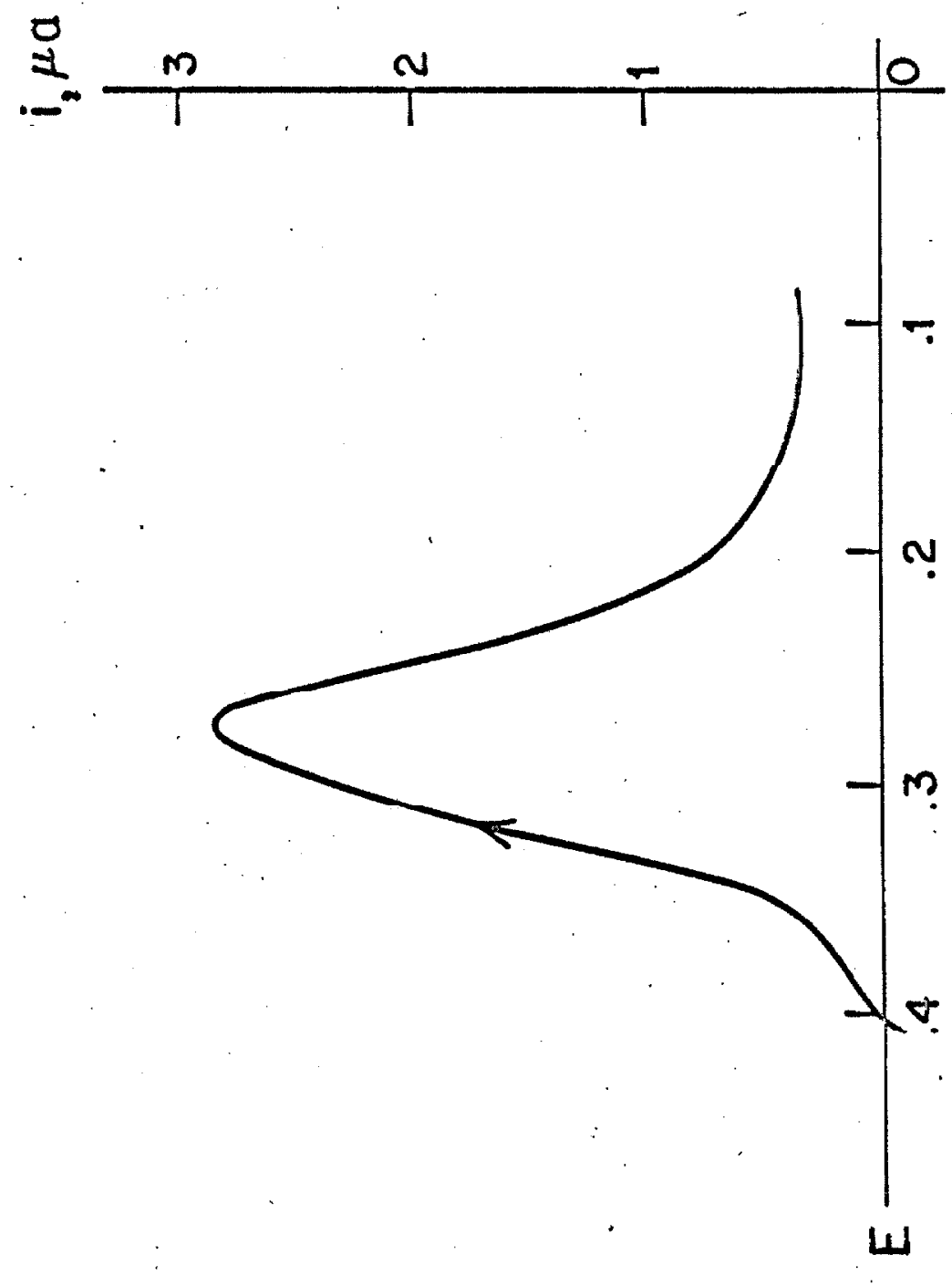




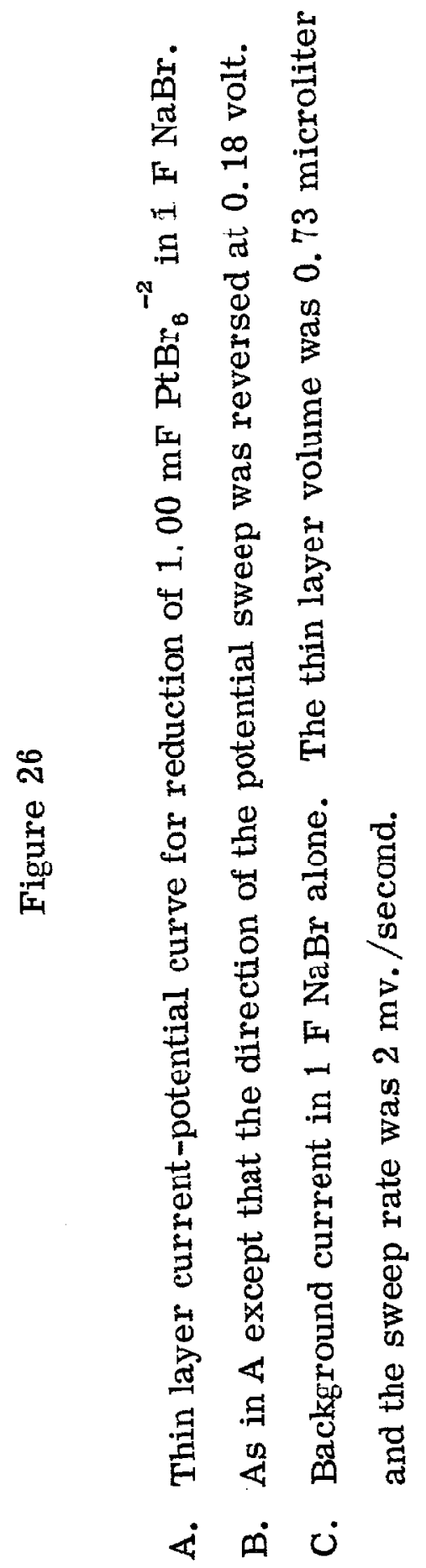


$-136-$

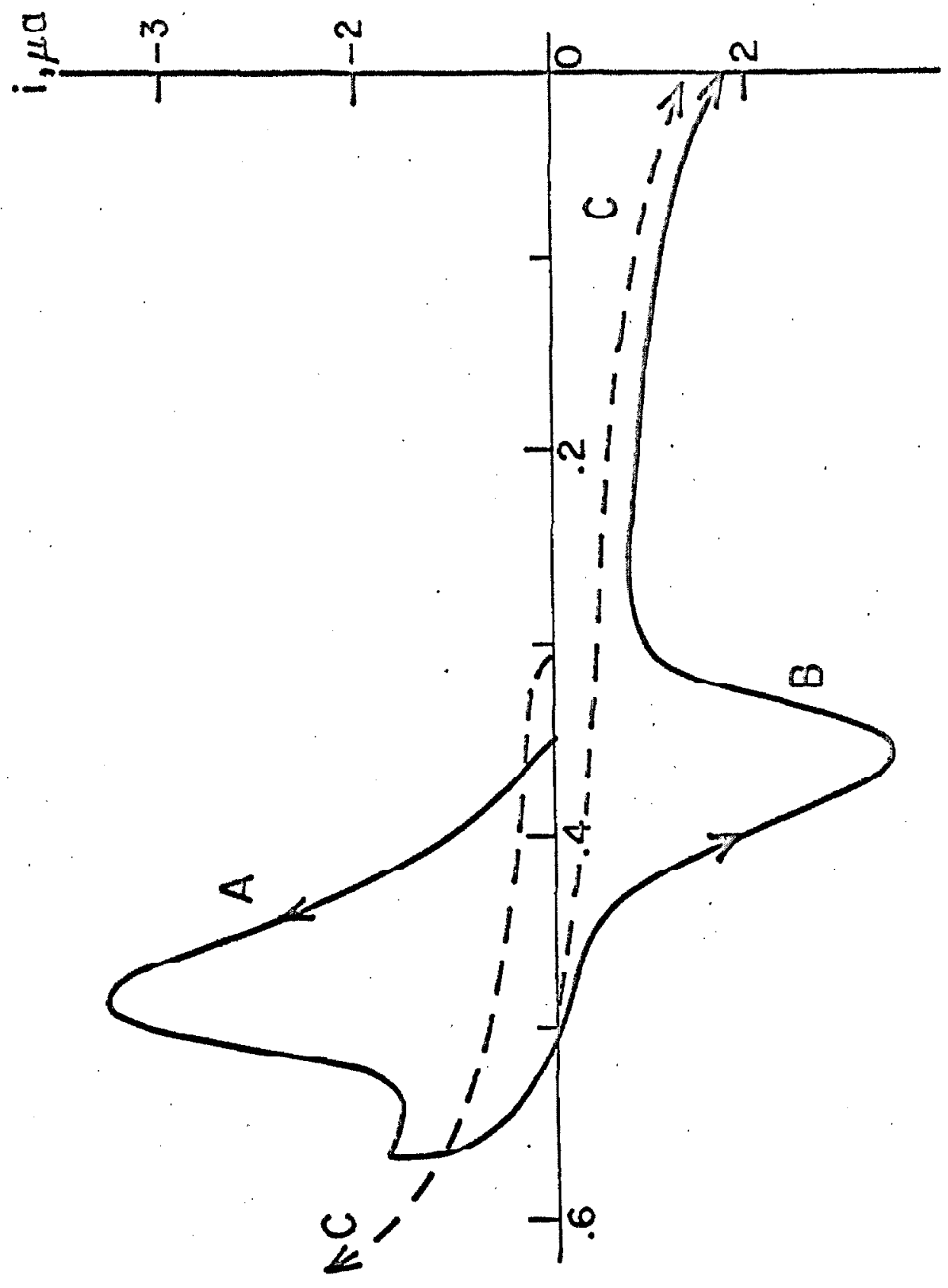


with $\mathrm{PtCl}_{6}{ }^{-2}$ no distinct second peak for the reduction of $\mathrm{PtBr}_{4}{ }^{-2}$ is present. However, it is certain that $\mathrm{PtBr}_{4}{ }^{2}$ is formed from the reduction of $\mathrm{PtBr}_{6}{ }^{-2}$ because reversal of the potential sweep direction immediately after the $\mathrm{PtBr}_{6}{ }^{-2}$ reduction wave leads to an anodic current peak (Figure 26, curve B) which is identical with the peak obtained with a separate solution of pure $\mathrm{PtBr}_{4}{ }^{-2}$ (Figure 27, curve A).

As can be seen from Figure 27, curve B, the final product of $\mathrm{PtBr}_{4}{ }^{-2}$ oxidation is simply $\mathrm{PtBr}_{6}{ }^{-2}$. If species such as $\mathrm{Pt}(\mathrm{OH})_{2} \mathrm{Br}_{4}{ }^{-2}$ are intermediates in the reaction they are apparently rapidly converted to $\mathrm{PtBr}_{6}{ }^{-2}$ in $1 \mathrm{~F}$ solutions of bromide.

$$
\text { (vi). Hydrolysis of } \mathrm{PtBr}_{6}{ }^{-2}
$$

Solutions of $\mathrm{PtBr}_{6}{ }^{-2}$ in water were hydrolyzed, aliquots of the hydrolyzed solutions were made $1 \mathrm{~F}$ in $\mathrm{NaClO}_{4}$, and the current-potential curves in Figure 28 obtained. The results indicate that $\mathrm{PtBr}_{6}{ }^{-2}$ undergoes hydrolysis similar to that observed with $\mathrm{PtCl}_{6}{ }^{-2}$; however, $\overline{\mathrm{m}}$ values could not be obtained by titration of the hydrolyzed solutions with $\mathrm{NaOH}$, apparently because the hydrolysis products (presumably $\mathrm{Pt}\left(\mathrm{H}_{2} \mathrm{O}\right)_{\mathrm{m}} \mathrm{Br}_{6-\mathrm{m}}^{\mathrm{m}-2}$ ) were not as acidic as the analogous chloro compounds. The current-potential curves obtained from hydrolyzed $\mathrm{K}_{2} \mathrm{PtBr}_{6}$ solutions which were made $1 \mathrm{~F}$ in $\mathrm{NaBr}$ displayed only the wave characteristic of $\mathrm{PtBr}_{6}{ }^{-2}$ reduction, indicating that bromide ion rapidly converts the products of hydrolysis back into $\mathrm{PtBr}_{6}{ }^{-2}$. 
$-138-$

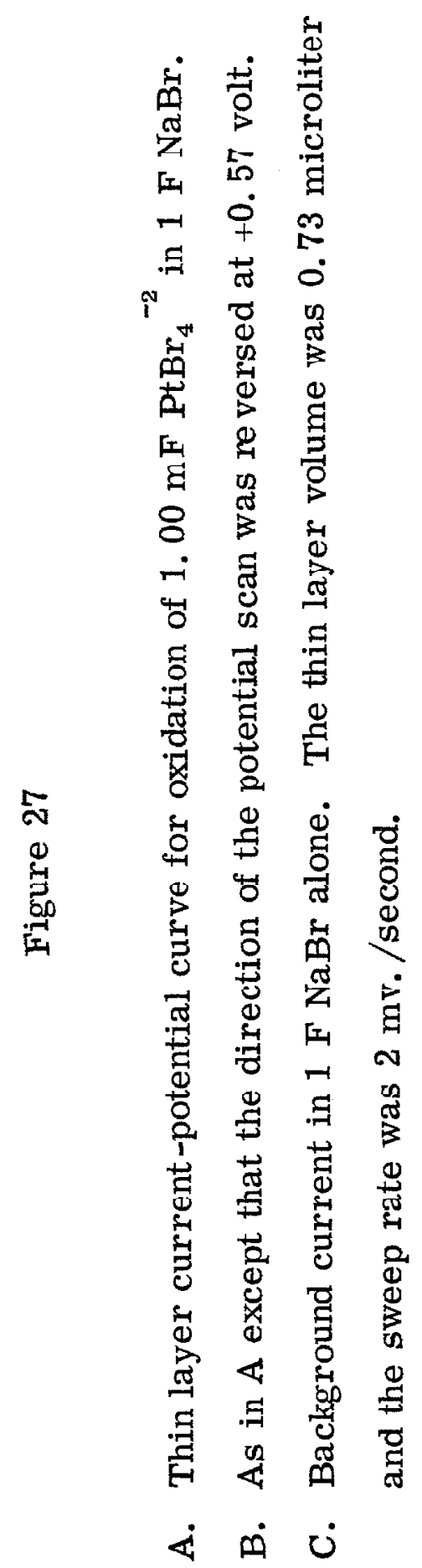




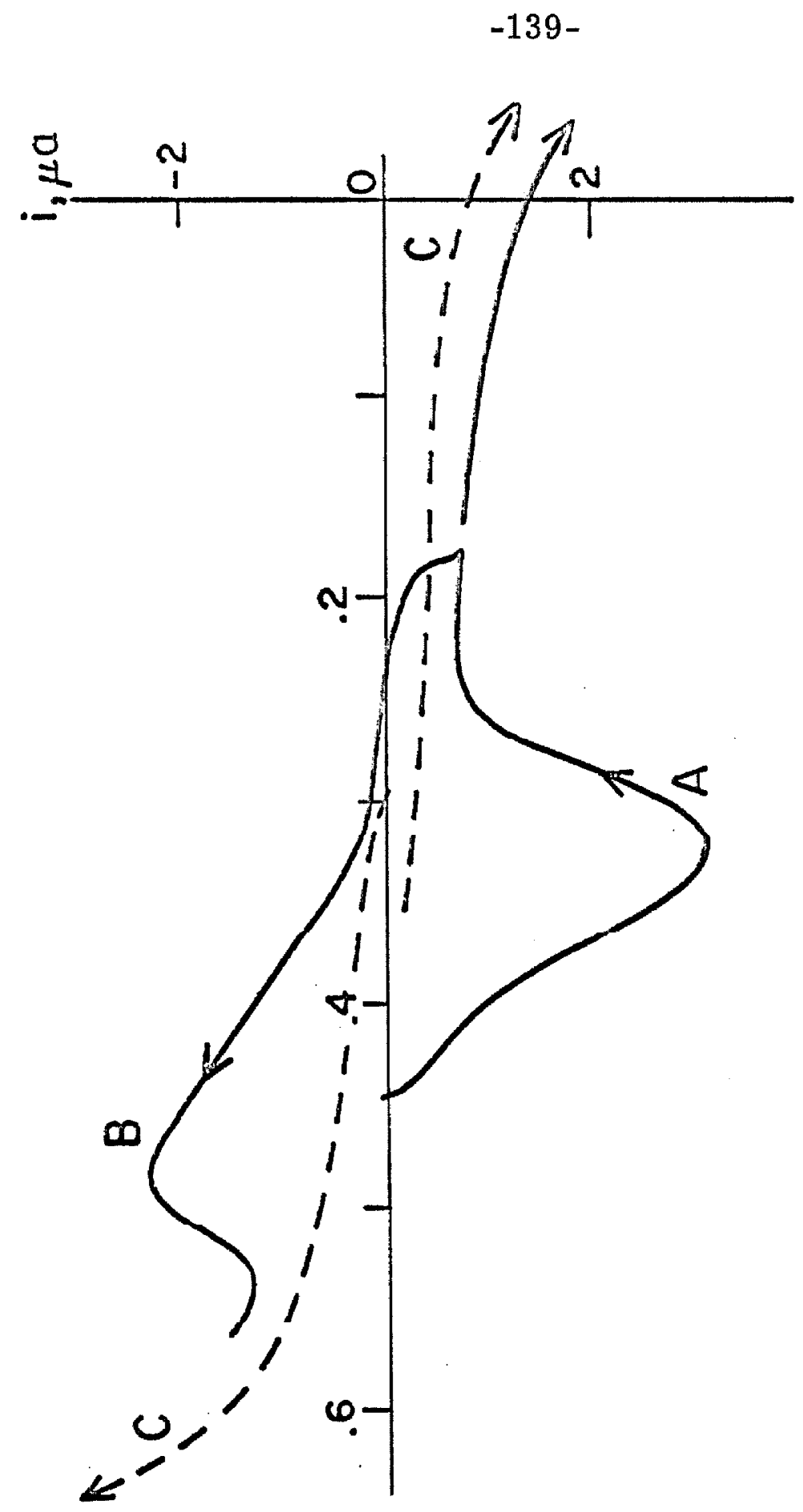




\section{Figure 28}

Thin layer current-potential curves for reduction of $\mathrm{PtBr}_{6}{ }^{-2}$ and its hydrolysis products in $1 \mathrm{~F} \mathrm{NaClO}_{4}$.

The thin layer volume was 0.73 microliter.

A. A hydrolyzed $\mathrm{K}_{2} \mathrm{PtBr}_{6}$ solution containing $20 \mathrm{mF}$ Pt(IV) was diluted to $16 \mathrm{mF}$ with $5 \mathrm{~F} \mathrm{NaClO}_{4}$. The sweep rate was $1 \mathrm{mv}$. / second and $\mathrm{x}=10$ microampere.

B. A hydrolyzed $\mathrm{K}_{2} \mathrm{PtBr}_{6}$ solution containing $10 \mathrm{mF}$ Pt(IV) was diluted to $8 \mathrm{mF}$ with $5 \mathrm{~F} \mathrm{NaClO}_{4}$. The sweep rate was $1 \mathrm{mv}$. /second and $\mathrm{x}=5$ microampere.

C. A hydrolyzed $\mathrm{K}_{2} \mathrm{PtBr}_{6}$ solution containing $5 \mathrm{mF}$ $\mathrm{Pt}(\mathrm{IV})$ was diluted to $4 \mathrm{mF}$ with $5 \mathrm{~F} \mathrm{NaClO}_{4}$. The sweep rate was $2 \mathrm{mv}$. $/$ second and $\mathrm{x}=5$ microampere.

D. A hydrolyzed $\mathrm{K}_{2} \mathrm{PtBr}_{6}$ solution containing $2.5 \mathrm{mF}$ $\mathrm{Pt}(\mathrm{IV})$ was diluted to $2.0 \mathrm{mF}$ with $5 \mathrm{~F} \mathrm{NaClO}_{4}$. The sweep rate was $1.6 \mathrm{mv} . /$ second and $\mathrm{x}=2$ microampere.

E. A hydrolyzed $\mathrm{K}_{2} \mathrm{PtBr}_{6}$ solution containing $1.25 \mathrm{mF}$ Pt(IV) was diluted to $1.0 \mathrm{mF}$ with $5 \mathrm{~F} \mathrm{NaClO}_{4}$. The sweep rate was $1.6 \mathrm{mv}$. / second and $\mathrm{x}=1$ microampere.

F. Background current in $1 \mathrm{~F} \mathrm{NaClO}_{4}$ alone. The sweep rate was $1.6 \mathrm{mv} . /$ second and $\mathrm{x}=1 \mathrm{microampere}$. 
$-141-$

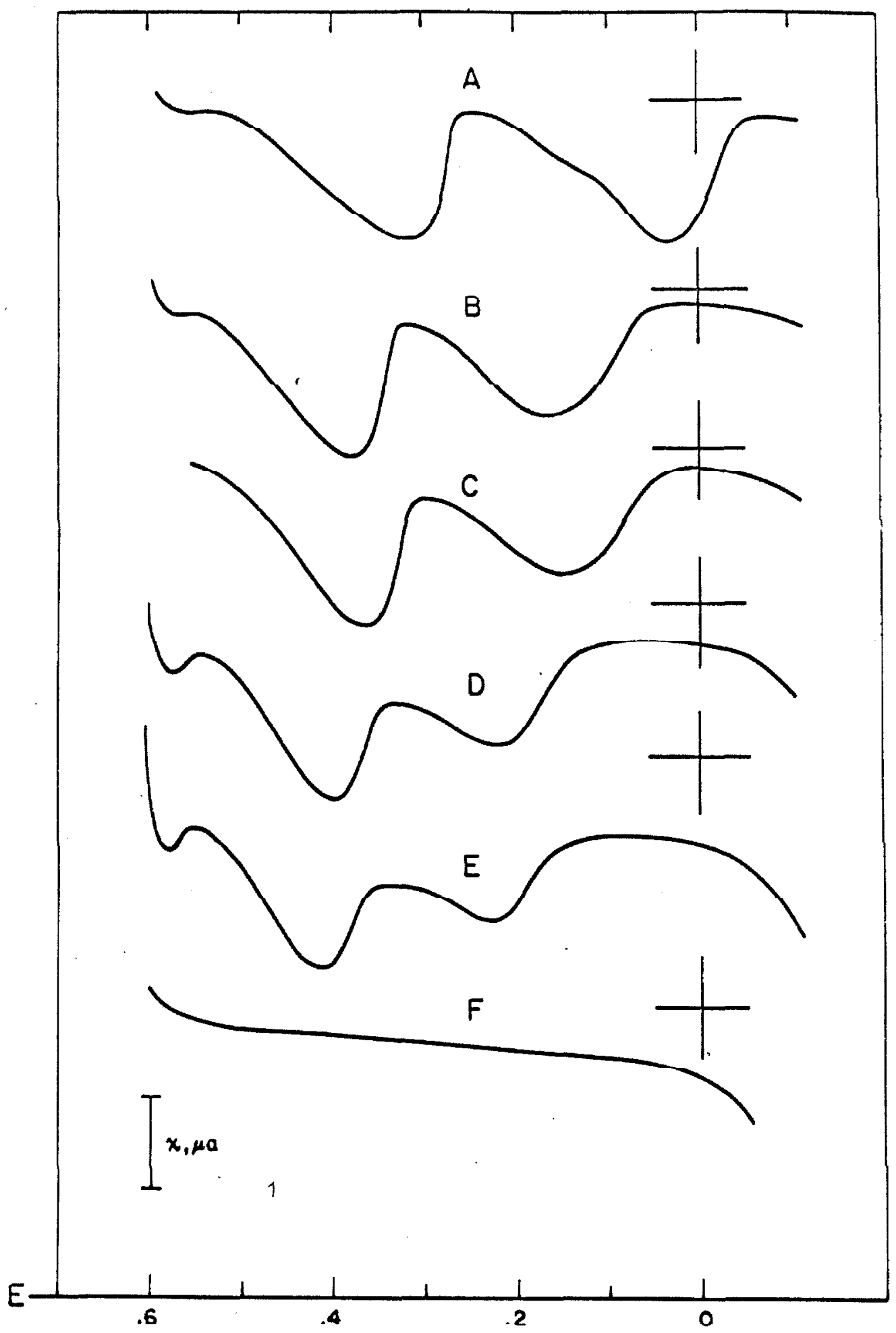


The results of thin layer chronocoulometric experiments with hydrolyzed $\mathrm{PtBr}_{6}{ }^{-2}$ and with $\mathrm{PtBr}_{4}{ }^{-2}$ solutions are summarized in Table XVI. 'l'he $\mathrm{n}$-value for $\mathrm{PtBr}_{6}{ }^{-2}$ reduction is 2 only in $1 \mathrm{~F}$ $\mathrm{Br}^{-}$solutions. In both $1 \mathrm{~F} \mathrm{HClO}_{4}$ and $1 \mathrm{~F} \mathrm{NaClO}_{4}$ solutions $\mathrm{n}$ is 4 . It is interesting, if unexplained, that $\mathrm{PtBr}_{4}{ }^{-2}$ gives a 2-electron reduction wave in $\mathrm{HClO}_{4}$ while $\mathrm{PtCl}_{4}{ }^{-2}$ does not.

$$
\text { (vii). } \mathrm{PtI}_{6}{ }^{-2} \text { and } \mathrm{PtI}_{4}{ }^{-2}
$$

Figure 29 shows the current-potential curve for reduction of $\mathrm{PtI}_{6}{ }^{-2}$ in $0.5 \mathrm{M} \mathrm{NaI}$ solution. The thin layer chronopotentiograms obtained with this solution showed two waves which occurred at the potentials anticipated from the sweep data; the number of coulombs required to reach the transition time for the first wave corresponds to an $n=2$ reaction. The peak potential ( +0.15 volt S. C. E. ) of the first reduction peak is in good agreement with the standard potential for the $\mathrm{PtI}_{e}{ }^{-2}-\mathrm{PtI}_{4}{ }^{-2}$ couple $\left(\mathrm{E}^{0}=+0.148\right.$ volt S. C. E. ) (35)

and the first wave thus corresponds to the reaction

$$
\mathrm{PtI}_{6}{ }^{-2}+2 \mathrm{e}^{-}-\mathrm{PtI}_{4}^{-2}+2 \mathrm{I}^{-} \text {. }
$$

Figure 29 (dashed curve) also shows the result of an anodic sweep initiated immediately after cessation of the first wave.

${ }^{35}$ A. A. Grinberg, et. al. , J. Phys. Chem. (USSR) 10, 661 (1937). 


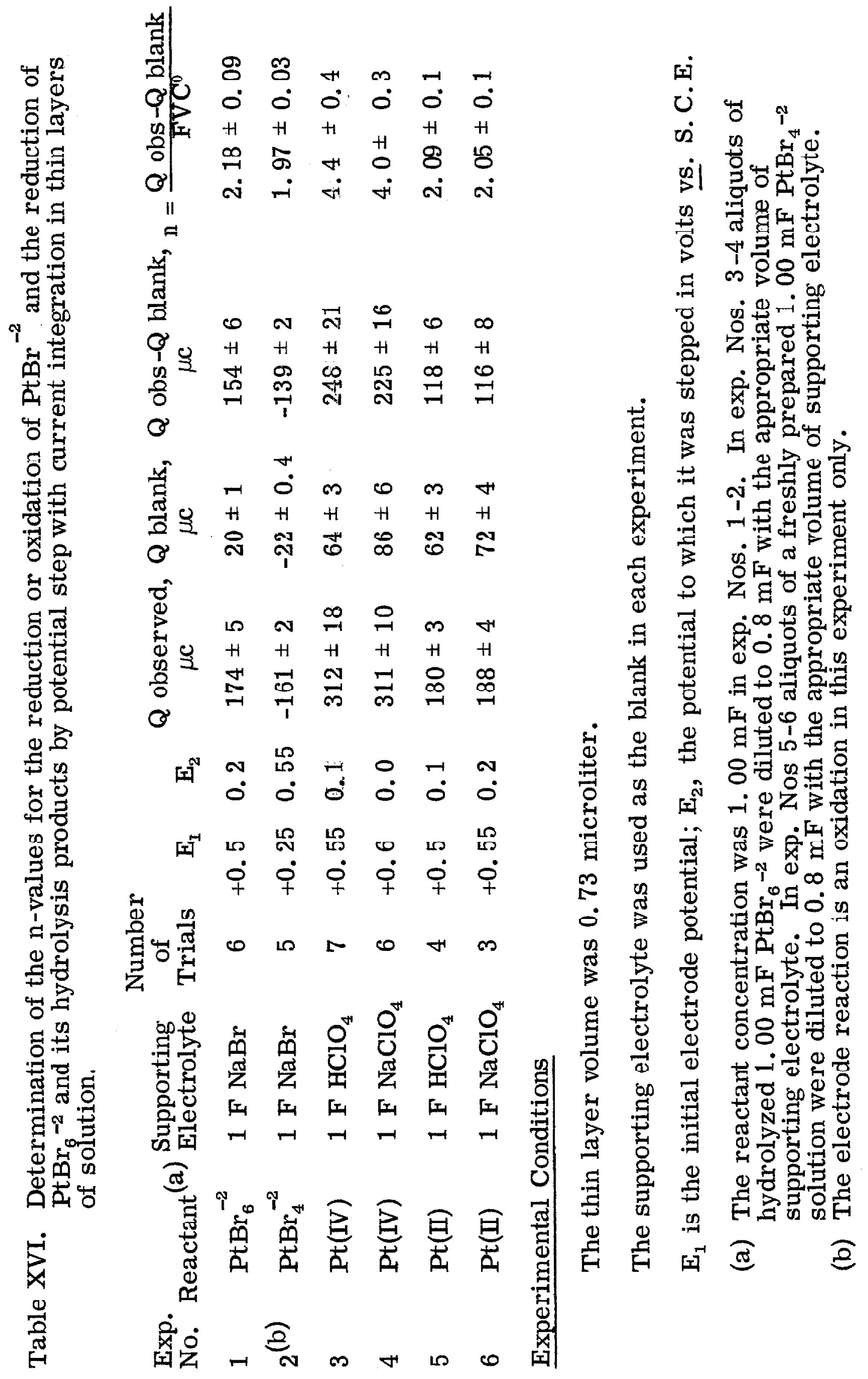


$-144=$

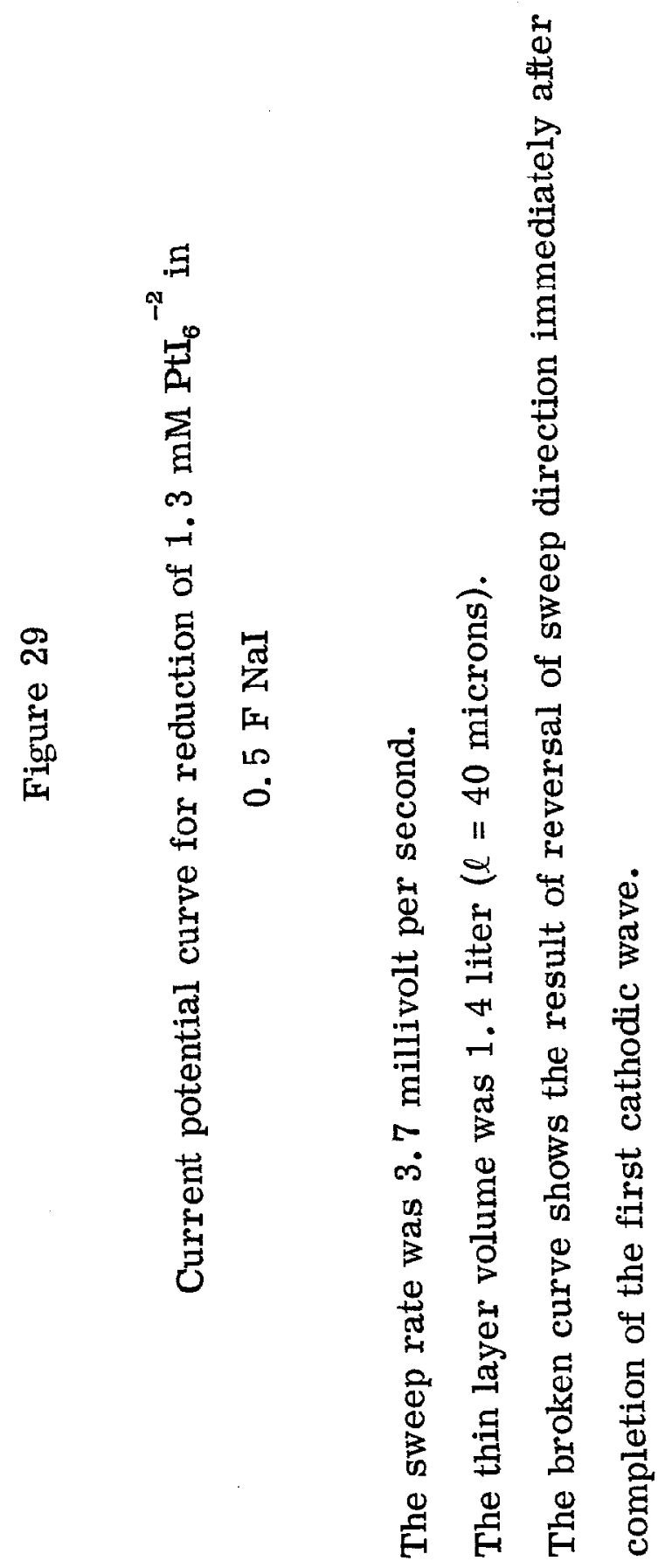




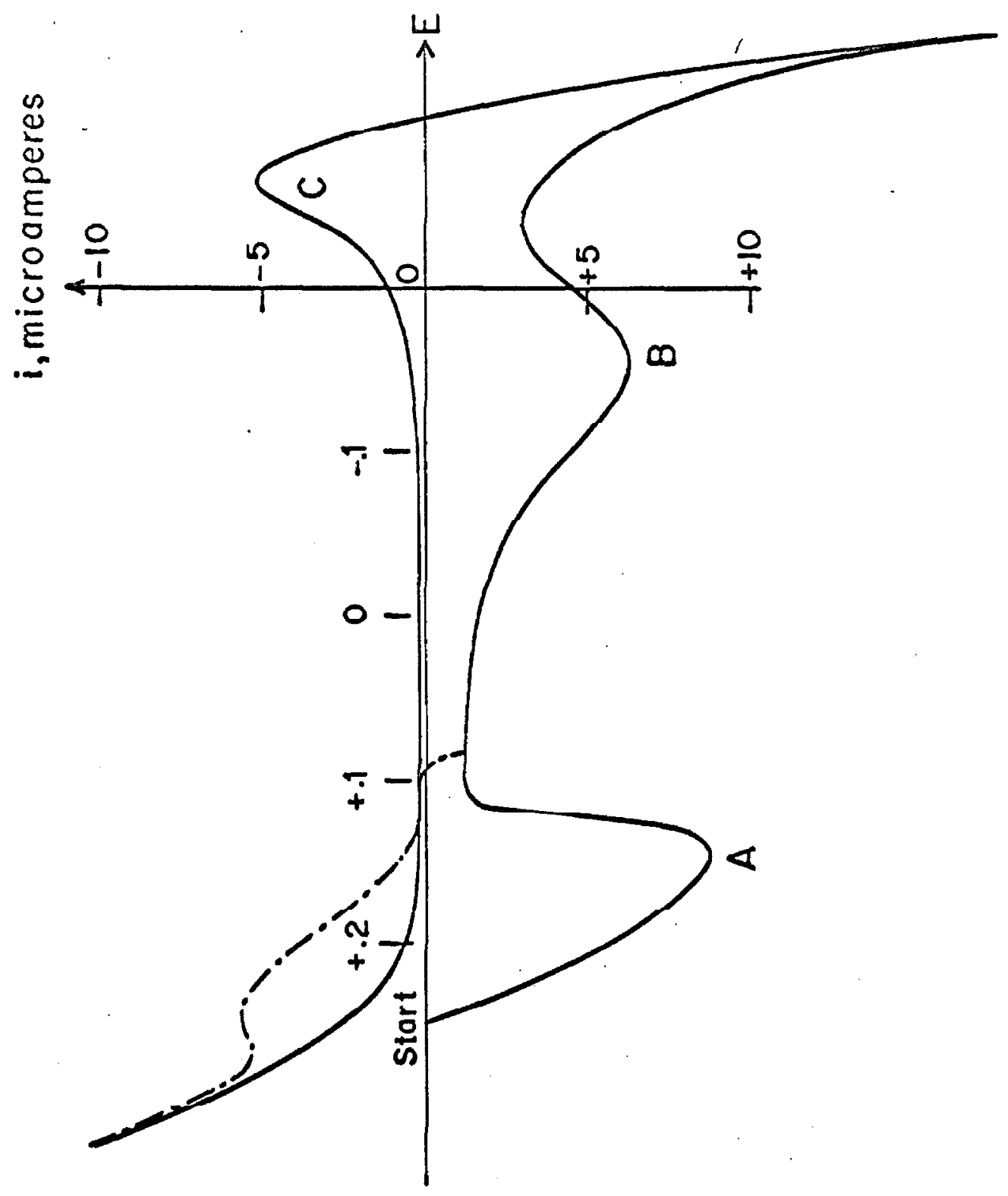


The anodic peak which results is due to the reaction

$$
\mathrm{PtI}_{4}^{-2}+2 \mathrm{I}^{-} \rightarrow \mathrm{PtI}_{6}^{-2}+2 \mathrm{e}^{-}
$$

This reaction does not take place if the $\mathrm{PtI}_{6}{ }^{-2}$ is reduced all the way to Pt metal due to the extremely small rate of the reaction

$$
\mathrm{Pt}+4 \mathrm{I}^{-}-\mathrm{PtI}_{4}{ }^{-2}+2 \mathrm{e}^{-} \text {. }
$$

The peak current due to $\mathrm{PtI}_{4}{ }^{-2}$ reduction (second peak) is somewhat smaller than that for $\mathrm{PtI}_{6}{ }^{-2}$ (first peak), apparently because of the lesser reversibility of the electrode reaction which is

$$
\mathrm{PtI}_{4}^{-2}+2 \mathrm{e}^{-} \rightarrow \mathrm{Pt}+4 \mathrm{I}^{-} \text {. }
$$

An important point here is that slow linear sweep voltammetry in thin layers allows the second reaction to be clearly distinguished from the background current. Chronopotentiometry, even in thin layers, did not yield a wave with a distinguishable transition time.

\section{(viii). Conclusions}

The thin layer electrochemical experiments described above suggest the following conclusions:

I. $\mathrm{PtCl}_{6}{ }^{-2}$ and $\mathrm{PtCl}_{4}{ }^{-2}$

A. In $1 \mathrm{~F} \mathrm{HCl}$ :

1. The oxidation of $\mathrm{PtCl}_{4}{ }^{-2}$ occurs according to $\mathrm{PtCl}_{4}{ }^{-2} \stackrel{\mathrm{HCl}}{\longrightarrow}$ ca. $1 / 3 \mathrm{Pt}(\mathrm{OH})_{2} \mathrm{Cl}_{4}{ }^{-2}+$ ca. $2 / 3 \mathrm{PtCl}_{6}{ }^{-2}+2 \mathrm{e}^{-}$ 
2. The reduction of $\mathrm{PtCl}_{6}^{-2}$ occurs according to $\mathrm{PtCl}_{6}^{-2}+2 \mathrm{e}^{-\frac{\mathrm{HCl}}{\text { or } \mathrm{HClO}_{4}}} \mathrm{PtCl}_{4}^{-2}+2 \mathrm{Cl}^{-}$

3. The reduction product of $\mathrm{Pt}(\mathrm{OH})_{2} \mathrm{Cl}_{4}^{-2}$ and $\mathrm{Pt}(\mathrm{OH})_{4} \mathrm{Cl}_{2}{ }^{-2}$ (produced by hydrolysis of $\mathrm{PtCl}_{6}^{-2}$ ) is $\mathrm{PtCl}_{4}^{-2}$.

B. In $1 \mathrm{~F} \mathrm{NaClO}_{4}$ solutions:

1. The reduction of $\mathrm{PtCl}_{6}^{-2}$ occurs according to $\mathrm{PtCl}_{6}^{-2}+4 \mathrm{e}^{-} \longrightarrow \mathrm{Pt}+6 \mathrm{Cl}^{-}$

2. The reduction of $\mathrm{PtCl}_{4}^{-3}$ occurs according to $\mathrm{PtCl}_{4}^{-3}+2 \mathrm{e}^{-}$ $\rightarrow \mathrm{Pt}+4 \mathrm{Cl}^{-}$

3. The reduction of $\mathrm{Pt}(\mathrm{OH})_{\mathrm{m}} \mathrm{Cl}_{6}-\mathrm{m}^{-2}$ occurs according to $\mathrm{Pt}(\mathrm{OH})_{\mathrm{m}} \mathrm{Cl}_{8-\mathrm{m}}{ }^{-2}+4 \mathrm{e}^{-} \longrightarrow \mathrm{Pt}+\mathrm{mOH}^{-}+(6-\mathrm{m}) \mathrm{Cl}^{-}$

II. $\mathrm{PtBr}_{6}{ }^{-2}$ and $\mathrm{PtBr}_{4}^{-2}$

A. In $1 \mathrm{~F} \mathrm{NaBr}$ :

1. The oxidation of $\mathrm{PtBr}_{4}^{-2}$ occurs according to $\mathrm{PtBr}_{4}^{-2} \rightarrow \mathrm{PtBr}_{6}^{-2}+2 \mathrm{e}^{-}$

2. The reduction of $\mathrm{PtBr}_{6}^{-2}$ occurs according to $\mathrm{PtBr}_{6}{ }^{-2}+2 \mathrm{e}^{-} \longrightarrow \mathrm{PtBr}_{4}{ }^{-2}+2 \mathrm{e}^{-}$

B. In $1 \mathrm{~F} \mathrm{NaClO}_{4}$ or $1 \mathrm{~F} \mathrm{HClO}_{4}$ :

1. The reduction of $\mathrm{PtBr}_{6}^{-2}$ occurs according to $\mathrm{PtBr}_{6}{ }^{-2}+4 \mathrm{e}^{-}$ $\rightarrow \mathrm{Pt}+6 \mathrm{Br}^{-}$

2. The reduction of $\mathrm{PtBr}_{4}^{-2}$ occurs according to $\mathrm{PtBr}_{4}^{-2}+2 \mathrm{e}^{-} \longrightarrow \mathrm{Pt}+4 \mathrm{Br}^{-}$

3. 'The reduction of $\mu \mathrm{t}\left(\mathrm{H}_{2} \mathrm{O}\right) \mathrm{m}^{\mathrm{Br}} \mathrm{Br}_{6-\mathrm{m}}^{\mathrm{m}-2}$ occurs according to $\mathrm{Pt}\left(\mathrm{H}_{2} \mathrm{O}\right)_{\mathrm{m}} \mathrm{Br}_{6-\mathrm{m}}^{\mathrm{m}-2}+4 \mathrm{e}^{-} \rightarrow \mathrm{Pt}+(6-\mathrm{m}) \mathrm{Br}^{-}+\mathrm{mH}_{2} \mathrm{O}$

III. $\mathrm{PtI}_{6}{ }^{-2}$ and $\mathrm{PtI}_{4}{ }^{-2}$

A. In $0.5 \mathrm{M}$ NaI: 
1. The reduction of $\mathrm{PtI}_{6}{ }^{-2}$ occurs according to $\mathrm{PtI}_{6}{ }^{-2}+2 \mathrm{e}^{-} \longrightarrow \mathrm{PtI}_{4}{ }^{-2}+2 \mathrm{I}^{-}$

2. The reduction of $\mathrm{PtI}_{4}^{-a}$ occurs according to $\mathrm{PtI}_{4}^{-4}+2 \mathrm{e}^{-} \longrightarrow \mathrm{Pt}+4 \mathrm{I}^{-}$

3. The oxidation of $\mathrm{PtI}_{4}{ }^{-2}$ occurs according to $\mathrm{PtI}_{4}^{-\mathrm{a}}+2 \mathrm{I}^{-} \longrightarrow \mathrm{PtI}_{6}^{-2}+2 \mathrm{e}^{-}$. 